\title{
CEsifo \\ WORKING

\section{The Saving Glut of the Rich and the Rise in Household Debt}

Atif Mian, Ludwig Straub, Amir Sufi 


\section{Impressum:}

CESifo Working Papers

ISSN 2364-1428 (electronic version)

Publisher and distributor: Munich Society for the Promotion of Economic Research - CESifo

$\mathrm{GmbH}$

The international platform of Ludwigs-Maximilians University's Center for Economic Studies and the ifo Institute

Poschingerstr. 5, 81679 Munich, Germany

Telephone +49 (0)89 2180-2740, Telefax+49 (0)89 2180-17845, email office@cesifo.de

Editor: Clemens Fuest

https://www.cesifo.org/en/wp

An electronic version of the paper may be downloaded

- from the SSRN website: www.SSRN.com

- from the RePEc website: $\quad$ www.RePEc.org

- from the CESifo website: https://www.cesifo.org/en/wp 


\title{
The Saving Glut of the Rich and the Rise in Household Debt
}

\begin{abstract}
Rising income inequality since the 1980s in the United States has generated a substantial increase in saving by the top of the income distribution, which we call the saving glut of the rich. The saving glut of the rich has been as large as the global saving glut, and it has not been associated with an increase in investment. Instead, the saving glut of the rich has been linked to the substantial dissaving and large accumulation of debt by the non-rich. Analysis using variation across states shows that the rise in top income shares can explain almost all of the accumulation of household debt held as a financial asset by the household sector. Since the Great Recession, the saving glut of the rich has been financing government deficits to a greater degree.
\end{abstract}

JEL-Codes: E210, E440, G510, D310.

Keywords: inequality, saving glut, household debt, unveiling.

\author{
Atif Mian \\ Princeton University \\ USA - Princeton, NJ 08544 \\ atif@princeton.edu
}

\author{
Ludwig Straub \\ Harvard University \\ USA - 02139, Cambridge, MA \\ ludwigstraub@fas.harvard.edu
}

\author{
Amir Sufi \\ Chicago Booth \\ USA - Chicago, IL 60637 \\ amir.sufi@chicagobooth.edu
}

March 2020

Sebastian Hanson, Bianca He, and Ian Sapollnik provided excellent research assistance. We are grateful to the following scholars who patiently answered questions on various conceptual and data issues: Jesse Bricker, Joseph Briggs, Jonathan Fisher, Fatih Guvenen, Jonathan Heathcote, Ralph Koijen, Eric Nielsen, Fabrizio Perri, Lukasz Rachel, Kamila Sommer, Alice Volz, Owen Zidar, and Gabriel Zucman. We also thank Heather Boushey, Greg Kaplan, Gianni La Cava, Lukasz Rachel, Harald Uhlig, Rob Vishny, and seminar participants at Brown University, Chicago Booth, the IMF, Princeton University, and the Reserve Bank of Australia. The replication kit (which is 16GB) for this study can be obtained by clicking here: http://scholar.harvard.edu/straub/MSS2020Marchreplicationkit 


\section{Introduction}

Rising income inequality since the 1980s in the United States has generated a large increase in saving by the top of the income distribution, which we call the saving glut of the rich. The additional savings have not been directed toward real investment. Instead, the saving glut of the rich has been linked to the substantial dissaving and large accumulation of household debt by the bottom $90 \%$.

The rise in savings due to the rise in income inequality is estimated using two separate techniques. The first relies on the National Income and Product Accounts (NIPA) together with an estimation of income and consumption across the income distribution. The second relies on household wealth reported in the Financial Accounts of the Federal Reserve and the evolution of wealth across the distribution over time. Both techniques find an annual increase in the savings of the top $1 \%$ of the distribution that is between 2.5 and 4 percentage points of national income when comparing the 1960s and 1970s with the post 2000 period.

To put this magnitude into perspective, the average annual savings of the top $1 \%$ of the income distribution have been larger than average annual net domestic investment since 2000 . The magnitude can also be compared to the global saving glut, which has been proposed as a reason behind the decline in real interest rates and rise in debt levels across advanced economies (e.g., Bernanke (2005)). Over the past 40 years, the saving glut of the rich in the United States has been on the same order of magnitude as the increase in the inflow of capital from overseas.

National accounting dictates that the saving glut of the rich must have been absorbed by some other part of the economy. In a closed economy, one natural place to look would be net domestic investment or a rise in government borrowing. However, investment has declined since the 1980s, and government deficits were stable until the Great Recession. In an open economy framework, it is also possible for some of the savings to have found its way overseas. But, as is well known, the current account position of the United States has moved in the opposite direction. The United States as a whole has borrowed more from the rest of the world during this time period.

This leaves only one remaining margin: the rest of the U.S. household sector must have reduced saving substantially. This is what the analysis finds. Saving by the bottom $90 \%$ of the income distribution has fallen significantly over this time frame. The rise in saving of the top $1 \%$ and the substantial dissaving by the bottom $90 \%$ are two sides of the same coin.

The decline in saving by the bottom $90 \%$ was masked by housing valuation gains until 2007; such housing gains kept annual changes in net worth stable despite a decline in saving and a rise in borrowing. This is closely related to a central result in Kuhn et al. (2019), who use a different data set to show that the rise in wealth of the bottom $90 \%$ before 2008 was driven almost entirely by strong house price growth. In addition, the results here show that the rise in household debt that started in the 1980s understates the dissaving of the bottom $90 \%$; the bottom $90 \%$ borrowed more, 
but they also substantially reduced their build-up of financial assets.

The second half of the study focuses on how much of the stock of household debt owed by the bottom $90 \%$ is held as a financial asset of the rich. Such an analysis directly ties the accumulated savings of the rich to the borrowing by the non-rich.

In order to estimate how much household debt is held as a financial asset by the rich, the methodology proceeds in two steps. First, total household debt owed by the household sector is allocated to three potential providers of capital: the rest of the world, the government, and the U.S. household sector. This allocation is done using the extensive information on the linkages within the financial sector that are detailed in the Financial Accounts. The allocation process is best viewed as an exercise seeking to remove the veil of financial intermediation: the financial linkages between institutions are used to uncover who ultimately holds U.S. household debt as a financial asset. To the best of our knowledge, this unveiling process is novel to the literature, and can be potentially done for other asset classes and in other countries.

The unveiling reveals how much household debt is held as a financial asset by the U.S. household sector in different asset classes. The second step then allocates this household debt across the income distribution based on ownership shares of each asset class. The final product from the methodology allows us to quantify exactly how much of household debt in the United States represents a financial asset held by the top of the income distribution.

The results show that the rise in household debt owed as a liability was driven by the bottom $90 \%$ of the income distribution, whereas the rise in household debt held as a financial asset was driven by the top $10 \%$ of the income distribution. This suggests that a better measure of household debt claims across the income distribution is net household debt owed, which is defined as gross household debt owed minus household debt held as a financial asset.

Net household debt positions clarify that rich Americans have increasingly financed the borrowing of non-rich Americans. The net household debt position of the top $1 \%$ fell by 15 percentage points of national income through 2007 which reflected their accumulation of household debt held as a financial asset. In contrast, the net household debt position of the bottom $90 \%$ increased by almost 40 percentage points. This implies that a substantial portion of the overall rise in household debt owed by the bottom $90 \%$ was financed by the top $1 \%$.

This study also presents a novel state-level data set that allows for a more powerful statistical test of the link between the rise in income inequality and the rise in household debt held as a financial asset of the rich. In particular, there was substantial variation across states in the rise in top income shares since the 1980s. The long-difference specification at the state-level relates the state-level rise in top income shares to the rise in household debt held as a financial asset by households in the state. Such a specification removes common aggregate patterns that occurred since the 1980s, and therefore brings us closer to the ideal thought experiment of examining economies with different 
shifts in top income shares while holding all else equal.

The state-level analysis confirms the close association of the rise in top income shares and the rise in household debt held as a financial asset by top income earners. The magnitude is substantial. Applying the coefficient estimate from the state analysis to the aggregate implies that the rise of top income shares explains almost the entire rise in household debt held as a financial asset by the household sector in the United States.

Since the Great Recession, household debt has fallen while government debt has expanded considerably. The rise in government debt is likely to accelerate given the enormous government spending proposals being discussed as a response to the economic dislocations caused by the COVID-19 health crisis. The final section of this study shows that the saving glut of the rich has financed a substantial fraction of the rise in government debt since 2007, and we anticipate this trend will accelerate in the coming years.

The baseline empirical analysis in this study uses the Distributional National Accounts (DINA) microfiles made available publicly by Piketty et al. (2018), which rely on the yearly public-use tax return files available at the National Bureau of Economic Research. However, the results are robust to the use of alternative data sets such as income shares from the Congressional Budget Office (CBO (2019)) and wealth shares from the Distributional Financial Accounts (described in Batty et al. (2019)). The results are also robust to issues related to the assumed interest rate on fixed income assets held by the rich (e.g., Bricker et al. (2018) and Smith et al. (2019b)).

Implications A central implication of the findings presented here is that a single factor-a rise in top income shares-could potentially explain two common patterns witnessed in many advanced economies since the 1980s: a substantial decline in interest rates (e.g., Summers (2014)) and a large rise in household debt (e.g., Jordà et al. (2016)). A companion study (Mian et al. (2019)) incorporates non-homothetic preferences over saving into an otherwise standard deterministic twoagent macroeconomic model, and it finds that a rise in income inequality generates more saving by the wealthy, more borrowing by the non-wealthy, and a decline in interest rates. The patterns shown here are consistent with these predictions.

Another implication is that aggregate measures of national saving should be treated with caution when evaluating the importance of a saving glut. ${ }^{1}$ Some have pointed to the decline in the aggregate personal saving rate as evidence against the idea that there has been a saving glut generated by the rise in income inequality. The analysis done here shows that such an argument is incorrect: a focus on the top $1 \%$ of the income distribution provides evidence in favor of the view that the rise in top income shares generated a substantial increase in saving. This saving, however, was associated with dissaving by the bottom $90 \%$, thereby eliminating any response of the national saving rate.

\footnotetext{
${ }^{1}$ A similar point is made by Pettis (2017).
} 
Finally, the findings suggest that borrowing by non-rich households from rich households has been an important factor sustaining aggregate consumption growth as income inequality has accelerated. The financial sector has been critical to this process by facilitating the rise in household borrowing. This offers a different perspective on the growth in the financial sector (e.g., Philippon (2015)). Rather than channeling the savings of the household sector into investment by the business sector, the growth in finance since the 1980s appears to be driven to a large degree by the channeling of savings by some households into borrowing by other households.

A note on causality. The rise in top income shares in the United States and world-wide is welldocumented (e.g., Katz and Murphy (1992), Piketty and Saez (2003), Autor et al. (2008), Atkinson et al. (2011), Piketty et al. (2018), CBO (2019), and Smith et al. (2019a)). There is substantial evidence in the literature that the rise in top income shares reflected shifts in technology and globalization that began in the 1980s. This view is supported by the fact that the rise in the share of income of the top 1\% is broad-based across many industries (e.g., Kaplan and Rauh (2013), Bakija et al. (2012)), and that much of these earnings are derived from human capital (Smith et al. (2019a)). For these reasons, we treat the rise in inequality that began in the early 1980s as the initial shift in the economy, and we speak of other aggregates as responding to this shift. The state-level analysis supports this interpretation. However, we acknowledge up front that there is no specific source of exogenous variation in the rise in inequality used in this study.

Related literature. Several studies have detailed the evolution of wealth inequality in the United States (e.g., Saez and Zucman (2016), Wolff (2017), Bricker et al. (2018), Batty et al. (2019), Kuhn et al. (2019), and Smith et al. (2019b)). This study is the first to our knowledge to focus on the holdings of household debt as a financial asset by the wealthy. The argument that a rise in inequality generates important dynamics for wealth and interest rates is developed in Straub (2019), who also emphasizes how aggregate saving rates can be misleading when discussing how rising income inequality affects wealth accumulation. ${ }^{2}$

There is also a growing literature focusing on the rise in household debt in the United States. Most of this literature is focused on trends immediately before the Great Recession. ${ }^{3}$ One exception is the recent working paper of Bartscher et al. (2019), which examines the rise in household debt since 1949 across the income distribution. Many of the results in Bartscher et al. (2019) are complementary to the analysis here. For example, from 1983 to 2016, Bartscher et al. (2019) find no material change in the debt to income ratio of households in the top $1 \%$ of the income distribution, but a dramatic rise in the debt to income ratio of households in the bottom $90 \%$ of the income

\footnotetext{
${ }^{2}$ Related arguments are made by Kaymak and Poschke (2016) and Auclert and Rognlie (2017).

${ }^{3}$ See, for example, Mian and Sufi (2015), Bhutta and Keys (2016), Mian and Sufi (2017), Adelino et al. (2018), Foote et al. (2016); and Albanesi et al. (2017)
} 
distribution. However, Bartscher et al. (2019) do not attempt to link the saving of the rich to the borrowing of the non-rich, which is the main focus of this study.

The findings presented here are also related to the literature exploring consumption, income, and wealth inequality more generally (e.g., Slesnick (2001), Krueger and Perri (2006), Blundell et al. (2008), Heathcote et al. (2010), Aguiar and Bils (2015), Attanasio and Pistaferri (2016), Meyer and Sullivan (2017), Guvenen et al. (2017), Fisher et al. (2016), Guvenen et al. (2019), and De Nardi et al. (2018)). As shown below, this literature is an important input into the measurement of the consumption share of the top $1 \%$ over time.

Cynamon and Fazzari (2015) show evidence that the bottom 95\% needed to borrow more after 1980 in order to keep consumption levels steady in the face of rising income inequality. A similar argument is made in Rajan (2011) and Bertrand and Morse (2016). In these studies, the emphasis is on an increase in credit demand by low income households because of lower income levels. Instead, this study emphasizes how an increase in credit supply coming from the top $1 \%$ contributed to higher debt levels of the bottom $90 \%$, which helps explain why interest rates fell during this period. To motivate their model, Kumhof et al. (2015) show a number of stylized aggregate facts that are consistent with the idea that rising income inequality led to rising household debt in the years prior to the Great Recession. However, there is no attempt to directly link the rise in saving of the rich to the dissaving of the non-rich, as is done here. The state-level analysis linking top income shares to increased holdings of household debt is novel to the literature.

The findings here are related to the secular stagnation literature (e.g., Summers (2014)). Studies suggest that rising inequality is a factor putting downward pressure on interest rates given high saving rates of the rich (e.g., Stiglitz (2016), Rachel and Smith (2017), and Rachel and Summers (2019)). The findings of this study support this view. As mentioned above, the model in Mian et al. (2019) with non-homothetic preferences over saving has the implication that a rise in income inequality can simultaneously explain a rise in household debt and lower interest rates.

\section{National Income and National Saving}

The goal of the empirical analysis is to measure the contribution to aggregate savings from different parts of the income. This section starts with aggregate savings and the describes how savings from different parts of the distribution are estimated.

\subsection{Aggregates}

The starting point of the measurement exercise is national income. National income is preferred to GDP for measuring saving behavior because national income excludes the non-economic income 
item capital depreciation (or "consumption of fixed capital" as it is called in the national accounts). Furthermore, national income includes payments to U.S. owners of capital which is located abroad, and it excludes payments to foreign owners of capital which is located in the United States.

Let $Y$ be GDP, $Z$ be National Income, $C$ be personal consumption expenditures, $G$ be government consumption, $I$ be total gross domestic investment (which includes both government and private domestic investment), and $(X-M)$ be net exports. The standard GDP equation is:

$$
Y=C+G+I+(X-M)
$$

Let $\delta$ be consumption of fixed capital, and $W$ be net income from abroad. ${ }^{4}$ The definition of national income is $Z=Y-\delta+W-\epsilon$. Then equation 1 can be written as:

$$
Z-C=G+I^{n}+F-\epsilon
$$

where $F=(X-M+W)$ is the current account of the United States, $I^{n}=I-\delta$ is net domestic investment and $\epsilon$ is the statistical discrepancy that equalizes Gross Domestic Income with Gross Domestic Product in the National Accounts. The term $G$ is related to taxes and transfers to the household sector through the government budget $S^{g}=T-R-G$, which then allows us to write equation 2 as:

$$
\Theta=Z-T+R-C=I^{n}+F-S^{g}-\epsilon
$$

This is the definition of aggregate private savings $(\Theta)$ : national income minus taxes plus transfers minus personal consumption expenditures. Notice that Account 6 of the NIPA gives us the equation: $S^{p}+S^{\pi}+S^{g}=I^{n}+F-\epsilon$. This gives us another definition of private savings:

$$
\Theta=Z-T+R-C=S^{p}+S^{\pi}=I^{n}+F-S^{g}-\epsilon
$$

This makes it clear that the definition of private savings $(\Theta)$ includes both personal savings $\left(S^{p}\right)$ and business savings $\left(S^{\pi}\right)$.

A problem with the notion of savings in national accounts is that the NIPA do not recognize differences in savings across the distribution of households. This problem is clear in equation 4. If one part of the household sector saves more than before, then private savings only increase in the aggregate if the savings are invested $\left(I^{n}\right)$, sent abroad $(F)$, or borrowed by the government $\left(-S^{g}\right)$.

\footnotetext{
${ }^{4}$ More specifically, $W$ comes from the Foreign Transactions Current Account (Account 5) and is defined as income and transfer receipts from the rest of the world minus income payments and transfers to the rest of the world.
} 


\subsection{Measuring saving by group $\left(\Theta_{i}\right)$}

The goal of this study is to measure $\Theta_{i}$, which is the savings of group $i$ of households. There are at least three ways to measure $\Theta_{i}$. The first approach, which is the main technique utilized here, is to utilize the following definition:

$$
\Theta_{i}=Z_{i}-T_{i}+R_{i}-C_{i}
$$

More specifically, $\Theta_{i}$ is pre-tax income minus taxes plus transfers minus consumption. This is referred to as the income less consumption approach. As discussed below, the first three terms are straight-forward to obtain using the Distributional National Accounts (DINA) microfiles made available publicly by Piketty et al. (2018), which rely on the yearly public-use tax return files available at the National Bureau of Economic Research. Obtaining an estimate of $C_{i}$ is also possible, although it requires stronger assumptions especially for those at the very top of the income distribution.

An alternative approach would be to use an estimate of after-tax saving rates from survey data such as the Panel Study of Income Dynamics or the Survey Consumer Finances. The main drawback of such an approach is that the relevant income measure for calculating the contribution to national savings from any group must include all income, not just income reported in surveys. The claim on business savings (or undistributed corporate profits, $S^{\pi}$ in equation 4 above) is one important example. Such saving has been rising over time (e.g., Chen et al. (2017)) and represented $4.2 \%$ of National Income from 2012 to 2015. This income would be missed in an approach using survey measures of saving rates.

Furthermore, Heathcote et al. (2010) show an average gap of 21 percentage points between the NIPA measure of personal income and the measure in the Current Population Survey. They show that most of the difference comes from the fact that NIPA includes employer contributions to pension and health care plans and the dividends and interest payments realized on pensions that are not distributed to households. The bottom line is that any approach using survey data to estimate the contribution to national savings from any group will be systematically underestimated given these important sources of savings that are missed in surveys.

A third approach relies on estimates of wealth and the consumer budget constraint that links savings to wealth accumulation, what we call the wealth-based approach. The basic idea is to infer savings from the evolution of net worth and an estimate of asset price inflation. This is similar to approaches taken in Saez and Zucman (2016), Kuhn et al. (2019), and Smith et al. (2019b).

Both the income less consumption approach and the wealth-based approach require assumptions given limited data availability. The income less consumption approach relies on assumptions about the distribution of consumption across groups over time, while the wealth-based approach relies on 
assumptions of asset price inflation. Section 3 presents the income less consumption approach and Section 5 presents the wealth-based approach. As we show, both approaches show a similar result: there has been a large increase in saving by the top $1 \%$ of the distribution which has corresponded to a large decline in saving by the bottom $90 \%$.

\section{Measuring the Saving Glut of the Rich}

\subsection{Shares of national income across income distribution}

Starting from equation 5, the DINA microfiles made available publicly by Piketty et al. (2018) are used to measure the first three terms that define $\Theta_{i}: Z_{i}, T_{i}$, and $R_{i}$. The benefit of the PSZ approach is that it allocates all of national income across the income distribution, not just fiscal income reported on tax filings. ${ }^{5}$ We follow PSZ in using the adult individual as the unit of observation and splitting income equally among spouses. ${ }^{6}$

The after-tax income shares $\left(\widehat{\alpha_{i}}\right)$ start with pre-tax income shares $\left(z_{i}\right)$, subtract taxes $\left(t_{i}\right)$, and add back government consumption expenditures $\left(g_{i}\right)$, transfers $\left(r_{i}\right)$, and the share of the government surplus for each group $\left(s_{i}\right)$. All lower case letters reflect the nominal amounts scaled by national income $(Z)$.

Formally, the after tax income shares are defined as:

$$
\widehat{\alpha_{i}}=\frac{z_{i} * Z-T_{i}+R_{i}+G_{i}+S_{i}}{Z}=z_{i}-t_{i}+r_{i}+g_{i}+s_{i}
$$

The first three terms are straight-forward, but some confusion may arise with the terms $g_{i}$ and $s_{i}$. PSZ add these terms back to the after-tax income shares to ensure that the sum of the after-tax income shares add up to national income. This follows from the government budget equation: $S^{g}=T-R-G$. Given this budget equation:

$$
\sum_{i=1}^{N} \widehat{\alpha_{i}} * Z=Z-T+R+G+S^{g}=Z
$$

However, as is clear in equation 3, we instead want to measure $z_{i}-t_{i}+r_{i}$. That is, we want to ignore the $g_{i}$ and $s_{i}$ terms in the PSZ definition of after-tax income shares in order to capture the household saving decision independent of what the government does with its own spending and

\footnotetext{
${ }^{5}$ In Section 4.3, the central results are also shown using the CBO income shares (CBO (2019)).

${ }^{6}$ As noted in PSZ, trends in marriage rates mean that the rise in income inequality is over-stated when using tax units as the unit of observation.
} 
borrowing policies. As a result, the final measures of after-tax income shares used in this study are:

$$
\alpha_{i}=\frac{z_{i} * Z-T_{i}+R_{i}}{Z}=z_{i}-t_{i}+r_{i}=\widehat{\alpha}_{i}-g_{i}-s_{i}
$$

Figure 1 plots the after-tax share $\left(\alpha_{i}\right)$ for the top 1\%. As it shows, the after-tax income share of the top $1 \%$ of the income distribution increased by 3.4 percentage points from 1980 to 1988 , by 5.5 percentage points by 2005, and by 7.7 percentage points by 2012 .

Figure 1: Top 1\% After-tax Shares of National Income

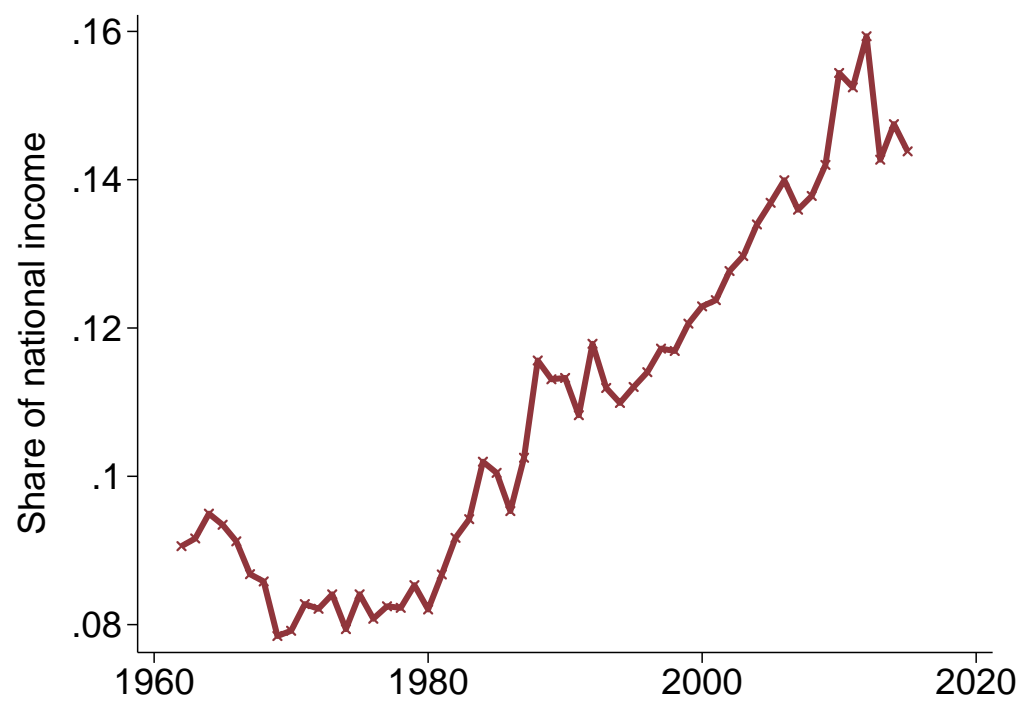

Data are from Piketty et al. (2018). This represents pre-tax income minus taxes plus transfers for the top $1 \%$, scaled by national income.

\subsection{Consumption expenditures across the income distribution}

The last component needed to measure savings of each income group $\left(\Theta_{i}\right)$ is consumption $\left(C_{i}\right)$. Measurement of the consumption of the top of the income distribution is a challenge given the lack of a comprehensive data set focused on consumption of the rich. The approach taken here is to rely on two items: the share of consumption across the income distribution in a given baseline year, and an assumption of the evolution of the consumption to income ratio of the top $1 \%$ over time.

There are three main groups that are the focus of the analysis below: the top $1 \%$ of the income distribution, the next 9\%, and the bottom 90\%. As a starting point, the consumption shares across these three groups are measured using the the Panel Study on Income Dynamics (PSID) for odd years from 2005 and 2013. The average consumption shares of the three main groups are calcu- 
lated for these five years, and this is the consumption share used for the baseline year $2009 .^{7}$ The consumption share of the top $1 \%$ using this technique is $3.8 \%$, and the consumption share of the next $9 \%$ is $18.5 \%$.

However, there is widespread evidence that the consumption share of the top of the income distribution is under-reported in survey evidence. ${ }^{8}$ To account for this under-reporting, in the baseline measurement of the saving glut of the rich, we assume that the consumption of the top $1 \%$ is under-reported by $50 \%$, and the consumption of the next $9 \%$ is under-reported by $15 \%$. This yields an average consumption share of the top $1 \%$ of 5.7 percentage points from 2005 to 2013, and an average consumption share of the next $9 \%$ of 21.2 percentage points. The total consumption that is added to the consumption of the top $1 \%$ and next $9 \%$ to correct for under-reporting is subtracted from the bottom $90 \% .^{9}$

The second critical input into the calculation of consumption shares is the assumption of the consumption to income ratio over time. The most conservative approach would be to assume that the consumption to income ratio of the top $1 \%$ has been constant over time, which would imply that the consumption shares and income shares have increased at the same growth rate. This is the baseline assumption made in the analysis below. Under this assumption, the top 1\% and next $9 \%$ are assumed to have a constant consumption to income ratio over time (which is the 2005 to 2013 average), and the bottom $90 \%$ are assigned the residual consumption.

This assumption, in our view, is likely excessively conservative given evidence in the literature. The average post-tax real income of the top $1 \%$ implied by their share of national income was $\$ 420$ thousand in 1982 and $\$ 1.11$ million in 2015 (in 2015 dollars). In contrast, the average post-tax real income of the bottom $90 \%$ increased from $\$ 29$ thousand to $\$ 44$ thousand. Given estimates in the literature, it is unlikely that the consumption to income ratio for the top $1 \%$ stayed constant given a rise in real income of a factor of almost three. For example, Straub (2019) finds an elasticity of consumption to changes in permanent income of 0.7 . This is for permanent income, not the actual income used here which includes both a permanent and transitory component. Furthermore, recent evidence in Guvenen et al. (2019) and De Nardi et al. (2018) shows that high income earners are

\footnotetext{
${ }^{7}$ The measure of consumption in the PSID was significantly expanded in 2005, and the consumption shares can be constructed for every other year from 2005 to 2013. Concern might arise that this measure is skewed by dynamics surrounding the Great Recession (e.g., Heathcote and Perri (2018)). However, all results are similar if the average is calculated for 2011 and 2013 and 2012 is used as the baseline year.

${ }^{8}$ There is a large literature discussing the potential under-reporting of consumption by the rich in various surveys, but the Consumer Expenditure Survey in particular. See for example, Aguiar and Bils (2015), Carroll et al. (2015), Attanasio and Pistaferri (2016), and Meyer and Sullivan (2017).

${ }^{9}$ Given that the saving glut of the rich is measured using changes in savings over time, the size of the saving glut is quite insensitive to the assumption on the level of the consumption share of the top $1 \%$ in the baseline year. The trend in the consumption share over time is more important, which is why the baseline analysis uses the most conservative assumption. A further discussion of consumption shares across the income distribution, including a comparison to shares from the existing literature, is in Appendix Section A.1.
} 
more likely to experience positive transitory shocks to their income process, bolstering the viewpoint that the consumption to income ratio almost assuredly declines with high income realizations.

Following the evidence in Straub (2019), an alternative assumption for the evolution of the consumption to income ratio of the top $1 \%$ would be:

$$
\frac{C_{i t}}{\overline{y_{t}}}=K *\left(\frac{y_{i t}}{\overline{y_{t}}}\right)^{\beta}
$$

where $y_{i t}$ is real post-tax income of the top $1 \%$ in year $t$ and $\bar{y}_{t}$ is average real post-tax income across all groups in year $t$. The scaling of all variables helps ensure that average changes in income over time do not induce changes in the consumption to income ratio. The constant $K$ is chosen so that the equation holds in the benchmark year, here $t=0: K=\frac{C_{i 0}}{\overline{y_{0}}} *\left(\frac{y_{i 0}}{\overline{y_{0}}}\right)^{-\beta}$.

The year $t=0$ is the benchmark year, which in this setting is 2009, the mid-point of 2005 to 2013. The critical parameter is $\beta$, which reflects the elasticity of consumption with respect to income, which Straub (2019) estimates to be 0.7 when the income measure is permanent income. In this specification, the consumption to income ratio is constant if $\beta=1$, but declines in income if $\beta<1$. Robustness tests reported below in Section 4.3 lower the assumption from $\beta=1$ (which is the baseline) to $\beta=0.7$ and $\beta=0.5$. When assuming $\beta=0.7$ or $\beta=0.5$ instead of $\beta=1$, the extra consumption removed from the top $1 \%$ is added to the next $9 \%$ and the bottom $90 \%$ proportional to their after-tax income shares. ${ }^{10}$

The solid red line in Figure 2 plots the consumption shares of the top $1 \%$ of the income distribution where the baseline level is adjusted for under-reporting and where $\beta=1$ in equation 8 . This is the baseline specification used going forward in the analysis, which produces the largest increase in the consumption share of the top $1 \%$ over time. A larger rise in the consumption share of the top $1 \%$ reduces the size of the saving glut of the rich over time, which is why we refer to this as the most conservative assumption. Under this assumption, the consumption share of the top $1 \%$ increased from $4.1 \%$ in 1982 to $6.1 \%$ in 2015 .

For the sake of completeness, the figure also plots the consumption shares for specifications where the under-reporting correction is not implemented, and for specifications with $\beta=0.5$ and $\beta=0.7$. As should be expected, the consumption share increases by less under the assumption that consumption to income ratios decline in income.

\footnotetext{
${ }^{10}$ The assumed consumption to income ratios overtime are meant to capture long-run trends as opposed to short-run changes due to cyclical factors. Heathcote and Perri (2018) show that such cyclical factors are important in explaining consumption to income ratios across the wealth distribution during recessions.
} 
Figure 2: Consumption Share of the Top 1\% National Income Earners

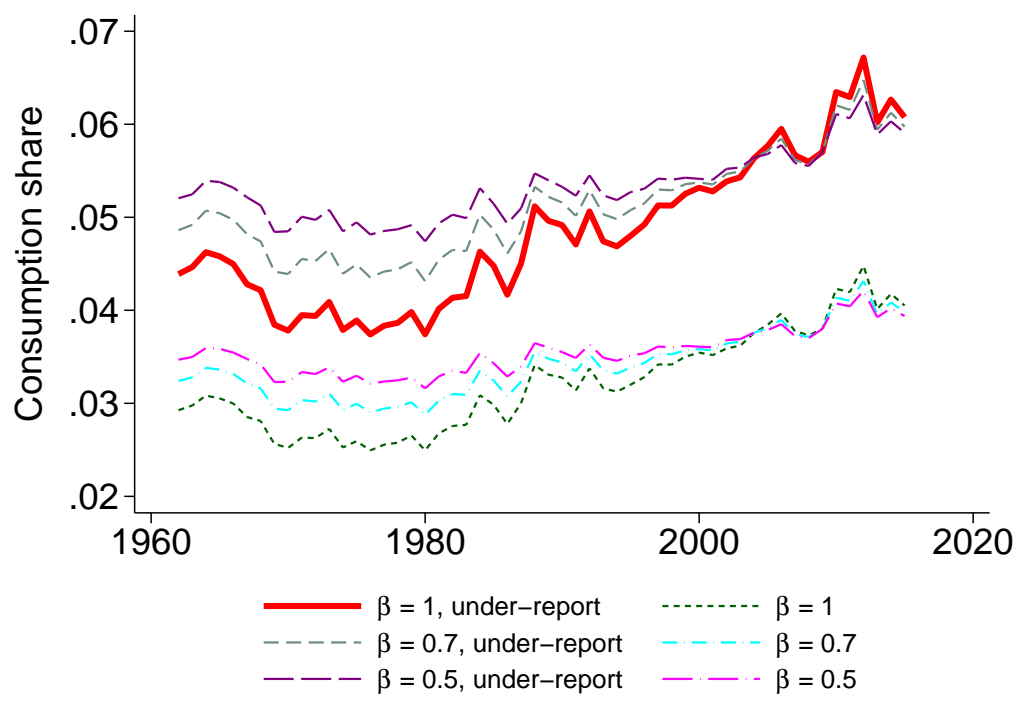

The average consumption share of the top $1 \%$ from 2005 to 2013 is calculated using the PSID, and the average is used for the baseline year 2009. Then the time series is generated using different assumptions on the evolution of the consumption to income ratio of the top $1 \%$. $\beta=1$ is a constant consumption to income ratio, and lower levels of $\beta$ reflect a steeper decline in the consumption to income ratio based on income. Under-report refers to the fact that the baseline consumption share is inflated by $50 \%$ to account for under-reporting of consumption in the PSID by the top $1 \%$. The solid red line is the baseline specification used going forward. Please see text for more details.

\subsection{The Saving Glut of the Rich}

Following equation 7 above, the saving glut of the rich over time is defined as:

$$
\theta_{t o p 1, t}=\frac{\left(Z_{t o p 1, t}-T_{t o p 1, t}+R_{t o p 1, t}-C_{t o p 1, t}\right)}{Z_{t}}=\alpha_{t o p 1, t}-c_{t o p 1, t}
$$

This captures the total amount of savings generated by the top $1 \%$ of the income distribution, scaled by national income in order to help interpret magnitudes. Figure 3 plots the saving glut of the rich under the various assumptions on the evolution of consumption of the top $1 \%$ discussed in Section 3.2 above. As Figure 3 shows, the rise in the saving glut of the rich is large under any of the assumptions. 
Figure 3: Saving Glut of the Rich

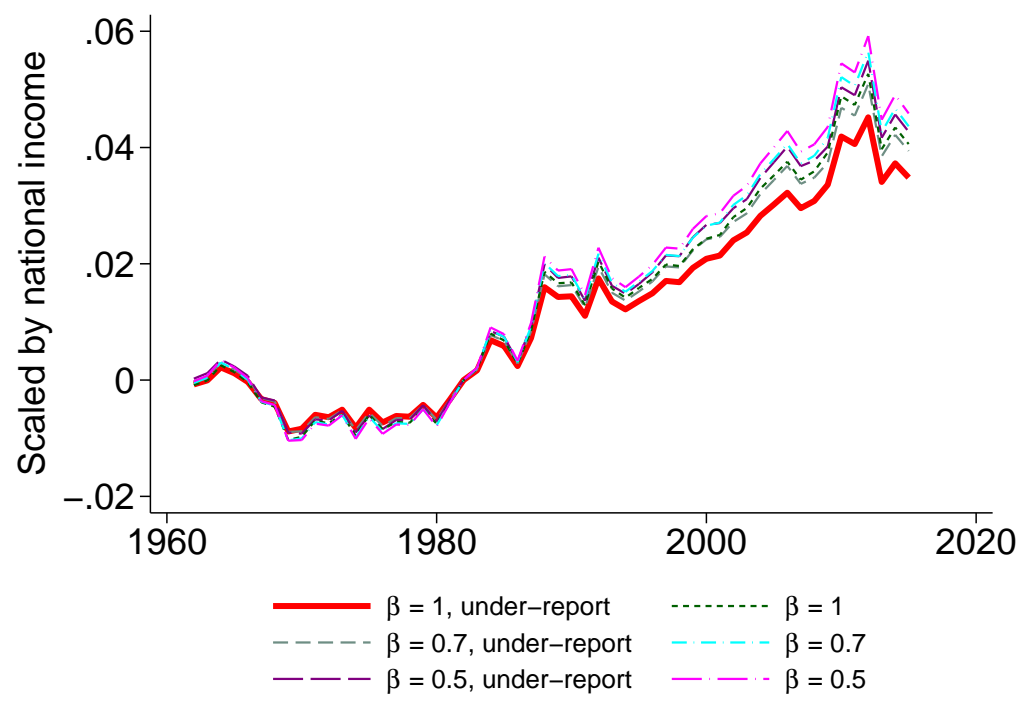

The saving glut of the rich is defined to be the after-tax income of the top $1 \%$ of the income distribution minus personal consumption of the top $1 \%$ of the income distribution, scaled by national income. All series are relative to 1982. Different series reflect different assumptions on the evolution of the consumption to income ratio of the top $1 \% . \beta=1$ is a constant consumption to income ratio, and lower levels of $\beta$ reflect a steeper decline in the consumption to income ratio based on income. Under-report refers to the fact that the baseline consumption share is inflated by $50 \%$ to account for under-reporting of consumption in the PSID. The solid red line is the baseline specification used going forward. Please see text for more details.

Table 1 presents the magnitude of the saving glut of the rich over time. The breaks in time chosen in Table 1 capture the main macroeconomic episodes of the time period. The rise in inequality and household debt began in the early 1980s; we choose 1983 as the initial breakpoint to avoid issues related to the recessions of 1980 and 1981-1982. The breakpoint in 1998 is meant to capture the period in which house price growth and household debt accelerated substantially. The breakpoint in 2008 captures the momentous Great Recession and its aftermath. For transparency, the full time series is always shown in addition to means by these four periods. ${ }^{11}$

\footnotetext{
${ }^{11}$ The breakpoints are similar to those used in Bartscher et al. (2019), who call the years between 1965 to 1983 the "stability" period, the 1983 to 2007 period the "second debt boom", and the years between 2007 to 2016 the period of "crisis and deleveraging."
} 
Table 1: Saving Glut of the Rich Over Time

\begin{tabular}{lc}
\hline Time Period & Baseline \\
\hline $63-82$ & 0.057 \\
$83-97$ & 0.073 \\
$98-07$ & 0.086 \\
$08-15$ & 0.099 \\
\hline
\end{tabular}

The saving glut of the rich is the after-tax income of the top $1 \%$ of the income distribution minus personal consumption of the top $1 \%$ of the income distribution, scaled by national income. The baseline estimate assumes a 50\% under-reporting of consumption by those in the top $1 \%$ of the income distribution from 2005 to 2013, and a constant consumption to income ratio over time. The table shows annual averages for each time period.

Under the baseline assumptions, the saving glut of the rich increased by an average of $4.2 \%$ percentage points of national income annually from the the first 20 years of the sample to the 2008 to 2015 period. The increase occurred almost linearly over time. From 1998 to 2015, the top 1\% saved an additional 3.5 percentage points of national income annually relative to the 1963 to 1982 period. ${ }^{12}$

\section{Absorption of the Saving Glut of the Rich}

\subsection{Traditional channels}

National accounting provides for a simple decomposition exercise to understand where the saving glut of the rich ultimately settled. Starting with equation 4 , we split savings across the income distribution, scale all terms by national income, and move all terms except for the savings of the rich to the right hand side to obtain:

$$
\theta_{t o p 1, t}=\frac{I_{t}^{n}}{Z_{t}}+\frac{F_{t}}{Z_{t}}-\theta_{n e x t 9, t}-\theta_{b o t 90, t}-\frac{S_{t}^{g}}{Z_{t}}
$$

The saving glut of the rich could have financed net domestic investment $I^{n}$ or it could have been invested in other countries $(F)$. If neither of these happened, then a rise in the saving glut of the rich must have increased net borrowing by other households or by the government $\left(-S^{g}\right)$.

\footnotetext{
${ }^{12} \mathrm{~A}$ discussion of the implied saving rate of the top $1 \%$ under the income less consumption approach and the wealth-based approach is located in Appendix Section A.2. As we show there, the implied saving rate of the top $1 \%$ is consistent with the existing literature once missing forms of income with a high saving rate are taken into account.
} 
Figure 4: Net Domestic Investment and the Current Account
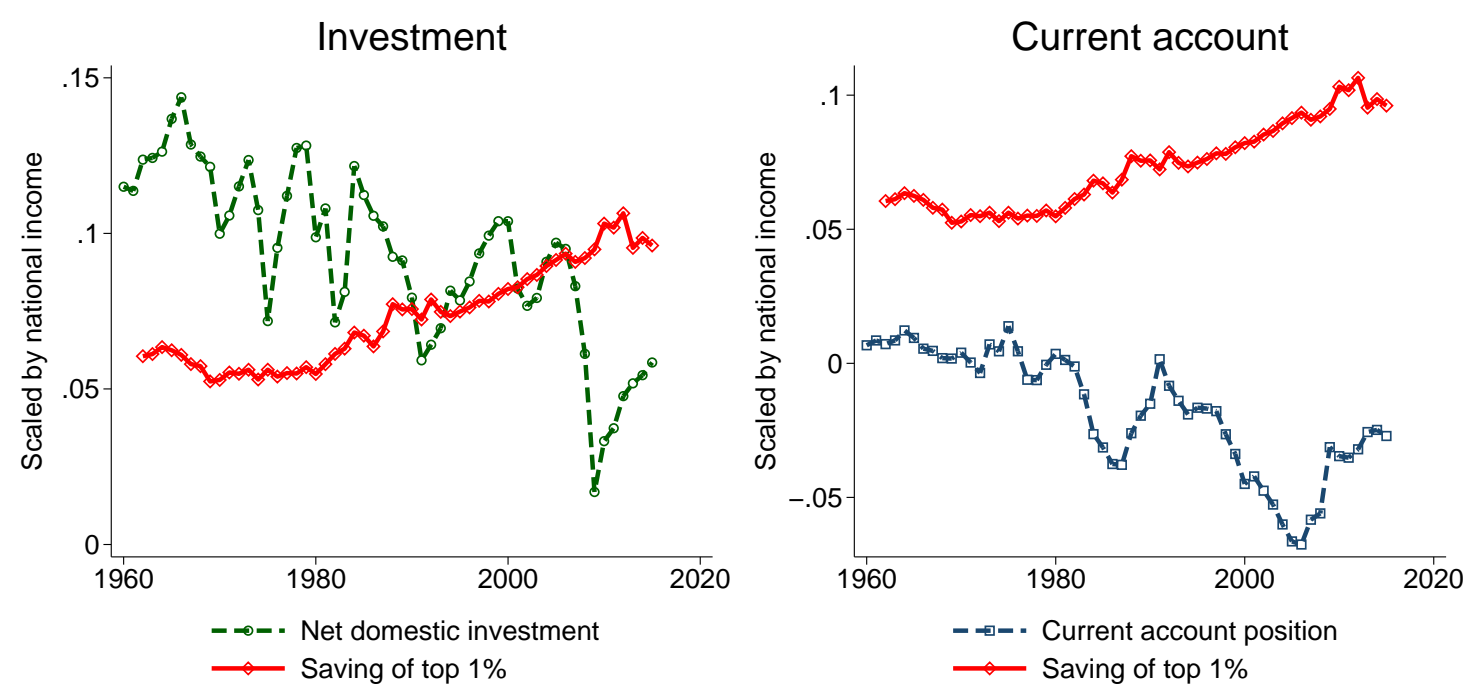

The saving of the top $1 \%$ is defined to be the after-tax income of the top $1 \%$ of the income distribution minus personal consumption of the top $1 \%$ of the income distribution, scaled by national income. Net domestic investment comes from the national accounts, and includes both government and private investment. The current account is net exports adjusted for net income flows based on the difference in how GDP and National Income account for net income and transfers to foreigners. All series are scaled by national income.

As the left panel of Figure 4 shows, net domestic investment moved in the opposite direction. As the saving glut of the rich increased, net domestic investment fell. In fact, the pattern is so strong that after the Great Recession, the rich were saving a higher percentage of national income than total net domestic investment. The right panel of Figure 4 shows that the current account position of the United States with the rest of the world also moved in the opposite direction. As is well known, the United States borrowed more from the rest of the world over time rather than investing more in it.

This pattern has been called the global saving glut, highlighted by Bernanke (2005). This is the idea that there has been an influx of foreign savings that have been transformed into borrowing by governments, firms, and households in many advanced economies. Using the current account of the United States, we can directly compare the global saving glut and the saving glut of the rich.

To do so, the global saving glut in the United States is measured as the current account multiplied by -1 . Figure 5 plots both saving gluts. As it shows, the global saving glut and the saving glut of the rich have been on the same order of magnitude. There have been periods in both the 1990s and 2010 s in which the saving glut of the rich has exceeded the global saving glut. 
Figure 5: Saving Glut of the Rich and the Global Saving Glut

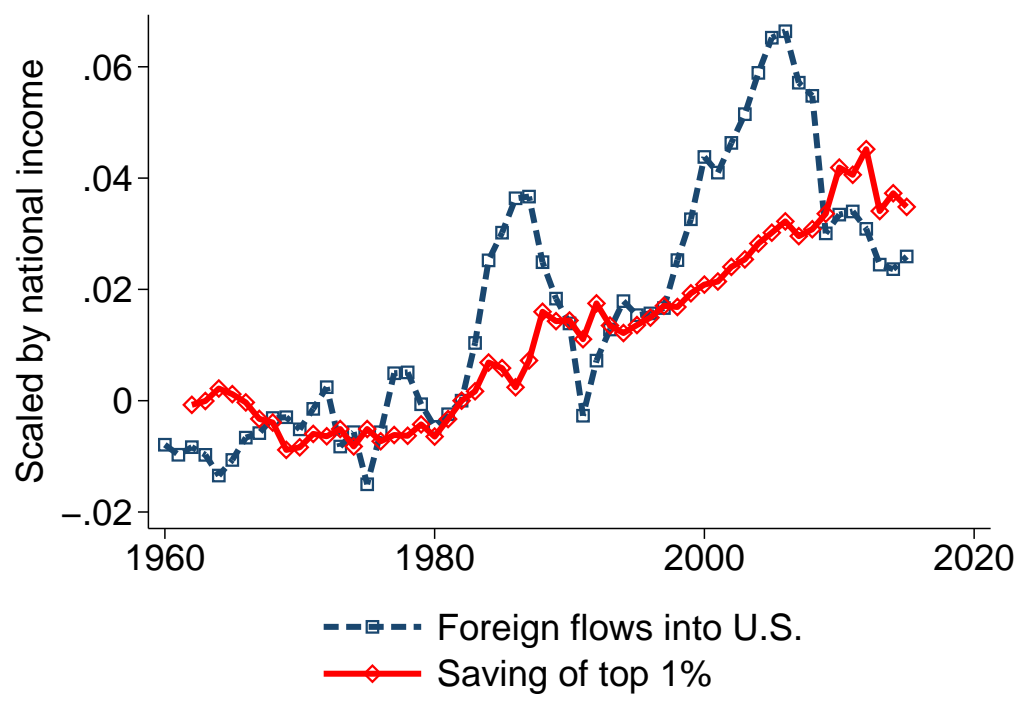

The saving of the top $1 \%$ is defined to be the after-tax income of the top $1 \%$ of the income distribution minus personal consumption of the top $1 \%$ of the income distribution, scaled by national income. Foreign flows into the U.S. is -1 multiplied by the current account of the United States. All series are scaled by national income and the 1982 level is subtracted for each series, respectively.

Table 2 summarizes these results. Net investment has fallen substantially during the period in which the saving glut of the rich accelerated. Prior to 2008, the saving glut of the rich was between three-fifths and two-thirds the size of the global saving glut. Since 2008, the saving glut of the rich has been larger than the global saving glut.

Table 2: Traditional Channels of Absorption

\begin{tabular}{lccc}
\hline Time Period & Saving glut & Investment & Current Account \\
\hline $63-82$ & 0.057 & 0.114 & 0.003 \\
$83-97$ & 0.073 & 0.088 & -0.020 \\
$98-07$ & 0.086 & 0.091 & -0.050 \\
$08-15$ & 0.099 & 0.045 & -0.033 \\
\hline
\end{tabular}

The saving glut of the rich is the after-tax income of the top $1 \%$ of the income distribution minus personal consumption of the top $1 \%$ of the income distribution, scaled by national income. Investment is net domestic investment and the current account is net exports adjusted for net income flows based on the difference in how GDP and National Income account for net income and transfers to foreigners. All series are scaled by national income. Annual averages for each period are shown. 


\subsection{Dissaving by the bottom $90 \%$ and by the government}

Given that investment and the current account did not increase as the saving glut of the rich increased, Equation 9 implies that either the government or households in the bottom $99 \%$ of the income distribution must have reduced saving significantly. The household side is shown in Figure 6. Annual savings of households in the 90th to 99th percentile of the income distribution (what we call the next $9 \%$ ) have been steady at about $4 \%$ of national income each year.

Figure 6: Saving Glut of the Rich and Saving of the non-Rich

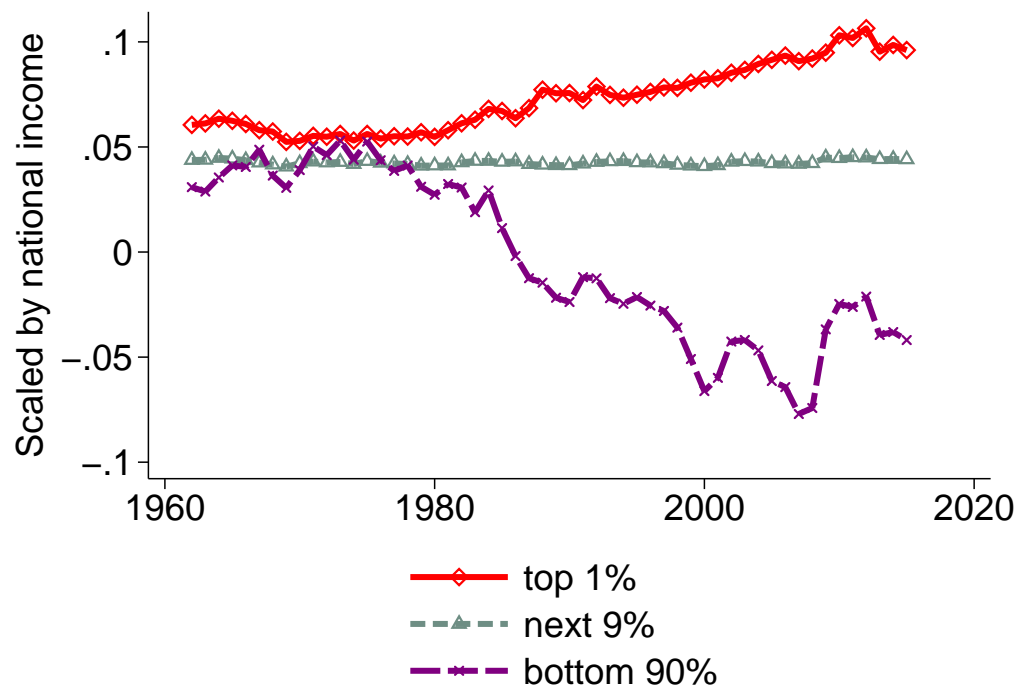

The saving glut of the rich is defined to be the after-tax income of the top $1 \%$ of the income distribution minus personal consumption of the top $1 \%$ of the income distribution, scaled by national income. The savings of the other two groups is similarly defined.

In contrast, there has been a large decline in the saving of the bottom $90 \%$ of the income distribution. Table 3 reports the annual savings of the top 1\%, next 9\%, and bottom 90\%, all scaled by national income. From 1998 to 2015, the bottom 90\% saved on average 8.7\% percentage points of total national income annually less than they did from 1963 to 1982. 
Table 3: Absorption by the Bottom 90\%

\begin{tabular}{lcccc}
\hline Time Period & Top 1\% & Next 9\% & Bottom 90\% & Gov Saving \\
\hline $63-82$ & 0.057 & 0.043 & 0.040 & -0.030 \\
$83-97$ & 0.073 & 0.043 & -0.011 & -0.051 \\
$98-07$ & 0.086 & 0.042 & -0.055 & -0.026 \\
$08-15$ & 0.099 & 0.044 & -0.038 & -0.089 \\
\hline
\end{tabular}

The savings of the top $1 \%$ are the after-tax income of the top $1 \%$ of the income distribution minus personal consumption of the top $1 \%$ of the income distribution, scaled by national income. Savings of the other two groups are similarly defined. Annual averages for each time period are shown.

This decline in savings of the bottom $90 \%$ has been significantly larger than the increase in savings of the top $1 \%$. This reflects the fact that both the global saving glut and the saving glut of the rich have increased substantially after 1982, and net domestic investment has actually fallen. Both the influx of foreign capital and the rise in savings of the top $1 \%$ have been associated with a large decline in saving by the bottom $90 \%$.

The final column of Table 3 examines the government deficit, which is the final margin of adjustment available to absorb the saving glut of the rich. As it shows, the government deficit was larger from 1983 to 1997, but was steady from 1998 to 2007. The government deficit increased by a large amount from 2008 to 2015. This was the same time period in which the net saving position of the bottom $90 \%$ increased by almost two percentage points of national income. The post Great Recession evidence suggests that the saving glut of the rich was absorbed by the government when consumption of the bottom $90 \%$ fell. This issue is explored further in Section 8 below.

Figure 7 accumulates all of these margins of absorption of the saving glut of the rich. Starting with equation 9, we re-arrange to obtain:

$$
\theta_{t o p 1, t}+\theta_{\text {next } 9, t}+\theta_{\text {bot } 90, t}-\left(\frac{I^{n}}{Z}\right)_{t}-\left(\frac{F}{Z}\right)_{t}+\left(\frac{S^{g}}{Z}\right)_{t}+\epsilon_{t}=0
$$

For each of the 7 variables, we construct $\hat{V}_{t}=V_{t}-V_{\text {pre }}$, where $V_{\text {pre }}$ is defined to be the average of variable $V$ in the 10 years prior to 1983. Then for each variable we sum across all $t$ to obtain $\bar{V}=\sum_{t=1983}^{2015} \hat{V}_{t}$ where $\bar{V}$ is the accumulation of the differences relative to the pre-period average. Therefore,

$$
\theta_{\text {top } 1}^{-}+\theta_{\text {next } 9}^{-}+\theta_{b o t 90}^{-}-\left(\frac{\overline{I^{n}}}{Z}\right)-\left(\frac{\bar{F}}{Z}\right)+\left(\frac{\overline{S^{g}}}{Z}\right)+\bar{\epsilon}=0
$$


Equation 10 implies that the accumulated saving glut of the rich $\left(\theta_{t o p 1}^{-}\right)$must be absorbed by one of the other 6 terms: dissaving of the bottom $90 \%\left(\theta_{b o t 90}^{-}\right)$, the next $9 \%\left(\theta_{\text {next } 9}{ }^{-}\right)$, or the government $\left(\frac{\overline{S^{g}}}{Z}\right)$; a rise in investment $\left(\frac{\overline{I^{n}}}{Z}\right)$; a rise in capital outflows to other countries $\left(\frac{\bar{F}}{Z}\right)$; or the statistical discrepancy $(\bar{\epsilon})$.

Figure 7: Absorption of the Accumulated Saving Glut of Rich

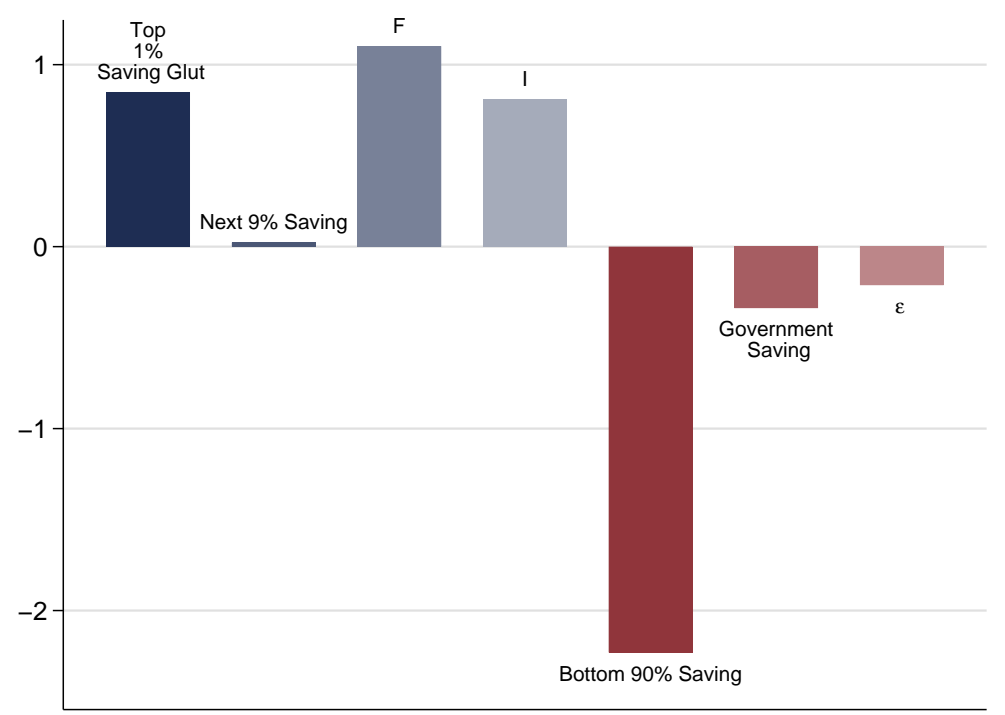

This figure presents the accumulated differences relative to the averages of the 1973 to 1982 levels in the equation: $\theta_{\text {top } 1}^{-}+\theta_{\text {next } 9}^{-}+\theta_{\text {bot } 90}^{-}-\left(\frac{\overline{I^{n}}}{Z}\right)-\left(\frac{\bar{F}}{Z}\right)+\left(\frac{\overline{S^{g}}}{Z}\right)+\bar{\epsilon}=0$. These terms represent saving of the top $1 \%$, next $9 \%$, and bottom $90 \%$, in addition to saving of the government $\left(\frac{\overline{S^{g}}}{Z}\right)$, investment $\left(\frac{\overline{I^{n}}}{Z}\right)$, capital outflows $\left(\frac{\bar{F}}{Z}\right)$, and the statistical discrepancy $(\bar{\epsilon})$.

Figure 7 shows the accumulation of each of the seven variables in equation 10. By construction, the bars sum to zero. The accumulated saving glut of the rich was on the same order of magnitude as national income from 1983 to 2015. Capital flows and investment move in the opposite direction as would be needed to absorb some of the saving glut of the rich, as already noted above. To maintain the accounting identity, the combined savings of both the government and the bottom $90 \%$ must have fallen substantially. Figure 7 shows that most of the decline in saving was by the bottom $90 \%$. The accumulated dissaving of the bottom 90\% from 1983 to 2015, relative to the average level from 1973 to 1982, was more than twice national income. The saving glut of the rich was associated with a substantial dissaving of non-rich households. 


\subsection{Robustness}

The size of the saving glut of the rich is robust to alternative assumptions on the evolution of consumption and income shares over time. Table 4 shows the saving glut of the rich under different assumptions, where the difference relative to the 1979 to 1982 period is shown in each column. ${ }^{13}$ The second and third column show the saving glut of the rich under the assumption that the consumption to income ratio falls in income. Recall that $\beta$ comes from equation 8 above, with a smaller $\beta$ implying a larger decline in the consumption to income ratio as income increases. The assumption of a lower $\beta$ produces a smaller increase in the consumption share of the top $1 \%$ over time, which leads to a larger size of the saving glut of the rich over time.

The three columns on the right show the size of the saving glut of the rich using the after-tax income shares reported by the Congressional Budget Office (CBO (2019)). The baseline analysis uses the Piketty et al. (2018) methodology to obtain income shares by income group because these shares add to national income by construction, and the documentation and construction of the shares make it easy to construct the shares used here $\left(z_{i}-t_{i}+r_{i}\right)$. The CBO shares are not designed to capture all of national income, and the documentation does not detail exactly what parts of national income are included.

To compare to the shares constructed using the Piketty et al. (2018) methodology, we operate under the assumption that the CBO after-tax income shares are designed to capture $z_{i}-t_{i}+r_{i}$ for each income group. Mechanically, to obtain the CBO income share for each group, we take the CBO after-tax income shares reported and multiply the share by $Z-T+R$. As a result, the aftertax income shares of PSZ and CBO add up to the same aggregate figure. As the three columns on the right show, the saving glut of the rich is 0.9 percentage points of national income larger annually from 1998 to 2007 when using the CBO income shares. However, the saving glut of the rich declined from 2008 to 2015 under the CBO income series, even though it continued to increase using the PSZ series. ${ }^{14}$

\footnotetext{
${ }^{13}$ The pre-period is 1979 to 1982 in Table 4 given that the CBO income share is not available prior to 1979 . This does not make a material difference given that the amount of savings of the top $1 \%$ as a share of national income using the PSZ income shares was flat from 1963 to 1982.

${ }^{14}$ Appendix Figure A1 shows the full time series of the saving glut of the rich for both the CBO and PSZ top 1\% income shares.
} 
Table 4: Robustness of the Saving Glut of Rich

\begin{tabular}{lccccccc}
\hline & \multicolumn{3}{c}{ PSZ } & & \multicolumn{3}{c}{ CBO } \\
\cline { 3 - 4 } Decade & $\beta=1$ & $\beta=0.7$ & $\beta=0.5$ & $\beta=1$ & $\beta=0.7$ & $\beta=0.5$ \\
\hline $79-82$ & 0.000 & 0.000 & 0.000 & 0.000 & 0.000 & 0.000 \\
$83-97$ & 0.015 & 0.016 & 0.018 & 0.017 & 0.018 & 0.020 \\
$98-07$ & 0.028 & 0.032 & 0.035 & 0.037 & 0.040 & 0.043 \\
$08-15$ & 0.041 & 0.046 & 0.049 & 0.031 & 0.035 & 0.039 \\
\hline
\end{tabular}

This table shows the average savings to national income ratio for the top $1 \%$ of the income distribution relative to the 1979 to 1982 period. In the first three columns, the Piketty et al. (2018) income shares are used. In the second three columns, the top $1 \%$ share of income is taken from the CBO (2019) instead of Piketty et al. (2018).

Overall, the increase in national savings driven by the saving glut of the rich was between 3 and 4.5 percentage points of national income if one compares the 1979 to 1982 period with the 1998 to 2015 period. The precise amount within this band varies with different assumptions, but the qualitative point is robust: there was a large increase in savings by the rich during the period of rising income inequality.

\section{Savings Using the Wealth-based Approach}

\subsection{Description of wealth-based approach}

An alternative way of measuring saving by different groups of households is the wealth-based approach that starts with the household budget constraint for group $i$ :

$$
Z_{i t}-T_{i t}+R_{i t}-C_{i t}=\sum_{j \in J}\left(P_{t}^{j} A_{i t}^{j}-P_{t}^{j} A_{i, t-1}^{j}\right)
$$

where $\Theta_{i t}=Z_{i t}-T_{i t}+R_{i t}-C_{i t}$ is savings of group $i$ and $A_{i t}^{j}$ is asset $j$ held by the group $i$. There are a total of $J$ asset types that households hold, with liabilities showing as negative values. Let $\pi_{t}^{j} \equiv \frac{P_{t}^{j}-P_{t-1}^{j}}{P_{t-1}^{j}}$ be asset inflation for asset $j$. Then equation (11) simplifies to:

$$
\Theta_{i t}=\sum_{j \in J}\left(\Delta W_{i t}^{j}-\pi_{t}^{j} W_{i, t-1}^{j}\right)
$$

where $W_{i t}^{j}=P_{t}^{A} A_{i t}^{j}$ is the nominal value of asset $j$ observed in data such as the Financial Accounts. 
We calculate $W_{i t}^{j}$ across the distribution using the capitalization methodology introduced by Saez and Zucman (2016) and Piketty et al. (2018) based on the flow of capital income reported on tax filings, and by including additional information to estimate the wealth associated with income that is not reported on tax filings. ${ }^{15}$ The PSZ methodology builds a total of six asset classes for each group $i$ : fixed income, housing, equity, business wealth, pensions, and debt. ${ }^{16}$ We further split debt into mortgage and non-mortgage debt, and pensions into its fixed income and corporate equity components. ${ }^{17}$

Measuring $\Theta_{i t}$ requires estimates of $\pi_{t}^{j}$ for each asset $j$. In theory, $\pi_{t}^{j}$ refers to asset price appreciation that is driven only by inflation or valuation effects. To use the consumer price analogy, $\pi_{t}^{j}$ is the change in nominal value of the asset holding constant the "quality" and identity of the asset. For example, the asset should not change in terms of expected cash flows. ${ }^{18}$

For housing assets, $\pi_{t}^{j}$ is estimated using a repeat-sales house price index that controls for any changes in housing size or quality. The results shown in this paper use the Jorda-Schularick-Taylor Macrohistory Database for the house price index because of its longer coverage. However, the JST index is highly correlated with other repeat-sales indices, such as CoreLogic. In a robustness check, we also allowed $\pi_{t}^{j}$ to vary by income cohort $i$ by using income-sorted zipcode-level house price index, but this did not change results materially.

For fixed income assets, $\pi_{t}^{j}$ is equal to zero given the manner in which the Financial Accounts are reported. However, in the case of debt, write downs must be taken into account, especially given the importance of debt write-downs during the Great Recession. Debt write-downs imply that $\pi_{t}^{j}$ needs to incorporate a valuation gain for the borrower. In the absence of such an adjustment, the methodology would incorrectly conclude that borrowers saved part of their income to pay down debt. The likelihood of debt write-downs varies considerably by income group $i$, with lower income borrowers more likely to default and therefore experience a write-down. Therefore, $\pi_{t}^{j}$ is calculated for mortgage and non-mortgage debt separately for the top $10 \%$ and bottom $90 \%$, with the valuation terms being indexed as $\pi_{t}^{i j}$.

\footnotetext{
${ }^{15}$ As shown in Appendix Section B, the results are qualitatively similar when assuming a higher earned interest rate on fixed income assets for the top 1\%, as suggested by Bricker et al. (2018) and Smith et al. (2019b).

${ }^{16}$ The total net worth of households in PSZ is less than the total net worth of households computed by the Financial Accounts. The difference between the two is mainly driven by the exclusion of consumer durables in PSZ. Housing in PSZ includes housing wealth from properties owned for rental purposes.

${ }^{17}$ We deviate from PSZ's aggregate measures of wealth in one substantial way. Whereas PSZ measure total mortgages on tenant-occupied properties using US Financial Accounts series FL113165005 (Nonfinancial noncorporate business; total mortgages; liability), we use the sum of FL113165105 (Nonfinancial noncorporate business; home mortgages; liability) and FL113165405 (Nonfinancial noncorporate business; multifamily residential mortgages; liability). The reason for this change is to ensure that the measure of mortgages for properties rented out does not include mortgages on properties used for other business purposes. On average, our total rental mortgage debt is 46\% of PSZ's total.

${ }^{18}$ The exact details of the computation of the various $\pi_{t}^{j}$ and total saving can be found in the data and code that is made public with this draft.
} 
The terms $\pi_{t}^{i j}=1-W D_{t}^{i j}$ where $W D_{t}^{i j}$ is the percentage of debt that is written down in a particular year for group $i$. $W D_{t}^{i j}$ is estimated by first calculating net chargeoffs as a share of outstanding debt on bank balance sheets, separately for mortgage and non-mortgage consumer credit. Since we know total outstanding debt in a given year, the net chargeoff ratio gives us the total amount of debt that is written down. We then distribute the written down debt to group $i$ based on the fraction of total defaults accounted for by group $i$. This number is computed using zip code level data on defaults and average income of households living in a zip code. ${ }^{19}$

Finally, $\pi_{t}^{j}$ must be estimated separately for corporate equities, assets which have within them other corporate equities (such as pensions), and non-corporate business equities. When estimating $\pi_{t}^{j}$ for equities, it is important to emphasize that $\pi_{t}^{j}$ is not the same as capital gains. The price of a share reflects savings done by the corporation on behalf of the shareholders. The appreciation in the price of the share that reflects such retained earnings should not be reflected in $\pi_{t}^{j}$, as this is actual saving.

Furthermore, a share may generate a yield, which shows up as $Z_{i t}$ in equation 11, through either dividends or share buybacks. In the case of the latter, this is because buybacks change the quality of the asset - a share after a buyback cannot be considered equivalent to a share before the buyback. For these reasons, the typical share price gain is not the same as $\pi_{t}^{j}$. An additional complication that arises in calculating $\pi_{t}^{j}$ for equities is that the observed equity wealth, such as the one reported Financial Accounts of the Federal Reserve, is itself imputed using various valuation metrics. As such, what we really need is the "inflation" in these valuation metrics over time.

Given all these considerations, estimating $\pi_{t}^{j}$ for corporate equities and other equity-like assets like private business is a challenge. However, given that we have estimated $\pi_{t}^{j}$ for all other asset types, $\pi_{t}^{j}$ can be calculated for equity as the residual pricing factor that ensures that aggregate private savings calculated using the wealth-based approach matches the aggregate private savings in NIPA $\left(S^{p}+S^{\pi}\right.$ in equation 4 above $) .{ }^{20}$

The wealth-based approach to calculation of savings across the distribution is also implemented in Saez and Zucman (2016), Kuhn et al. (2019), and Smith et al. (2019b). However, there are two key differences. First, the methodology here accounts for saving done by corporations on behalf of the household sector, which should be included in savings calculated using the household budget constraint. This has a material effect on savings given the large increase in corporate savings in the United States over time (e.g., Chen et al. (2017)). Second, debt write-downs are modeled here as a valuation gain instead of as active saving. This more accurately captures the nature of debt write-downs, which are not "saving" in the sense of earned income being used to pay back debt.

\footnotetext{
${ }^{19}$ The complete details of this methodology are shown in Appendix Section A.4.

${ }^{20}$ Appendix Section A.4 shows that the resulting $\pi_{t}^{j}$ for equity is highly correlated with the equity capital gains from the JST Macrohistory Database.
} 
The DINA micro-files are a repeated cross-section, not a panel of individuals. This does not present any issues for the income less consumption approach to calculation of savings of Section 3. For the income less consumption approach, savings in a given year are calculated as the savings of individuals that are in the top $1 \%$ in the same year. These need not be the same individuals over time.

However, the repeated cross-section nature of the DINA files introduces an issue for the wealthbased approach, given that the wealth-based approach relies on changes in asset values from the past year to this year. For example, consider the group of individuals that are in the top $1 \%$ of the income distribution. For the top $1 \%$ in a given year $t$, the change in the assets held from year $t-1$ to $t$ for this specific group is not possible to recover given the repeated cross-section nature of the data. As a result of this problem, the wealth-based methodology follows the literature (Saez and Zucman (2016), Kuhn et al. (2019), and Smith et al. (2019b)) by sorting individuals by wealth instead of income. The logic of this decision is to try to reduce the amount of migration by individuals across groups; an individual's place in the wealth distribution is more stable than the individual's place in the income distribution over time.

\subsection{Savings across the distribution using the wealth-based approach}

Figure 8 presents the savings across the wealth distribution, using the wealth-based approach. For every year savings by each group $i$ is scaled by national income. Then five-year averages of the annual savings to national income ratio are taken for each group. These averages are plotted in Figure 8, benchmarked to the average savings for the group in question from 1977 to $1982 .^{21}$

\footnotetext{
${ }^{21}$ Five year averages are taken given that variable asset price inflation makes the year-to-year changes in savings using the wealth-based approach noisy. This is similar to the approach taken in Piketty et al. (2018) and Smith et al. (2019b).
} 
Figure 8: Savings across the Wealth Distribution, Wealth-based Approach

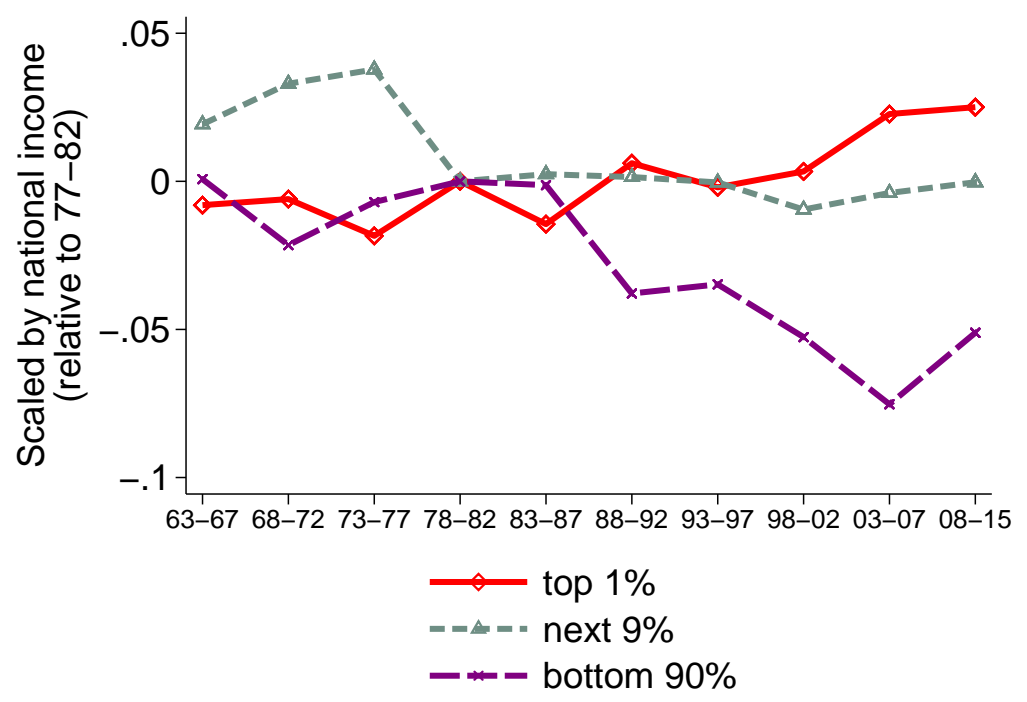

This figure presents average annual savings to national income ratios across the wealth distribution. Savings are calculated using the wealth-based technique: $\Theta_{i t}=\sum_{j \in J}\left(\Delta W_{i t}^{j}-\pi_{t}^{j} W_{i, t-1}^{j}\right)$. Each point represents the average of the annual savings to national income ratio for the five year period, and all series are benchmarked to their respective value for the 1977 to 1982 period.

Table 5 presents the averages for the same four periods as shown above in Table 3 . The saving glut of the rich increased by 2.1 percentage points of national income from the pre-period to the 1998 to 2007 period, and 3.3 percentage points from 2008 to 2015.

Table 5: Savings across the Wealth Distribution, Wealth-based Approach

\begin{tabular}{cccc}
\hline Period & Top 1\% & Next 9\% & Bottom 90\% \\
\hline $63-82$ & 0.035 & 0.062 & 0.040 \\
$83-97$ & 0.040 & 0.041 & 0.023 \\
$98-07$ & 0.056 & 0.033 & -0.017 \\
$08-15$ & 0.068 & 0.040 & -0.004 \\
\hline
\end{tabular}

This table presents average annual savings to national income ratios across the wealth distribution. Savings are calculated based on the wealth-based ratio: $\Theta_{i t}=\sum_{j \in J}\left(\Delta W_{i t}^{j}-\pi_{t}^{j} W_{i, t-1}^{j}\right)$.

The two approaches to calculating savings across the distribution yield qualitatively similar results. The one exception is that the income less consumption approach shows steady saving by 
the next $9 \%$ throughout the sample, whereas the wealth-based approach shows a sharp decline from the pre-1977 period to the post-1977 period.

Both approaches show a rise in saving by the rich, and a decline by the bottom $90 \%$. Comparing magnitudes, the wealth-based approach produces a smaller spread over time in the gap between saving by the top $1 \%$ and bottom $90 \%$. For example, the income less consumption approach shows an increase in the savings by the top $1 \%$ of 2.9 percentage points of national income from the preperiod to the 1998 to 2007 period. The wealth-based approach shows an increase of 2.1 percentage points. For the bottom $90 \%$, the respective numbers are a decline in 9.5 percentage points versus a decline in 5.8 percentage points.

\subsection{Borrowing and dissaving of the bottom $90 \%$}

One advantage of the wealth-based approach relative to the income less consumption approach is that it allows for a decomposition of the components of savings for a given group. This section focuses on the bottom $90 \%$ to provide insight into how the bottom $90 \%$ reduced saving so substantially over time.

Starting with equation 12, let $\Delta N W_{b o t 90, t}=\sum_{j \in J} \Delta W_{b o t 90, t}^{j}$ be the annual change in net worth of the bottom $90 \%, \Delta V_{b o t 90, t}=\sum_{j \in J} \pi_{t}^{j} W_{b o t 90, t-1}^{j}$ be the valuation effect, and $\Theta_{b o t 90, t}$ be savings. By equation 12, $\Delta N W_{b o t 90, t}=\Delta V_{b o t 90, t}+\Theta_{b o t 90, t}$. These three terms are calculated for each year, and scaled by national income in that year. Figure 9 plots the averages over time, where the pre-period is subtracted to focus on the differences.

The solid black line shows that the annual changes in net worth of the bottom $90 \%$ were steady from the pre-period through 2007. However, a focus on net worth hides an important pattern: the bottom $90 \%$ experienced strong valuation gains as they saved less. This is especially true of the 1998 to 2007 period, when house price appreciation was historically strong. During this period, households in the bottom $90 \%$ reduced saving by an annual average of 5.8 percentage points relative to the 1963 to 1982 , but strong valuation gains kept their annual changes in net worth similar to the pre-period. The net worth of the bottom 90\% fell substantially from 2008 to 2015, as the housing market collapsed. During this period, both low savings and a decline in house prices contributed to the substantial decline in net worth. 
Figure 9: Net worth evolution for bottom 90\%

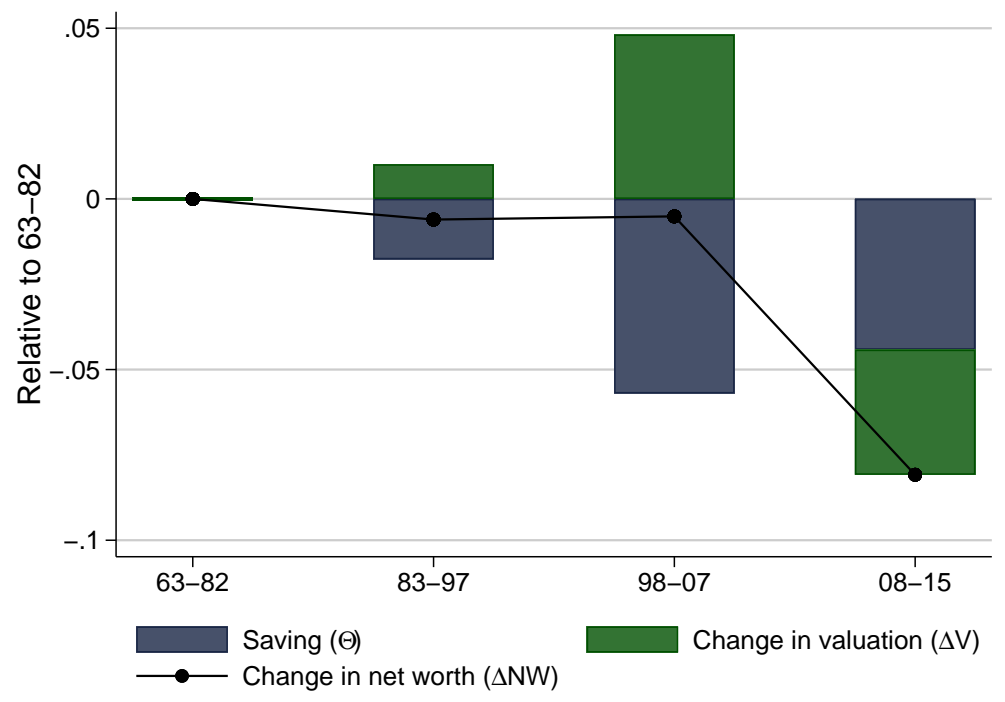

This figure decomposes average annual changes in net worth scaled by national income into two components: the change in the valuation of assets and saving: $\Delta N W_{b o t 90, t}=\Delta V_{b o t 90, t}+\Theta_{b o t 90, t}$. Annual changes are scaled by national income, and then the average is taken for the period in question. The averages for the 1963 to 1982 period are subtracted.

How much of the dissaving was due to debt accumulation versus lower contributions into assets? Starting from equation 12 once again, we can separate the right hand side into debt (D) and assets (A). Given that $\pi_{b o t 90}^{D}$ is zero, we can define contributions as $N=\sum_{j \in J n o t d e b t} \Delta A_{b o t 90, t}^{j}-$ $\pi_{t}^{j} A_{b o t 90, t-1}^{j}$ and rewrite equation 12 as $\Theta_{b o t 90, t}=N_{b o t 90, t}-\Delta D_{b o t 90, t}{ }^{22}$ Annual savings can be broken down into contributions to assets $(N)$ minus additional borrowing $(\Delta D)$. Contributions $N$ can be broken down further into housing and non-housing assets, yielding the equation: $\Theta_{b o t 90, t}=N_{h, b o t 90, t}+N_{n h, b o t 90, t}-\Delta D_{b o t 90, t}$.

Figure 10 plots savings, debt accumulation, and contributions for the bottom $90 \%$, again differenced relative to the pre-period. The dissaving of the bottom 90\% from 1983 to 1997 relative to the pre-period was driven by all three components: an increase in debt, a decline in contributions to housing assets, and a decline in contributions to non-housing assets. In contrast, dissaving in the 1998 to 2007 period was driven by both a large decline in contributions to non-housing assets and a large rise in debt, while contributions to housing assets were similar to the pre-period.

The findings in Figure 10 show that debt accumulation by the bottom 90\% from 1982 to 2007 actually understates the decline in saving. Not only did the bottom $90 \%$ take on substantially more debt, but they also reduced saving in financial assets in particular.

\footnotetext{
${ }^{22}$ Notice we have flipped the sign on debt to make clear that a rise in debt lowers savings.
} 
Figure 10: Debt accumulation and reduction in saving contributions for bottom $90 \%$

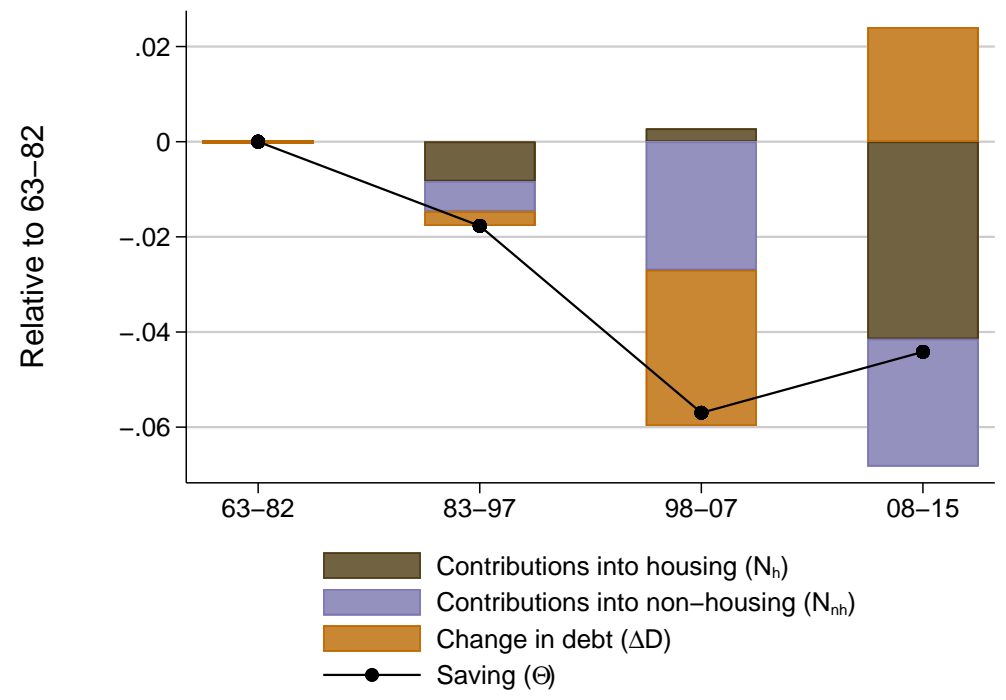

This figure decomposes average annual changes in saving scaled by national income into three components: the change in the contributions to housing assets, the change in contributions to nonhousing assets, and the increase in borrowing: $\Theta_{b o t 90, t}=N_{h, b o t 90, t}+N_{n h, b o t 90, t}-\Delta D_{b o t 90, t}$. Annual changes are scaled by national income, and then the average is taken for the period in question. The averages for the 1963 to 1982 period are subtracted.

The broad patterns in this sub-section are consistent with two recent studies using the SCF+: Kuhn et al. (2019) and Bartscher et al. (2019). The focus of this study is on savings, whereas the focus of these two studies is on the evolution of wealth and debt for the bottom $90 \%$. However, it is reassuring that the two studies find similar results using different data sets. For example, Kuhn et al. (2019) find that "price effects account for a major part of the wealth gains of the middle class and the lower middle class," and that these price effects are driven by house price gains. They show that fixing house prices would lead to a substantial decline in the wealth share of households in the 50th to 90th percentile of the wealth distribution from 1989 to 2007, which is related to the finding here that high valuation gains masked a decline in savings for the bottom $90 \%$ during this period.

Furthermore, Bartscher et al. (2019) find that the rise in household debt for the bottom $90 \%$ was mainly driven by a response to higher house prices, which is consistent with the finding here that the bottom $90 \%$ increased their debt the most from 1998 to 2007 when house price growth was strongest. The findings here suggest that in addition to borrowing, the bottom $90 \%$ also reduced savings in non-housing assets substantially from 1998 to 2007. 


\section{Financing the Rise in Household Debt}

This section turns to an examination of whether the rise in the stock of household debt owed by the non-rich has been financed by the rich. The switch from the flow of savings to the stock of household debt offers a number of new insights. While the ultimate destination of the flow of saving from the rich is difficult to measure, it is possible to measure how much of the rise in household debt reflects a rise in the amount of household debt held as a financial asset by the rich. Furthermore, as shown below, it is possible to measure the amount of debt held as a financial asset by the rich across different states within the United States, which allows for a cleaner empirical test of the effect of inequality on the holdings of household debt as a financial asset by the rich.

In addition, recent research demonstrates that financial assets should not be viewed as perfect substitutes (e.g., Koijen and Yogo (2019)). This imperfect substitution in the demand for assets implies that holdings of specific asset classes by wealthy Americans could matter for aggregate financing patterns. Finally, a focus on the stock of household debt is important given recent research suggesting that household debt is an important predictor of economic and financial cycles (e.g., Jordà et al. (2016), Mian et al. (2017)).

\subsection{Unveiling who holds household debt as a financial asset}

Figure 11 shows the rise in total household debt to national income in the United States. From 1982 to 2007 , the household debt to national income ratio rose by 57 percentage points. The rise of the stock of household debt over time is the accumulation of the annual additional borrowing shown in Figure 10 above.

Who ultimately financed the rise in household debt? The Financial Accounts of the United States allow for a detailed decomposition to answer this question. The process described in this sub-section is best thought of as an attempt to remove the veil of financial intermediation. Financial intermediaries are the immediate holders of household debt as a financial asset, but who holds the financial securities of the financial intermediaries? This question can be answered given the extensive information in the Financial Accounts on holdings of securities by different groups. 
Figure 11: Household Debt to National Income Ratio

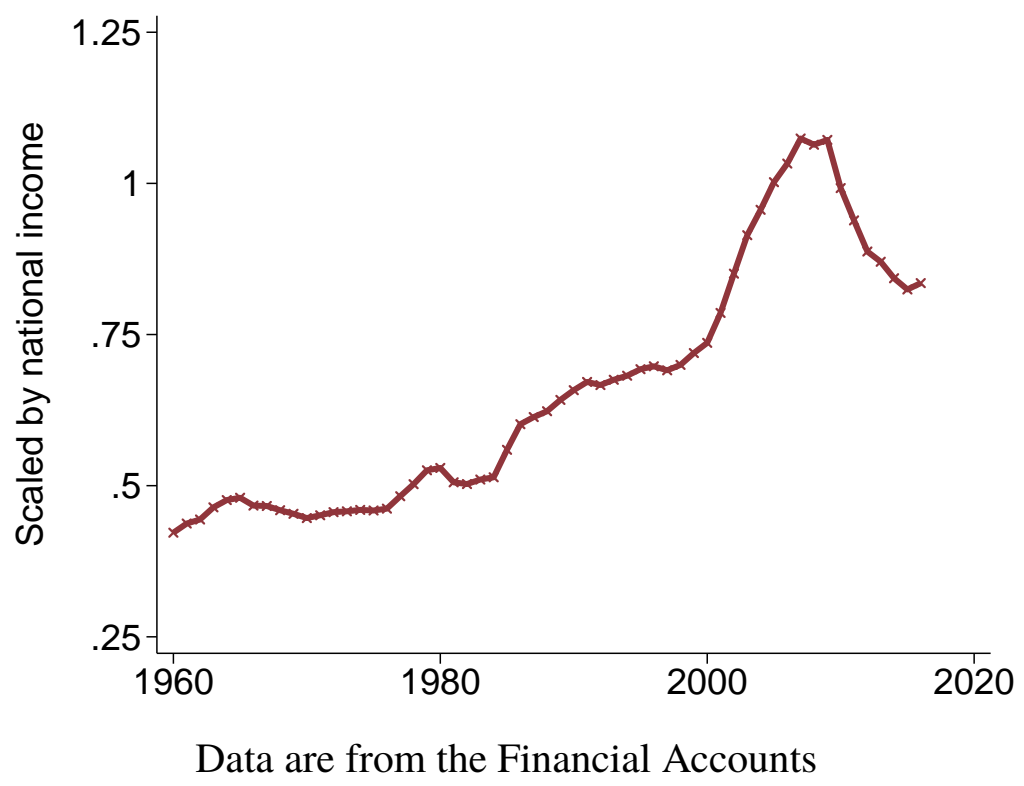

\section{Overview}

In the most general form, for each group $i$, the methodology explained here is designed to measure the total amount of household debt which is held as an asset by $i$ at time $t$, or $A_{i t}$. In total, there are $I$ disjoint groups. Formally, we are looking for the vector

$$
A_{t}=\left[\begin{array}{c}
A_{1, t} \\
A_{2, t} \\
\vdots \\
A_{I, t}
\end{array}\right] .
$$

Going forward, for simplicity, the time subscript $t$ is dropped when writing specific elements of a matrix or vector, with the understanding that everything is measured for each year $t$. The time subscript $t$ is kept when denoting entire matrices and vectors.

Household debt is held by households through various financial asset types, indexed by $c$. In particular, there are $C$ total classes through which household debt is held, and these include pensions, mutual funds, time deposits, annuities of life insurance companies, and GSE securities, to name a few examples. We call $F_{c, t}$ the total amount of household debt that is held through asset class $c$ by households, which we calculate through an unveiling process, described in detail below. Group $i$ 's share of asset class $c$ is $\omega_{i, c, t}$, and the assumption is made that group $i$ 's share of household 
debt held through asset class $c$ is also $\omega_{i, c, t} \cdot{ }^{23}$ By construction, in any year $t, \sum_{i=1}^{I} \omega_{i, c, t}=1$.

Therefore,

$$
\left[\begin{array}{c}
A_{1} \\
A_{2} \\
\vdots \\
A_{I}
\end{array}\right]=\left[\begin{array}{ccccc}
\omega_{1,1} & \omega_{1,2} & \cdots & \cdots & \omega_{1, C} \\
\omega_{2,1} & \omega_{2,2} & \cdots & \cdots & \omega_{2, C} \\
\vdots & \vdots & \ddots & \ddots & \vdots \\
\omega_{I, 1} & \omega_{I, 2} & \cdots & \cdots & \omega_{I, C}
\end{array}\right]\left[\begin{array}{c}
F_{1} \\
F_{2} \\
\vdots \\
F_{C}
\end{array}\right]
$$

or equivalently

$$
\underset{I \times 1}{A_{t}}=\underset{I \times C}{\Omega_{t}} \times \underset{C \times 1}{F_{t}}
$$

The unveiling exercise can therefore be separated into two steps. The first step is to calculate the total amount of household debt held by households in each Financial Accounts asset class $c$ to get $F_{t}$. The second step is constructing $\Omega_{t}$, which contains the shares of each asset $c$ held by group $i$.

\section{Unveiling to obtain $F_{t}$}

Figure 12 presents a graphical overview of the unveiling methodology. In the left most column, the figure starts with total household debt (home mortgages plus consumer credit) in the Federal Reserve Financial Accounts owed by the U.S. household sector as of 2005, scaled by national income. This happens to be almost exactly $100 \%$ of national income.

The end result in the right most column is the holdings of household debt as a financial asset by the U.S. household sector, by asset class ( $F_{t}$, where $t$ is 2005). The total amount held by the U.S. household sector is lower than the total amount owed by the U.S. household sector because the U.S. government and the rest of the world also hold household debt owed by the U.S. household sector.

\footnotetext{
${ }^{23}$ It may be the case that this is not true. For example, if richer households own riskier mutual funds than poorer households, then the share of mutual funds that is household debt might be higher for poorer households.
} 
Figure 12: Overview of Unveiling of Household Debt for 2005
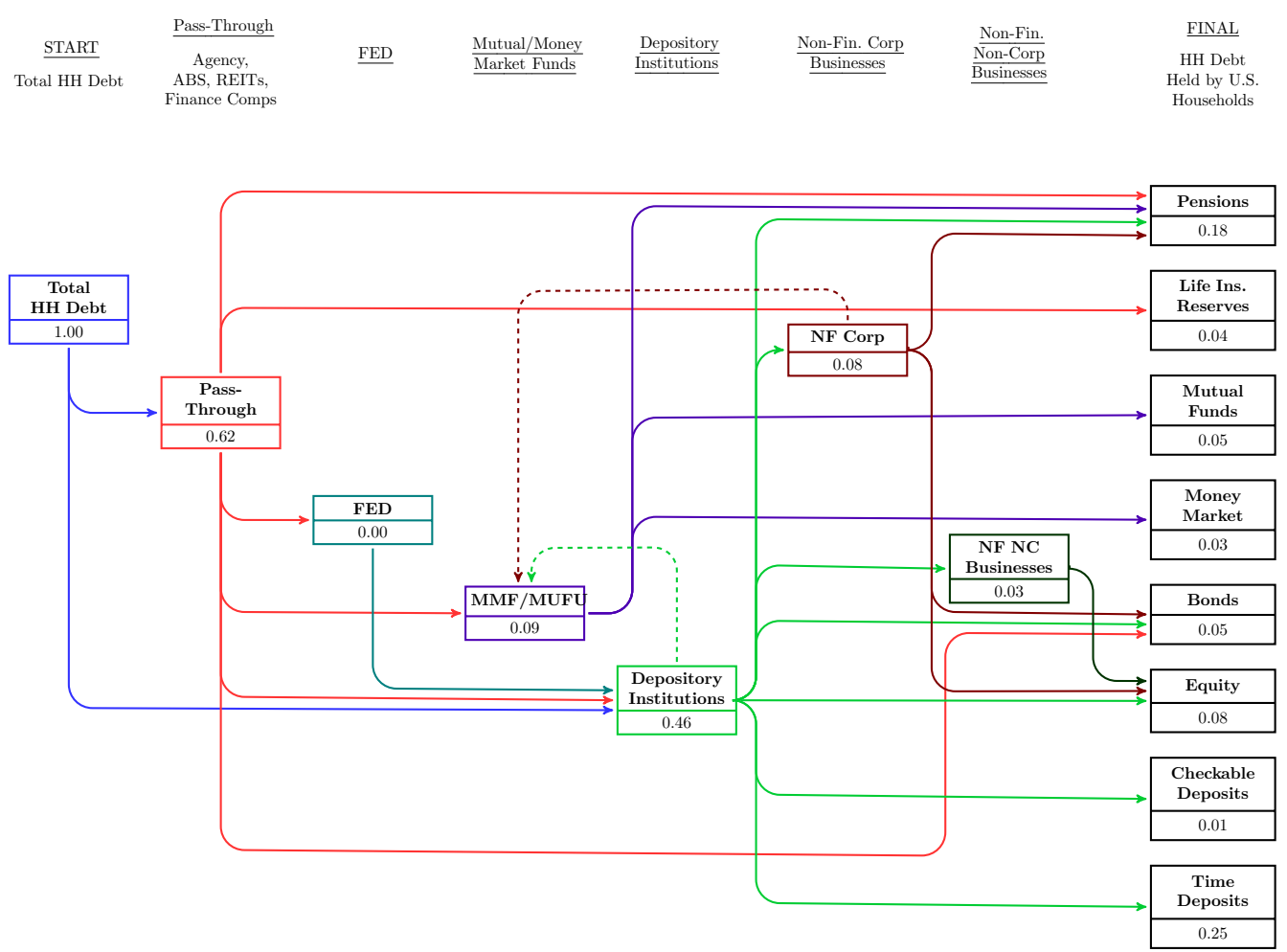

This is a visual representation of the unveiling of household debt for the year 2005. The left most column is total household debt for U.S. households, and the right most column reflects the household debt held as a financial asset by the U.S. household sector. The numbers in each box are total household debt for that box scaled by national income.

Moving from left to right represents each round of unveiling. An arrow going into the box represents where the household debt comes from, and the arrows going out of the box represent where it goes to. The number in each box represents the total amount of household debt scaled by national income held in this category after taking into account all of the unveiling from previous rounds. As a result, the numbers add up to more than the total in the left most column. For example, depository institutions hold a large amount of pass-through debt, and so the 0.46 in this box reflects both household debt held directly and household debt held through holdings of agency GSE debt.

Figure 12 does not include every linkage, and it excludes the holdings of the rest of the world and the U.S. government. For these latter two categories, there should be arrows going out of each box that go to the rest of the world and to the government. This can be thought of as "leakage" from the system. All linkages are taken into account in the methodology, but for the sake of clarity not all of these linkages are shown in Figure 12. 
The first round places household debt into the two major initial intermediaries: pass-throughs (which include the Government Sponsored Enterprises and issuers of asset-backed securities) and private depository institutions. The second round then unveils the pass-throughs. Pass-through debt is held by a large number of intermediaries, and also by the household sector itself through its holdings of pensions, life insurance, and bonds.

The third round unveils the Fed, which is held primarily by the depository institutions. The Fed held no household debt in 2005, because at this point it had yet to buy any Agency GSE debt. But after 2009, the Fed held substantial household debt through its holdings of Agency GSE debt. The fourth round unveils mutual funds and money market funds.

The fifth round is quantitatively the most important. Depository institutions hold a huge amount of household debt through both their direct holdings (portfolio mortgages for example) and their purchases of pass-through debt. Post 2009, they also hold a large amount of household debt through their reserves at the Fed. As the graph shows, the claim on the depository institutions is quantitatively meaningful for many players in the economy, including non-financial corporations, nonfinancial non-corporate businesses, and the household sector. This is primarily due to holdings of deposits, but it is also because of the equity claim on the depository institutions.

The final two rounds unveil the non-financial business sector. This is also a quantitatively important step, because the savings of the business sector have increased substantially after 1990. For example, non-financial businesses increased their holdings of deposits and money market funds by 10 percentage points of National Income (see Appendix Figure A10). These are indirect claims on household debt through the holdings of liabilities in commercial banks and money market funds. As a result, the household sector held a substantial amount of household debt through their claims on the non-financial business sector.

How do we measure the arrows that come out of each box? We are able to do so because of the excellent data in the Financial Accounts that details the claims on any given institution by other institutions. For example, let us consider the Government-Sponsored Enterprises (GSEs), which are important immediate holders of household debt. Tables L.125 and L.126 in the Financial Accounts document the amount of home mortgages and consumer credit held as an asset by the GSEs. Table L.211 of the Financial Accounts documents the total debt issued by the GSEs, and the groups to which they owe these liabilities.

Take the orange arrow from the Pass-throughs to mutual funds. Table L.211 lists the share of total agency GSE liabilities held by mutual funds. The main assumption used to create the arrow is a proportionality assumption: the share of the total liabilities of the Agency GSEs held by mutual funds is assumed to be the same as the share of the total amount of household debt held by mutual funds through their holdings of Agency GSE liabilities. Then, Table L.224 of the Financial Accounts lists the groups that own shares of mutual funds, which can then be further unveiled in 
the next round. This is an example of how the unveiling process works. It can be done for all intermediaries to determine ultimately who holds the household debt as a financial asset.

In addition to the vector $F_{t}$ (which is the right most column in Figure 12), this process also produces the amount of household debt held by the government, the rest of the world, and a residual category that the methodology is unable to assign. Further details of the unveiling process are in Appendix Section C.1, and all replication data and code are available in the replication kit.

\section{Distributing the unveiling}

Turning now to $\Omega_{t}$, recall that $\omega_{i, c}$ is group $i$ 's share of asset $c$. The primary approach that is used to obtain $\Omega_{t}$ relies on estimates from the DINA micro-files from Piketty et al. (2018), but the Distributional Financial Accounts of the Federal Reserve (described in Batty et al. (2019)) are also used as a robustness test. ${ }^{24}$ Given that the DFA is based on the same asset classes as the Financial Accounts, $\omega_{i, c}$ from the DFA is also group $i$ 's share of household debt in $c$ in the matrix $\Omega_{t}^{D F A}$.

The PSZ approach uses the individual-level microfiles which contain income and wealth data, along with state identifiers back to 1979 . However, instead of the many asset classes that are covered in the Financial Accounts, PSZ report their wealth shares in terms of only 5 asset classes: business, equity, fixed income, housing, and pensions. Debt is a sixth asset class which is by definition a negative asset holding. It is therefore necessary to convert from group $i$ 's share of PSZ asset class $l, \theta_{i, l}$, into $\omega_{i, c}$. This is done as follows:

$$
\left[\begin{array}{ccccc}
\omega_{1,1}^{P S Z} & \omega_{1,2}^{P S Z} & \cdots & \cdots & \omega_{1, C}^{P S Z} \\
\omega_{2,1}^{P S Z} & \omega_{2,2}^{P S Z} & \cdots & \cdots & \omega_{2, C}^{P S Z} \\
\vdots & \vdots & \ddots & \ddots & \vdots \\
\omega_{I, 1}^{P S Z} & \omega_{I, 2}^{P S Z} & \cdots & \cdots & \omega_{I, C}^{P S Z}
\end{array}\right]=\left[\begin{array}{cccc}
\theta_{1,1} & \theta_{1,2} & \cdots & \theta_{1,5} \\
\theta_{2,1} & \theta_{2,2} & \cdots & \theta_{2,5} \\
\vdots & \vdots & \ddots & \vdots \\
\theta_{I, 1} & \theta_{I, 2} & \cdots & \theta_{I, 5}
\end{array}\right]\left[\begin{array}{ccccc}
\mu_{1,1} & \mu_{1,2} & \cdots & \cdots & \mu_{1, C} \\
\mu_{2,1} & \mu_{2,2} & \cdots & \cdots & \mu_{2, C} \\
\vdots & \vdots & \ddots & \ddots & \vdots \\
\mu_{5,1} & \mu_{5,2} & \cdots & \cdots & \mu_{5, C}
\end{array}\right]
$$

or equivalently

$$
\underset{I \times C}{\Omega_{t}^{P S Z}}=\underset{I \times 5}{\Theta_{t}} \times \underset{5 \times C}{M_{t}}
$$

Here, $\mu_{l, c}$ is the share of debt-holding Financial Accounts household asset class $c$ that is categorized as PSZ asset class $l$. Thus, since

\footnotetext{
${ }^{24}$ The main advantage of the PSZ approach is that the data are available back to 1962 , whereas the DFA is available only back to 1989. Furthermore, the DFA is only available for select cuts of the income and wealth distribution, whereas the PSZ microfiles allow us to do cuts of the distribution more flexibly.
} 
$0 \leq \theta_{i, l}, \mu_{l, c} \leq 1, \sum_{i=1}^{I} \theta_{i, l}=1 \quad$ and $\quad \sum_{l=1}^{5} \mu_{l, c}=1, \quad$ then $\quad \sum_{i=1}^{I} \omega_{i, c}^{P S Z}=1 \quad$ and $\quad 0 \leq \omega_{i, c}^{P S Z} \leq 1$.

We obtain the individual $\mu_{l, c}$ numbers directly from the mapping embedded in PSZ that constructs the 5 PSZ wealth classes from the Financial Accounts. In effect, this means that $\mu_{\text {Housing,c }}=$ 0 for all $c$, since households do not hold any debt as a financial asset through their holdings of housing assets. Furthermore, for almost all Financial Account assets $c, \mu_{l, c}=0$ for all but one $l^{*}$, for which $\mu_{l^{*}, c}=1$. To explain why this is, take time deposits $(T D)$ as an example: all time deposits are classified as fixed income $(F I)$ by PSZ. Therefore, $\mu_{T D, F I}=1$ and $\mu_{T D, l}=0$ for all other PSZ assets. In fact, the only case where this does not hold is when $l$ is mutual funds $(M F)$. Mutual funds are distributed according to the proportion of mutual fund assets that correspond to fixed income and to equity in each year. Therefore, $\mu_{l, M F}=0$ when $l$ is housing, business, or pensions, but non-zero for both fixed income and equity. Table 6 shows the exact mapping between PSZ and FA asset classes that we use.

Table 6: Mapping Between FOF \& PSZ Asset Classes

\begin{tabular}{|ll|}
\hline Flow of Funds Asset & PSZ Asset Class \\
\hline Home mortgages & Fixed Income \\
GSE securities & Fixed Income \\
Corporate bonds & Fixed Income \\
Money market funds & Fixed Income \\
Mutual funds & Fixed Income and Equity \\
Time deposits & Fixed Income \\
Checkable deposits & Fixed Income \\
Monetary authority holdings & Fixed Income \\
Depository institution bonds & Fixed Income \\
Private depository institutions equity & Equity \\
Nonfinancial corporate equity & Equity \\
Nonfinancial noncorporate equity & Business \\
Government retirement funds & Pension \\
Pensions & Pension \\
Reserves and annuities of life insurance companies & Pension \\
Prop insurance companies & Pension \\
Nonfinancial corporate bonds & Fixed Income \\
\hline
\end{tabular}


We therefore compute $A_{t}$ in one of two ways. Using the DFA, we obtain $A_{D F A, t}=\Omega_{t}^{D F A} F_{t}$. Using PSZ, we obtain $A_{P S Z, t}=\Omega_{t}^{P S Z} F_{t}=\Theta_{t} M_{t} F_{t}$. We choose PSZ as our baseline estimate given that the DFA is only available back to 1989 , and only certain cuts of the distribution are available from the DFA.

\subsection{Household debt held by the rich}

Figure 13 shows the ultimate holders of household debt owed by U.S. households. The four lines in the left panel add up to total household debt in the United States. As the left panel shows, the lion's share of household debt is held as a financial asset by U.S. households. This is true even post 2000, when a rising share of total household debt has been held by the rest of the world.

Figure 13: Who Holds Household Debt as a Financial Asset?
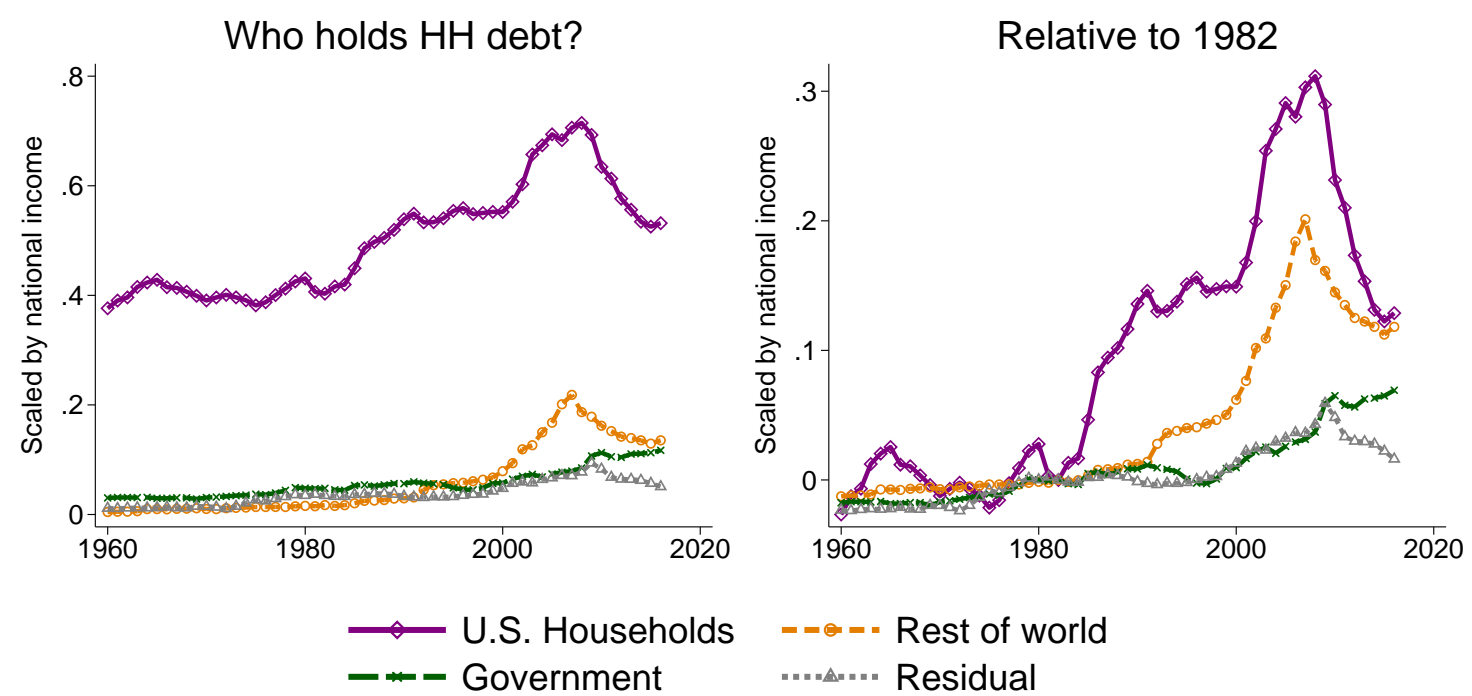

This is the result of the unveiling exercise described in detail in Section 6.1. All series are scaled by national income.

Furthermore, as the right panel shows, the rise in household debt has been primarily financed by U.S. households. This is particularly the case from 1982 to the late 1990s. From 1982 to 1996, the rise in the overall household debt to national income ratio was 19.5 percentage points. The U.S. household sector accounted for 15.6 percentage points of this increase. After 1996, the rest of the world began to provide substantial amounts of funding for U.S. household borrowing, primarily through purchases of agency GSE and other asset-backed securities. However, even post 1996, a substantial fraction of the increase in U.S. household borrowing was financed by U.S. households. ${ }^{25}$

\footnotetext{
${ }^{25}$ Appendix Figure A8 shows the precise asset classes through which households held household debt as a financial
} 
Figure 14 splits household debt held by the U.S. household sector by the top $10 \%$ of the income distribution and bottom $90 \%$ of the income distribution. The split is done using the PSZ approach described in Section 6.1. ${ }^{26}$

Figure 14: Who Holds Household Debt across the Income Distribution?

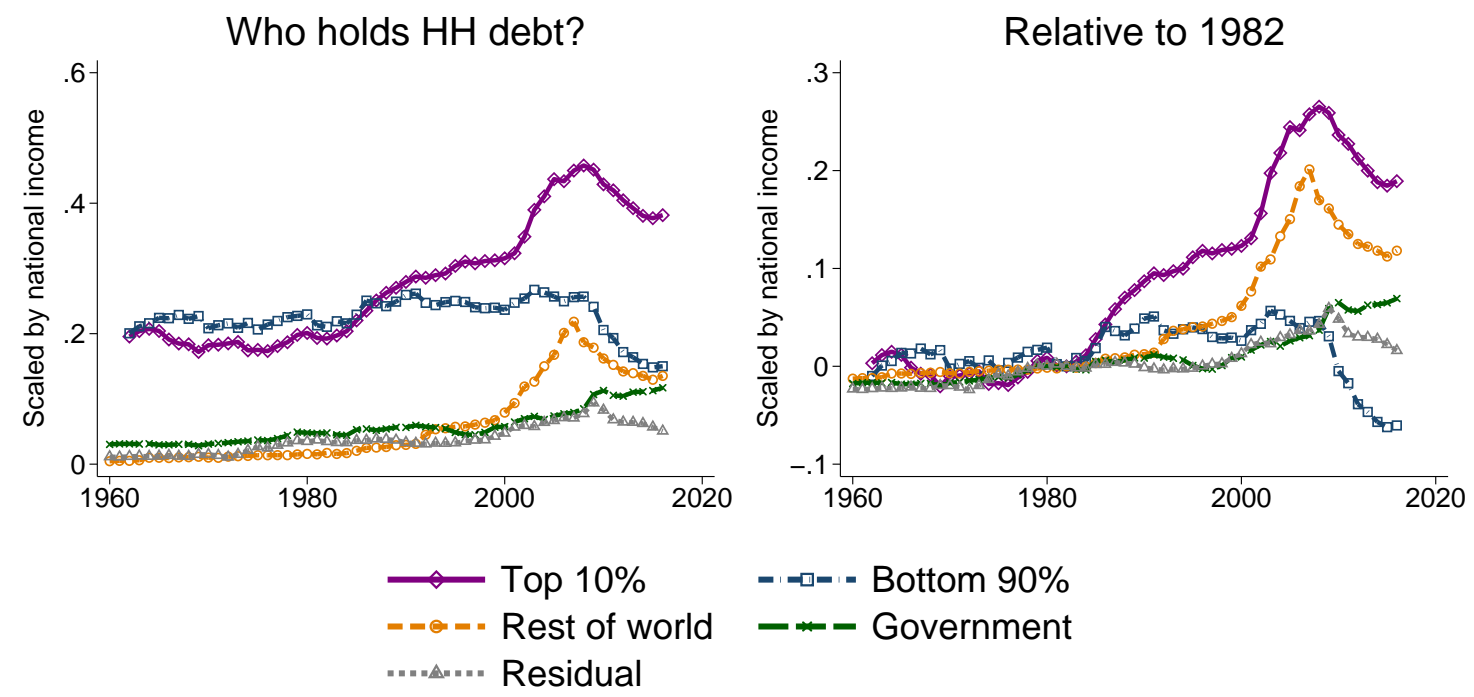

This figure decomposes the holdings of household debt by the U.S. household sector across the income distribution. All series are scaled by national income.

Figure 14 shows that a substantial fraction of the rise in household debt from 1982 to 2007 was financed by the top $10 \%$ of the income distribution. Households in the top $10 \%$ of the income distribution increased their holdings of U.S. household debt by 26 percentage points of national income from 1982 to 2007, which is almost half of the overall rise in household debt during this period. Prior to 1996, the fraction is significantly higher. The total rise in the household debt to national income ratio from 1982 to 1996 was 19.5 percentage points, and the top $10 \%$ of the income distribution accounted for 11.8 percentage points of the total increase. The saving glut of the rich was financing the rise in household debt in the United States before the global saving glut was.

The fact that households at the top of the income distribution hold a substantial amount of household debt as a financial asset suggests that a more appropriate calculation of intra-household

asset over time.

${ }^{26}$ The rich are measured as the top $10 \%$ of the income distribution instead of the top $1 \%$ of the income distribution when evaluating the holdings of household debt as a financial asset. This is because the DFA and PSZ wealth shares imply similar holdings of household debt by the top $10 \%$ of the distribution, but substantial differences between the top $1 \%$ and next $9 \%$ holdings of household debt. PSZ wealth shares imply that most of the rise in household debt held as a financial asset occurs among the top $1 \%$ of the income distribution, whereas the DFA wealth shares imply the rise is more evenly split among the top 1\% and the next 9\%. Results for the top 1\% and next 9\% using the DFA and PSZ are shown in Appendix Section C.3. 
sector borrowing should examine the net debt position of each wealth group. That is, the gross household debt positions of different groups within the household sector may give a misleading impression of the net borrowing and lending position of these groups. The net debt position of any group within the household sector is the gross amount of household debt owed minus the amount of household debt held as a financial asset.

Figure 15: Net Household Debt across Income Distribution Relative to 1982

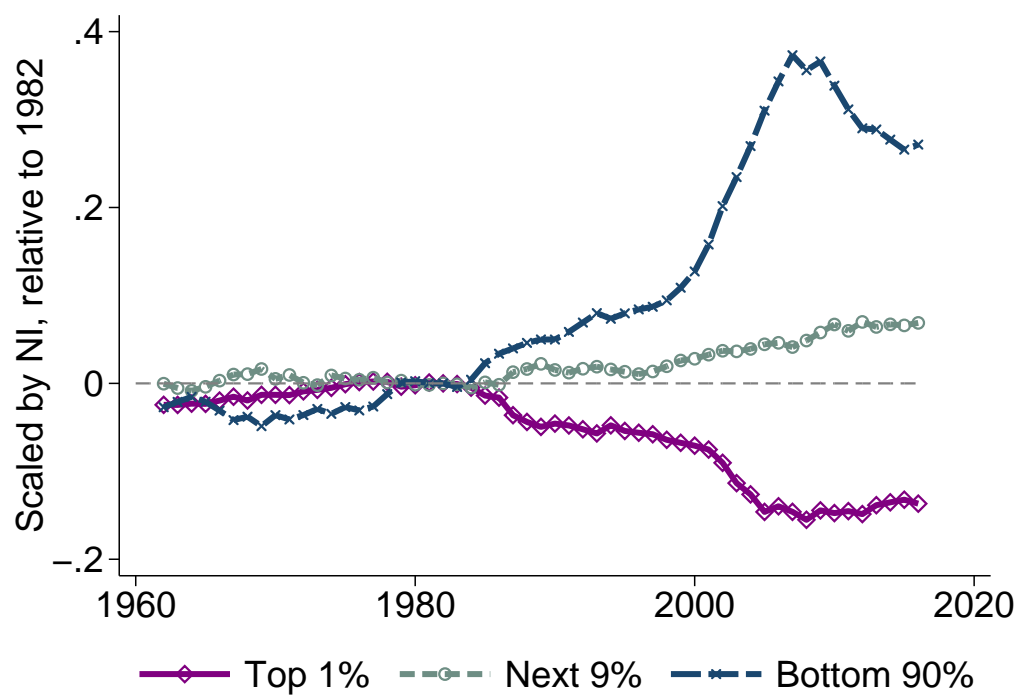

This figure shows net household borrowing by the U.S. household sector across the income distribution. Net household borrowing is defined as gross household borrowing minus household debt held as a financial asset. All series are scaled by national income, and the 1982 level is subtracted.

Figure 15 shows the net amount of debt owed by the top 1\%, next 9\%, and bottom $90 \%$ using the PSZ wealth shares, and subtracting the 1982 level. The net debt positions make clear that the top $1 \%$ of the income distribution helped finance the rise in household debt for the bottom $90 \%$ of the distribution. Their net debt position fell significantly since 1982. The next $9 \%$ was somewhere in the middle. They increased borrowing after 1982 but not nearly to the same degree as the bottom $90 \%$. The net debt position of the bottom $90 \%$ increased substantially.

In Section C. 2 of the appendix, results are shown when households are sorted by wealth instead of income. Given that high income realizations lead to an accumulation of wealth, this may be a more natural sort when evaluating the household debt held as a financial asset by the rich. As the results in the appendix show, both the level and rise of household debt held as a financial asset are even larger for the top $10 \%$ of the wealth distribution compared to the top $10 \%$ of the income distribution.

In Section B.3 of the appendix, results are shown using a higher assumed interest rate on fixed 
income asset holdings of the top 1\%, following Bricker et al. (2018) and Smith et al. (2019b). As the results show, the assumption of a higher interest rate for the top $1 \%$ has almost no effect on the results prior to 2008 , and only a small effect on the results after 2008. In Section C. 3 of the appendix, results are shown using the wealth shares from the Distributional Financial Accounts instead of the wealth shares implied by PSZ. As the results show, the DFA also show a substantial rise in the amount of household debt held as a financial asset by the rich, although it is slightly smaller during the time-frame for which both data sets are available. While the exact magnitude differs across the methodologies, all show a substantial increase in the holdings of household debt as a financial asset by the rich.

\subsection{How the rich hold household debt}

It may be surprising that the top $10 \%$ hold such a large share of household debt, given that the popular view is that the portfolios of the top $10 \%$ are focused primarily on corporate and noncorporate business equity. To explore this question further, we focus on the DFA from the Federal Reserve, which has a more detailed composition of asset holdings across the distribution. ${ }^{27}$

Appendix Figure A9 shows the five largest asset classes through which the top 10\% of the wealth distribution held household debt as of 2007, and the five largest classes in terms of the rise in debt holdings of the top $10 \%$ from 1992 to 2007. As of 2007, the top $10 \%$ held a substantial amount of household debt through time deposits at private depository institutions (17 percentage points of national income). Time deposits were also the main source through which the top $10 \%$ increased their holdings of household debt from 1992 to 2007. As of 2007, the top 10\% held 61 percent of all time deposits held by U.S. households, up from 52 percent in 1992.

Equity was the second most common instrument through which the top $10 \%$ held household debt. Part of this reflected equity ownership of private depository institutions, but an even larger fraction comes from the fact that non-corporate and corporate businesses had large balances in deposits and money market funds. From 1992 to 2016, non-financial businesses increased their holdings of deposits and money market funds by 10 percentage points of National Income (see Appendix Figure A10). The rich, as the primary equity-holders in businesses, held substantial amounts of household debt through the business deposit channel.

\footnotetext{
${ }^{27}$ As discussed in Section C.3 of the appendix, the DFA require us to focus on the top $10 \%$ of the wealth distribution, because wealth shares of the top $10 \%$ of the income distribution are not available.
} 


\section{State-level Analysis}

At the national level, the rise in savings generated by the top $1 \%$ was closely linked to the rise in household debt held as a financial asset by rich Americans. State-level analysis provides evidence of a more direct connection between the rise in top income shares and the rise in household debt held as a financial asset by the rich. There was large variation at the state-level in the rise in top income shares from 1982 to 2007, as shown in Figure 16. States like Florida, New York, and Nevada witnessed a larger increase in the top 1\% share of income relative to states such as Michigan, Arizona, or California.

Figure 16: Change in Top 1\% Share of Income Across States

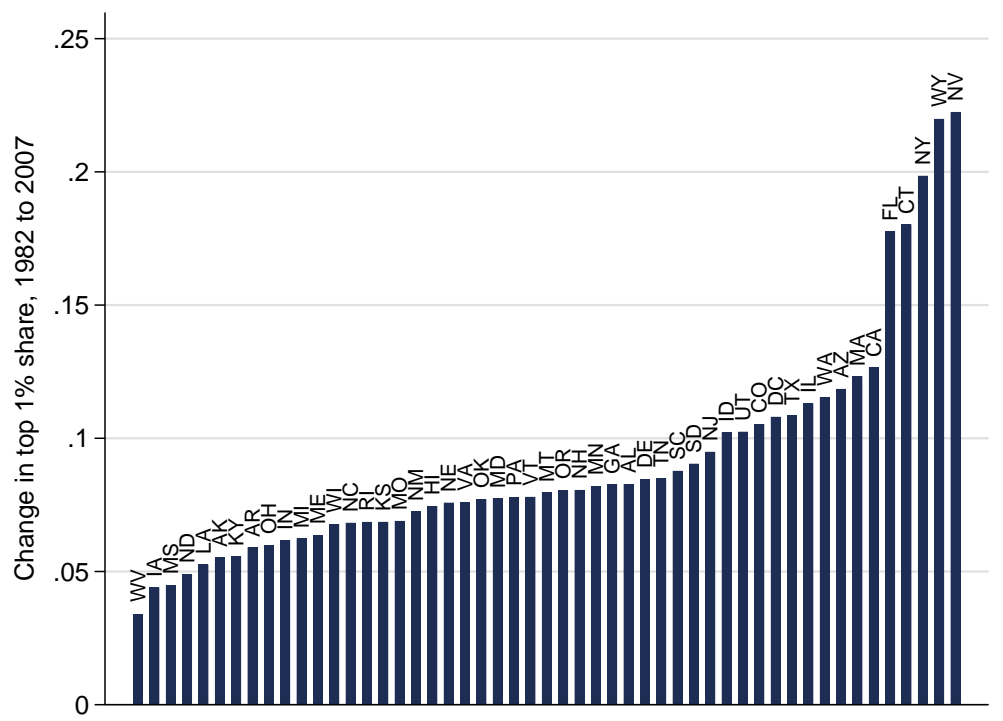

Data are from the World Inequality Database.

The state-level analysis in this section tests whether states with a higher increase in top income shares experienced a greater increase in the holdings of household debt as a financial asset. And if they did, it tests whether such acccumulation of household debt as a financial asset was primarily driven by those at the top of the income distribution. ${ }^{28}$ The advantage of the state-level analysis is that it brings us closer to an ideal experiment in which, all else equal, some economies experience a larger increase in top income shares than others, and we can track whether there is more asset accumulation in the economies with the larger increase in top income shares. This helps address

\footnotetext{
${ }^{28}$ Given that financial markets are well-integrated across the United States, the state-level variation in the rise in top income shares is only related to asset accumulation. The associated household borrowing can of course happen anywhere across the United States, and it does not need to take place in the specific state that is experiencing the rise in top income shares.
} 
concerns with the aggregate analysis that there were important changes from 1982 to 2007 other than the rise in top income shares that could have independently led to wealthy Americans holding more household debt as a financial asset.

\subsection{Measuring household debt held as financial asset at the state level}

Household debt held by group $i$ at time $t$ in state $s, A_{i, s, t}$, can be estimated much the same way as $A_{i, t}$ was estimated in section 6.1 given the availability of state identifiers in the DINA microfiles. However, there are a few limitations for the state level analysis.

First, state-level information is available from 1979 to 2008, which means the state level analysis must end in 2008. Second, other than the year 1982, the state level identifiers are suppressed for any tax return with an adjusted gross income (AGI) above 200,000 dollars in nominal terms. In order to overcome this issue, the analysis uses state-level tax tables provided by the Statistics of Income Division (SOI) of the Internal Revenue Service. These tables contain the total number of returns, interest income, dividend income, capital gains, and taxable pension income at the state level. Furthermore, these tables break down this information separately for filers with AGI above 200,000 dollars. These data enable us to create a group in each state-year cell that contains all individuals that earn more than 200,000 dollars in AGI.

Using information from the SOI, Figure 17 plots the share of tax filings with AGI above \$200K in each state by year. The shaded area covers the full variation across states in the share of units with AGI above $\$ 200 \mathrm{~K}$ each year. Given the $\$ 200$ thousand limit, we cannot form a group for the top $1 \%$ in each state-year cell. As shown in Figure 17, the fraction of filers below $\$ 200$ thousand is always below $6 \%$ for every state-year observation. As a result, the top $6 \%$ is chosen as the main "top income" category in the state-level analysis. ${ }^{29}$ The SOI data for the group of individuals in each state-year observation with AGI above \$200 thousand allows us to apply the capitalization methodology to estimate the holdings of household debt by the top $6 \%$ in each state. More details on the construction of the state-level data is available in Section D of the appendix.

\footnotetext{
${ }^{29}$ The top $6 \%$ group for each state-year observation is the top $6 \%$ of tax units within the state, not tax units in the top $6 \%$ of the national distribution. Figure A11 in the appendix shows a strong relationship between the rise in the top $1 \%$ share of income in a state from 1982 to 2007 and the rise in top 6\% share of income in the same year. The top 1\% share of income at the state level is available from the World Inequality Database.
} 
Figure 17: Percentage of Filers with AGI Above $\$ 200,000$

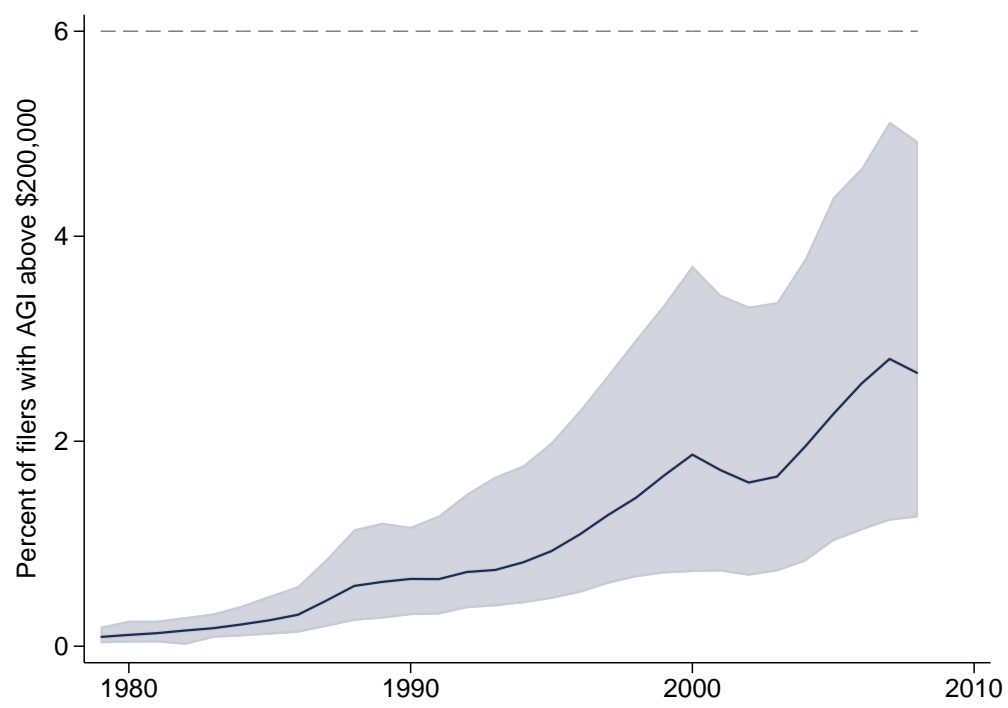

The solid line shows the percentage of tax filers in the U.S. with AGI above $\$ 200,000$ over time. The shaded area represents the interval that contains this percentage for all states.

The state-level analysis is based on long differences. The year 1982 is picked as the base year because state identifiers are available in the DINA micro data files for this year, and this year is also close to the start of the rise in top income shares. For the end period, the averages from 2004 through 2007 are used. ${ }^{30}$

\subsection{Top income shares and household debt holdings of the rich}

Let $Y_{i s t}=\frac{A_{i s t}}{S N I_{s t}}$, which is the ratio of holdings of household debt as a financial asset by income group $i$ in state $s$ in year $t$ to state national income, which is the amount of post-tax national income earned by the state's residents. The dependent variable is the change in $Y_{i s t}$ between 1982 and 2004-2007: $\Delta_{82,07} Y_{i s}=\frac{A_{i s, 2004-07}}{S N I_{s, 2004-07}}-\frac{A_{i s, 1982}}{S N I_{s, 1982}}$. The primary estimation equation is:

$$
\Delta_{82,07} Y_{i s}=\alpha+\beta_{i} * \Delta_{82,07} \text { Top } 6 \text { Share }_{s}+\Gamma * X_{s}+\varepsilon_{s}
$$

where $X_{s}$ are potential control variables. Given that $\Delta_{82,07} Y_{s}=\sum_{i} \Delta_{82,07} Y_{i s}$, the sum of $\beta_{i}$ across all income groups within a state reflects the total contribution of the rise in top-income shares on the rise in household debt holdings as a share of state income.

\footnotetext{
${ }^{30} \mathrm{We}$ exclude 2008 given the onset of the Great Recession, and the average from 2004 to 2007 is taken to minimize any measurement error associated with the imputation of tax data for filers above \$200 thousand AGI as explained above.
} 
Column 1 of Table 7 presents the estimates of equation 17 for all income groups collectively. The rise in the top $6 \%$ income share has a statistically significant positive effect on the rise in household debt holdings in a given state. Columns 2 and 3 split the total effect into the effect coming from accumulation of household debt holdings by the top $6 \%$ versus the rest of the population. The entire increase in the holdings of household debt as a financial asset that is associated with the rise in the top income share is driven by holdings of household debt by the top $6 \%$ of the income distribution. This is a powerful test indicating that the rise in the income share of the top of the income distribution in particular leads to a rise in household debt accumulation of the rich.

Table 7: Rise in Top Income Shares and Holdings of Household Debt as a Financial Asset

\begin{tabular}{|c|c|c|c|c|c|c|}
\hline & (1) & (2) & (3) & (4) & $(5)$ & $(6)$ \\
\hline \multirow[t]{2}{*}{$\Delta_{82,07}$ Top $6 \%$ Share } & $1.957^{* * *}$ & $1.969^{* * *}$ & -0.0118 & $1.774^{* * *}$ & $1.767^{* * *}$ & -0.00603 \\
\hline & $(0.174)$ & $(0.115)$ & $(0.136)$ & $(0.223)$ & $(0.205)$ & $(0.130)$ \\
\hline \multirow[t]{2}{*}{ Top 6\% Share 1982} & & & & 0.0419 & $0.675^{*}$ & $-0.642^{*}$ \\
\hline & & & & $(0.300)$ & $(0.255)$ & $(0.259)$ \\
\hline \multirow[t]{2}{*}{$\Delta_{82,07} \log$ Per Capita Income } & & & & 0.0859 & 0.0615 & 0.0274 \\
\hline & & & & $(0.059)$ & $(0.043)$ & $(0.038)$ \\
\hline \multirow[t]{2}{*}{ Log Per Capita Income 1982} & & & & $0.184^{*}$ & 0.0736 & $0.109^{*}$ \\
\hline & & & & $(0.083)$ & $(0.066)$ & $(0.054)$ \\
\hline \multirow[t]{2}{*}{$Y_{i s, 1982}$} & & & & $-0.547^{* * *}$ & $-0.495^{*}$ & $-0.509^{* * *}$ \\
\hline & & & & $(0.082)$ & $(0.196)$ & $(0.085)$ \\
\hline Group & All & Top 6 & Bot. 94 & All & Top 6 & Bot. 94 \\
\hline$R^{2}$ & 0.66 & 0.85 & 0.00 & 0.85 & 0.89 & 0.50 \\
\hline Observations & 51 & 51 & 51 & 51 & 51 & 51 \\
\hline
\end{tabular}

The magnitude of the saving glut of the top $6 \%$ is large. Over the same period, the rise in the share of the top $6 \%$ income share is $14.9 \%$ at the aggregate level. The estimated coefficient in column 1 implies that a $14.9 \%$ rise in the share of top $6 \%$ income in a state is associated with a 29.1 percentage point increase in the holdings of household debt as a share of national income. For comparison, the total rise in household debt held as a financial asset by households as a share of national income at the aggregate level between 1982 and 2007 was 30.3 percentage points. ${ }^{31}$ The

\footnotetext{
${ }^{31}$ The total rise in household debt to national income from 1982 to 2007 was 57 percentage points. Recall that some
} 
coefficient in column 1 implies that almost the entire rise in household debt held as a financial asset by the household sector is due to the rise in top income shares.

The addition of control variables in columns 4 through 6 does not change the results qualitatively. These controls move the specification closer to the ideal thought experiment of keeping income growth and initial conditions constant while changing the rise in top income shares. ${ }^{32}$ The inclusion of the last control, the initial holdings of household debt by income group $i$ as a share of total state income, ensures that the estimates are not driven by any mechanical "valuation effects." 33

Figure 18 summarizes the core finding graphically. The left panel shows the bivariate relationship estimated in column 2 for the top 6\%, and the right panel shows the same for the bottom 94\%. The contrast between the two figures illustrates that the entire increase in the holdings of household debt as a financial asset as top income shares rise is driven by top earners.

Figure 18: Change in Household Debt Holding Against Rise in Top Income Share
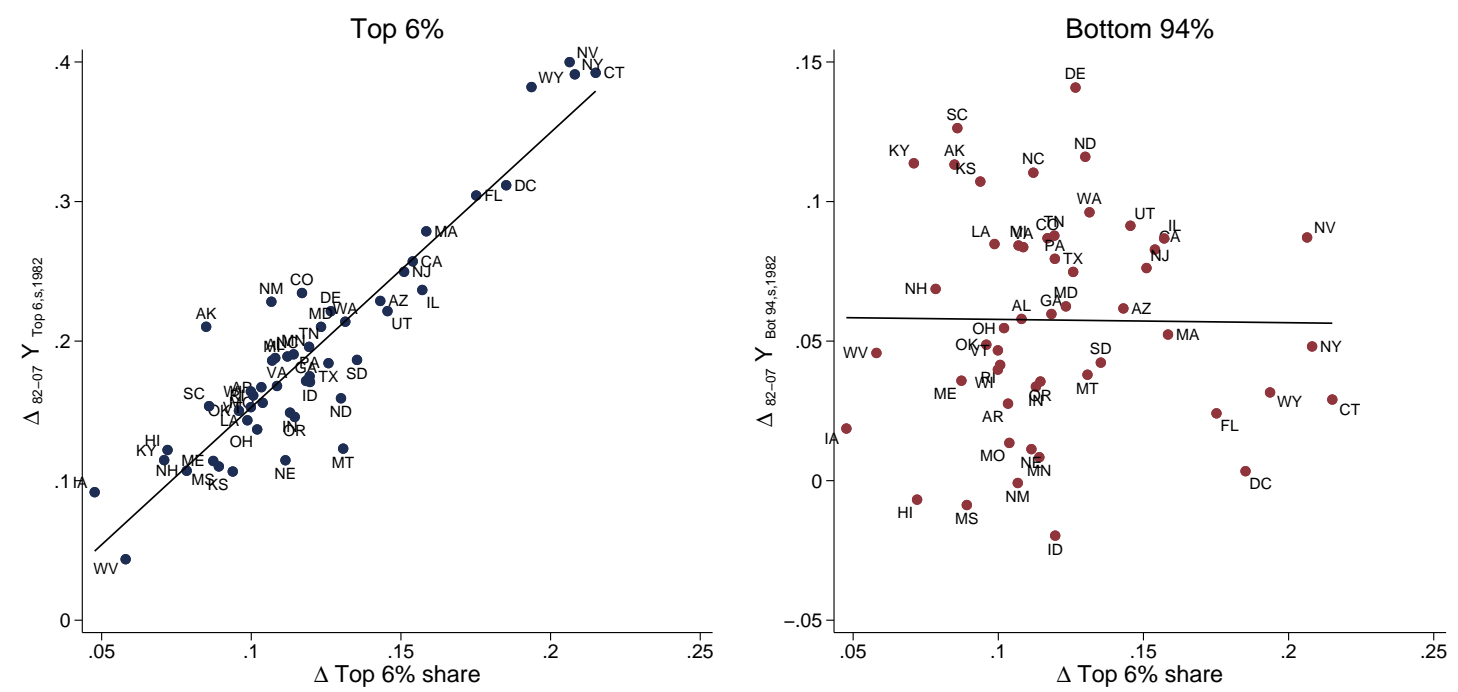

$\Delta_{82,07} Y_{i s}$ is the change in household debt held as a financial asset by group $i$ in state $s$ scaled by state national income. $i$ is the top $6 \%$ in the left panel and the bottom $94 \%$ in the right panel.

As discussed above, the top-income group is defined as the top 6\% to ensure that no household with above $\$ 200 \mathrm{~K}$ in AGI is outside the top income group for that state-year. However, the topincome group can be narrowed further at the cost of losing the richer states for whom the topincome AGI threshold would fall above $\$ 200 \mathrm{~K}$. Table A7 in the appendix progressively narrows

of the rise in household debt is financed by the rest of the world and the government.

${ }^{32}$ Table A6 in the appendix shows how the rise in top income share is correlated with these four controls.

${ }^{33}$ The specific concern is that the drop in long-term interest rates gives all holders of wealth a capital gain. Mechanically, states where the rich hold more initial wealth as a share of income will see a larger increase in wealth. But this change is entirely driven by the "valuation effect" of lower interest rates, and has nothing to do with the saving glut of the rich. The addition of initial holdings of household debt as a control variable mitigates this concern. 
the top-income group from the top $6 \%$ to the top $2 \%$. Going to the top $2 \%$ leaves only 7 states and therefore little statistical power. However, the evidence suggests that the overall increase in holdings of household debt is concentrated even further within the top $6 \%$, and likely comfortably within the top $3 \%$.

An advantage of the state-level analysis is that it allows us to control for other secular trends that may be responsible for both the rise in top income shares and the rise in household debt held as a financial asset by the rich. Table A8 in the appendix reports results analogous to column 5 of Table 7 with additional controls for demographics; the share of employment in the financial, manufacturing, and construction sector; and measures of financial deregulation. Inclusion of these controls does not affect the estimate on top income shares. This suggests that factors related to demographic change or changes in the industrial structure of employment are unlikely to explain the close link between the rise in top income shares and the rise in household debt held as a financial asset of the rich.

One concern with the results in Table 7 is that they are partially mechanical given that capital income is both an input into the measurement of the holdings of household debt as a financial asset on the left hand side, and the top income share on the right hand side. Table A9 in the appendix shows that the results are similar when only labor income is used to measure the rise in the top $6 \%$ income share. ${ }^{34}$

Finally, while the focus of this study is on the rise in household debt held as a financial asset by the rich, the state-level analysis can also be used to explore whether states with a larger rise in top income shares experienced a larger increase in overall wealth. The construction of overall wealth held by a given income group in a given state in a given year follows a similar approach used to construct the holdings of household debt as a financial asset. Tables A10 and A11 in the appendix show that states that witnessed a larger increase in top income shares also experienced a larger increase in wealth to income ratios.

\section{The Rise in Government Debt}

The post-Great Recession period has been one in which households have reduced borrowing while the government has borrowed to a greater degree. The right column of Table 3 above shows that the average annual government deficit was 9 percentage points of national income from 2008 to 2015 compared to 3 percentage points of national income from 1998 to 2007 . These deficits have led to a substantial increase in the government debt to national income ratio, which from 2007 to 2016

\footnotetext{
${ }^{34}$ In addition, Appendix Tables A3 and A4 address the capitalization factor issue raised by Bricker et al. (2018) and Smith et al. (2019b) in the context of the state-level analysis. More specifically, the amount of household debt held as a financial asset held by households is calculated using a higher assumed interest rate for the top $6 \%$ of the income distribution. The results are qualitatively similar.
} 
increased by 47.6 percentage points. This rise in government debt should be expected to accelerate given the massive government spending proposals being discussed (as of March 2020) in response to the economic dislocations caused by the COVID-19 health crisis.

What has been the role of the saving glut of the rich in this process? To answer this question, government debt is unveiled and assigned across the income distribution in a process similar to the one described in Section 6.1 for household debt. This allows for an analysis of how much of the rise in government debt since 2007 was financed by the top $10 \%$ of the income distribution. Figure 19 presents the evidence.

Figure 19: Who Financed the Rise in Government Debt?

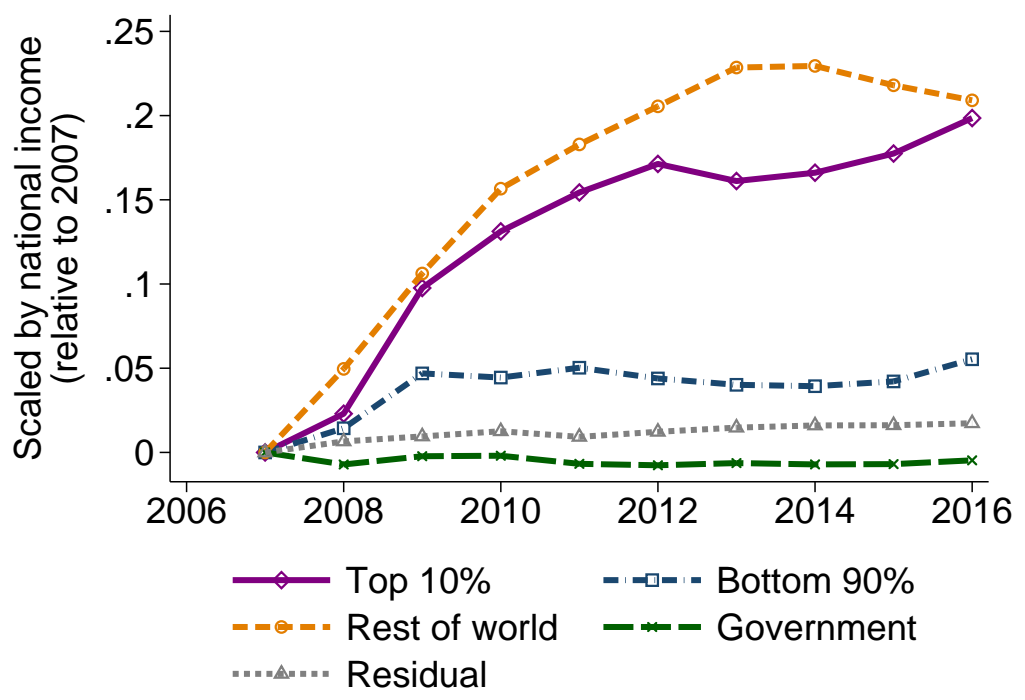

This figure decomposes the holdings of government debt by the U.S. household sector across the income distribution. All series are scaled by national income.

As the figure shows, there have been two main sources of incremental financing for the U.S. government since 2007: the top 10\% of the income distribution of U.S. households and the rest of the world. The two groups have financed government deficits to a similar degree. The top 10\% of the income distribution has financed 20 percentage points of the total 48 percentage point rise in the government debt to national income ratio from 2007 to 2016. The saving glut of the rich has played an important role in financing the government as it has stepped in to make-up for the reduction in household consumption after the recession. 


\section{Conclusion}

The rise in top income shares in the United States since the 1980s has generated a saving glut of the rich. The evidence in this study suggests that much of this savings has been channeled into borrowing by the non-rich. There has been a close connection between the rise in top income shares, dissaving of the bottom $90 \%$ of the income distribution, and the accumulation of household debt. The state-level analysis provides support to the view that the rise in top income shares has led to an accumulation of household debt as a financial asset in the portfolios of the wealthy.

This study focuses on the United States, but the findings may be applicable to other countries. Australia, Canada, and the United Kingdom, for example, have all witnessed a substantial increase in top income shares and large increases in household debt. Figure 20 shows cross-country averages in the share of income earned by the top $1 \%$ and the household debt to GDP ratio for 14 advanced countries. The saving glut of the rich may be linked to the rise in household debt worldwide.

Figure 20: Top income shares and rising household debt across countries

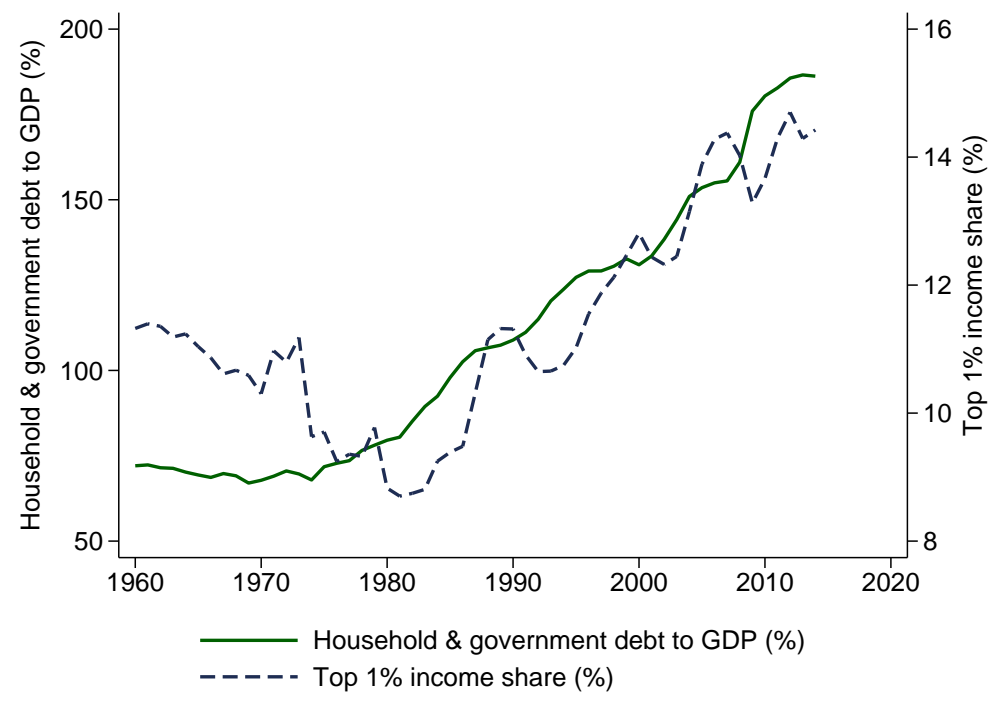

Series are cross-country averages, weighted by real GDP in 1970. The countries in the sample are Australia, Canada, Finland, France, Germany, Italy, Japan, New Zealand, Norway, Portugal, Spain, Sweden, United States and United Kingdom. Data come from the World Inequality Database, IMF Global Debt Database, the Jorda-Schularick-Taylor Macrohistory Database, and the New Zealand Treasury. See Mian et al. (2019) for more details.

Finally, many countries have run large government deficits in recent years, and this trend is likely to accelerate in the wake of the economic dislocations caused by the COVID-19 crisis. The evidence here suggests that rich Americans have been important financiers of higher government deficits in the United States. This raises interesting issues regarding the relationship between inequality and government deficits; we look forward to future research addressing these questions. 


\section{References}

Adelino, Manuel, Antoinette Schoar, and Felipe Severino, "Dynamics of housing debt in the recent boom and great recession," NBER Macroeconomics Annual, 2018, 32 (1), 265-311.

Aguiar, Mark and Mark Bils, "Has consumption inequality mirrored income inequality?," American Economic Review, 2015, 105 (9), 2725-56.

Albanesi, Stefania, Giacomo De Giorgi, and Jaromir Nosal, "Credit growth and the financial crisis: A new narrative," Technical Report, National Bureau of Economic Research 2017.

Atkinson, Anthony B, Thomas Piketty, and Emmanuel Saez, "Top incomes in the long run of history," Journal of economic literature, 2011, 49 (1), 3-71.

Attanasio, Orazio P and Luigi Pistaferri, "Consumption inequality," Journal of Economic Perspectives, 2016, 30 (2), 3-28.

Auclert, Adrien and Matthew Rognlie, "Aggregate demand and the top 1 percent," American Economic Review P\&P, 2017, 107 (5), 588-92.

Autor, David H, Lawrence F Katz, and Melissa S Kearney, "Trends in US wage inequality: Revising the revisionists," The Review of economics and statistics, 2008, 90 (2), 300-323.

Bakija, Jon, Adam Cole, and Bradley Heim, "Jobs and Income Growth of Top Earners and the Causes of Changing Income Inequality: Evidence from US Tax Return Data," Technical Report, Department of Economics, Williams College 2012.

Bartscher, Alina K, Moritz Kuhn, Moritz Schularick, and Ulrike I Steins, "Modigliani Meets Minsky: American Household Debt, 1949-2016,” Technical Report, Mimeo 2019.

Batty, Michael, Jesse Bricker, Joseph Briggs, Elizabeth Holmquist, Susan McIntosh, Kevin B Moore, Sarah Reber, Molly Shatto, Tom Sweeney, and Alice Henriques, "Introducing the Distributional Financial Accounts of the United States," 2019.

Bernanke, Ben, "The global saving glut and the US current account deficit," Technical Report, Board of Governors of the Federal Reserve System (US) 2005.

Bertrand, Marianne and Adair Morse, "Trickle-down consumption," Review of Economics and Statistics, 2016, 98 (5), 863-879.

Bhutta, Neil and Benjamin J Keys, "Interest rates and equity extraction during the housing boom," American Economic Review, 2016, 106 (7), 1742-74.

Blundell, Richard, Luigi Pistaferri, and Ian Preston, "Consumption inequality and partial insurance,” American Economic Review, 2008, 98 (5), 1887-1921.

Bricker, Jesse, Alice Henriques, and Peter Hansen, "How much has wealth concentration grown in the United States? A re-examination of data from 2001-2013,” 2018. 
Carroll, Christopher D, Thomas F Crossley, and John Sabelhaus, Improving the Measurement of Consumer Expenditures, Vol. 74, University of Chicago Press, 2015.

CBO, “The distribution of household income, 2016," CBO Slides, 2019, . (.), .

Chen, Peter, Loukas Karabarbounis, and Brent Neiman, "The global rise of corporate saving," Journal of Monetary Economics, 2017, 89, 1-19.

Cynamon, Barry $\mathbf{Z}$ and Steven M Fazzari, "Inequality, the Great Recession and slow recovery," Cambridge Journal of Economics, 2015, 40 (2), 373-399.

Devlin-Foltz, Sebastian, Alice Henriques Volz, and John Sabelhaus, "Are Disappearing Employer Pensions Contributing to Rising Wealth Inequality?," FED Notes, 2019, (2019-02), 01.

Dynan, Karen E, Jonathan Skinner, and Stephen P Zeldes, "Do the rich save more?,' Journal of political economy, 2004, 112 (2), 397-444.

Fisher, Jonathan, David Johnson, Timothy M Smeeding, and Jeffrey P Thompson, "Inequality in 3-D: Income, Consumption, and Wealth," 2016.

Foote, Christopher L, Lara Loewenstein, and Paul S Willen, "Cross-sectional patterns of mortgage debt during the housing boom: evidence and implications," Technical Report, National Bureau of Economic Research 2016.

Guvenen, Fatih, Fatih Karahan, Serdar Ozkan, and Jae Song, "What do data on millions of US workers reveal about life-cycle earnings risk?," Technical Report, National Bureau of Economic Research 2019.

_ , Greg Kaplan, Jae Song, and Justin Weidner, "Lifetime incomes in the United States over six decades," Technical Report, National Bureau of Economic Research 2017.

Heathcote, Jonathan and Fabrizio Perri, "Wealth and volatility," The Review of Economic Studies, 2018, 85 (4), 2173-2213.

_, _ , and Giovanni L Violante, "Unequal we stand: An empirical analysis of economic inequality in the United States, 1967-2006," Review of Economic dynamics, 2010, 13 (1), 15-51.

Jordà, Òscar, Moritz Schularick, and Alan M Taylor, “The great mortgaging: housing finance, crises and business cycles," Economic Policy, 2016, 31 (85), 107-152.

Kaplan, Steven $\mathbf{N}$ and Joshua Rauh, "It's the market: The broad-based rise in the return to top talent," Journal of Economic Perspectives, 2013, 27 (3), 35-56.

Katz, Lawrence F and Kevin M Murphy, "Changes in relative wages, 1963-1987: supply and demand factors," The quarterly journal of economics, 1992, 107 (1), 35-78.

Kaymak, Barış and Markus Poschke, "The evolution of wealth inequality over half a century: The role of taxes, transfers and technology," Journal of Monetary Economics, 2016, 77, 1-25. 
Koijen, Ralph SJ and Motohiro Yogo, "A demand system approach to asset pricing," Journal of Political Economy, 2019, 127 (4), 1475-1515.

Krueger, Dirk and Fabrizio Perri, "Does income inequality lead to consumption inequality? Evidence and theory," The Review of Economic Studies, 2006, 73 (1), 163-193.

Kuhn, Moritz, Moritz Schularick, and Ulrike I Steins, "Income and wealth inequality in america," Journal of Political Economy, 2019.

Kumhof, Michael, Romain Rancière, and Pablo Winant, "Inequality, leverage, and crises," American Economic Review, 2015, 105 (3), 1217-45.

Meyer, Bruce D and James X Sullivan, "Consumption and Income Inequality in the US Since the 1960s,” Technical Report, National Bureau of Economic Research 2017.

Mian, Atif, Amir Sufi, and Emil Verner, "Household debt and business cycles worldwide," The Quarterly Journal of Economics, 2017, 132 (4), 1755-1817.

_, , , and _, "How does credit supply expansion affect the real economy? the productive capacity and household demand channels," The Journal of Finance, 2020.

_ and _, House of debt: How they (and you) caused the Great Recession, and how we can prevent it from happening again, University of Chicago Press, 2015.

_ , Ludwig Straub, and Amir Sufi, “Indebted Demand,” Technical Report, Working paper 2019.

Mian, Atif R and Amir Sufi, "Household Debt and Defaults from 2000 to 2010: The Credit Supply View," Evidence and Innovation in Housing Law and Policy, 2017.

Nardi, Mariacristina De, Giulio Fella, and Gonzalo Paz-Pardo, "Nonlinear household earnings dynamics, self-insurance, and welfare," Journal of the European Economic Association, 2018.

Pettis, Michael, "Why a savings glut does not increase savings," Technical Report, Carnegie Endowment for International Peace 2017.

Philippon, Thomas, "Has the US finance industry become less efficient? On the theory and measurement of financial intermediation," American Economic Review, 2015, 105 (4), 1408-38.

Piketty, Thomas and Emmanuel Saez, "Income inequality in the United States, 1913-1998," The Quarterly journal of economics, 2003, 118 (1), 1-41.

_, _, and Gabriel Zucman, "Distributional national accounts: methods and estimates for the United States," The Quarterly Journal of Economics, 2018, 133 (2), 553-609.

Rachel, Lukasz and Lawrence H Summers, "On falling neutral real rates, fiscal policy and the risk of secular stagnation," in "Brookings Papers on Economic Activity BPEA Conference Drafts, March 7-8” 2019.

- and Thomas D Smith, "Are low real interest rates here to stay?," International Journal of Central Banking, 2017, 13 (3), 1-42. 
Rajan, Raghuram G, Fault lines: How hidden fractures still threaten the world economy, princeton University press, 2011.

Saez, Emmanuel and Gabriel Zucman, "Wealth inequality in the United States since 1913: Evidence from capitalized income tax data," The Quarterly Journal of Economics, 2016, 131 (2), $519-578$.

Slesnick, Daniel T, Consumption and social welfare: Living standards and their distribution in the United States, Cambridge University Press, 2001.

Smith, Matthew, Danny Yagan, Owen Zidar, and Eric Zwick, "Capitalists in the Twenty-first Century," The Quarterly Journal of Economics, 2019, 134 (4), 1675-1745.

_ , Owen M Zidar, and Eric Zwick, "Top Wealth in the United States: New Estimates and Implications for Taxing the Rich,” Technical Report, Working Paper 2019.

Stiglitz, Joseph E, "Inequality and economic growth," in "Rethinking Capitalism" 2016, pp. 134155.

Straub, Ludwig, "Consumption, Savings, and the Distribution of Permanent Income," Unpublished manuscript, Harvard University, 2019.

Summers, Lawrence H, "US economic prospects: Secular stagnation, hysteresis, and the zero lower bound," Business Economics, 2014, 49 (2), 65-73.

Wolff, Edward N, "Household wealth trends in the United States, 1962 to 2016: has middle class wealth recovered?," Technical Report, National Bureau of Economic Research 2017. 


\section{A Appendix for Sections 3 through 5}

\section{A.1 Consumption share of the top $1 \%$}

The baseline consumption share of the top $1 \%$ of the income distribution used in the calculation of the saving glut of the rich is $5.7 \%$ from 2005 to 2013 . Unfortunately, few existing research studies report an estimate of the consumption share of the top $1 \%$ of the income distribution, which makes comparisons difficult. However, our reading of the literature is that there is no systematic evidence that this top $1 \%$ consumption share is too low. In fact, our reading of the literature suggests that it may be on the high end.

The PSID data set used by Heathcote and Perri (2018) yields a similar estimate of the consumption share of the top $1 \%$ before the under-reporting correction of $50 \%$. This gives us confidence that the baseline PSID consumption share of $3.8 \%$ (before the under-reporting correction) used here is robust.

Since 2014, the Consumer Expenditure Survey has reported the consumption share of the top $10 \%$ of the income distribution, which they report in 2014 as 23.5\%. Fisher et al. (2016) report a consumption share of the top 5\% of the income distribution using the Survey of Consumer Finances of $17.1 \%$ in 2013. Given the under-reporting assumptions made in the baseline, the implied average consumption share of the top $10 \%$ is $26.9 \%$ from 2005 to 2013 in the methodology used in this study.

\section{A.2 Implied saving rate for the top 1\%}

Table A1 shows the average saving rate out of income for the top $1 \%$ across the different approaches used to measure savings in Sections 3 and 5. The first three columns show the implied saving rate for the income less consumption approach, and the final column shows the implied saving rate for the wealth-based approach. The average saving rates for the top $1 \%$ vary between 0.51 and 0.68 .

Table A1: Implied Saving Rates across Income Distribution, Income less Consumption Approach

\begin{tabular}{ccccc}
\hline Period & $\beta=1$ & $\beta=0.7$ & $\beta=0.5$ & Wealth-based \\
\hline $63-82$ & 0.668 & 0.623 & 0.589 & 0.516 \\
$83-97$ & 0.668 & 0.646 & 0.631 & 0.431 \\
$98-07$ & 0.668 & 0.666 & 0.664 & 0.518 \\
$08-15$ & 0.668 & 0.674 & 0.678 & 0.515 \\
\hline
\end{tabular}

This table presents the average annual saving rates out of income across the sample, where income is the total amount of national income earned by each group. 
The saving rate of the top $1 \%$ of the income distribution in the literature using survey evidence such as the Survey of Consumer Finances is 0.5 (Dynan et al. (2004)). However, the saving rate from survey data is not directly comparable to the saving rate calculated in this study because survey data miss important income that has a $100 \%$ saving rate. The most obvious example is undistributed corporate profits. Undistributed corporate profits represent saving by shareholders; such saving is captured in the methodology used in this study but missed in surveys. In addition, as mentioned in the text, Heathcote et al. (2010) show an average gap of 21 percentage points between the NIPA measure of personal income and the measure in the Current Population Survey. It is likely that a substantial amount of this missing income represents income with a high saving rate, such as employer contributions to pension plans or the internal dividends and interest payments earned by pensions.

Formally, suppose the saving rate of the top $1 \%$ estimated in survey data is $\hat{\phi_{t o p} 1}=\frac{\Theta_{t o p 1}}{Y_{t o p} 1}$. Furthermore, let $\psi_{t o p 1}$ be income missing in surveys of the top $1 \%$ that has a $100 \%$ saving rate. Then the correct saving rate for the top $1 \%$ would be: $\phi=\frac{\Theta+\psi}{Y+\psi}$ where the subscript is removed in order to reduce clutter. The incorrect saving rate would have to be adjusted to:

$$
\phi=\frac{\hat{\phi}+\frac{\psi}{Y}}{1+\frac{\psi}{Y}}
$$

The critical ratio $\left(\frac{\psi}{Y}\right)$ is the amount of income missing in surveys that has a $100 \%$ saving rate relative to the amount of reported income in surveys. If this ratio is 0.3 , for example, then the saving rate of the top $1 \%$ from surveys of 0.50 would imply a true saving rate of 0.62 .

This ratio is difficult to estimate, given the lack of estimates of the income that accrues to the top $1 \%$ that is not included in surveys. However, as a lower-bound estimate, one can calculate the part of $\psi$ that comes from the top $1 \%$ claim on undistributed corporate profits, which we know is not included in surveys as income and has a 100\% saving rate. From 1998 to $2015, \frac{\psi}{Y}$ is estimated to be 0.23 using undistributed corporate profits alone, which would imply a true saving rate of 0.59 given a survey-reported saving rate of 0.50 . This lower bound estimate convinces us that a saving rate of 0.5 to 0.67 is realistic for the top $1 \%$ once all sources of income are included.

One can also put a lower bound on the saving rate of the top $1 \%$ by estimating what a given saving rate implies about the consumption share of the top 1\%. For example, an assumed average annual saving rate of the top $1 \%$ from 1998 to 2015 of 0.3 would imply an average annual consumption share of the top $1 \%$ of $12.2 \%$. An assumed saving rate of 0.4 would imply an average consumption share of the top $1 \%$ of $10.4 \%$. These consumption shares are far higher than any estimate in the literature. The large amount of income earned by the top $1 \%$ implies unrealistic consumption shares of the top $1 \%$ unless the rich save a fraction of their income that is 0.5 or above. 


\section{A.3 Saving glut of rich using CBO top income share}

Figure A1: Saving glut of rich using CBO top income share

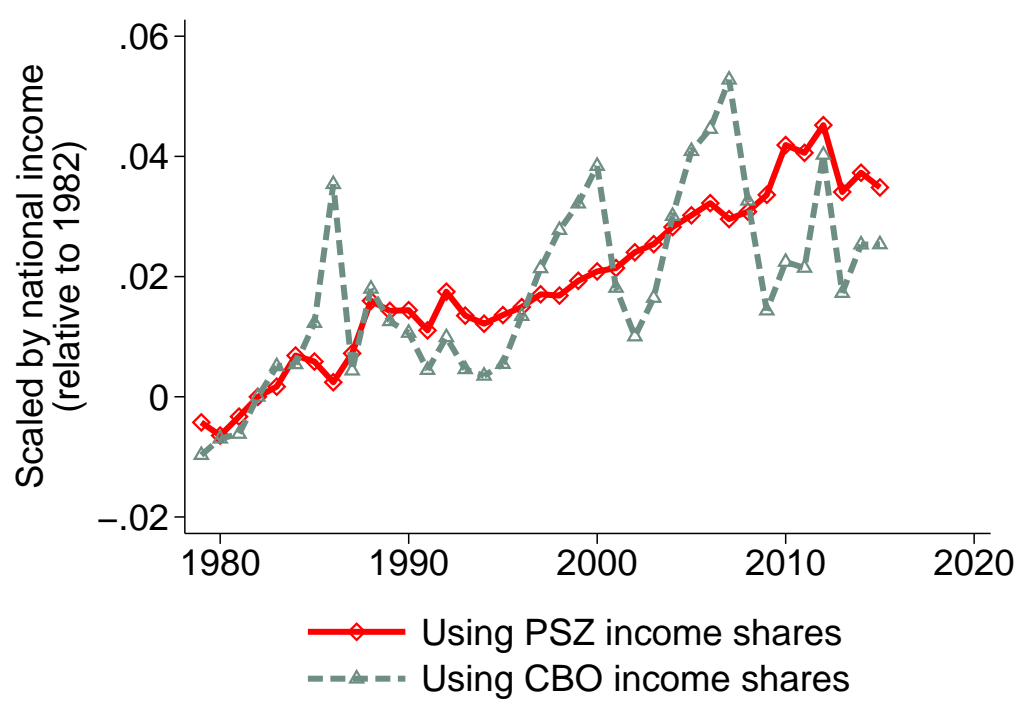

This figure plots the saving glut of the rich relative to 1982 using the income share estimate for the top $1 \%$ for both PSZ and CBO.

\section{A.4 More details on wealth-based approach to measuring savings}

This section describes the data underlying the asset inflation measures, and explores alternative methods for calculating the synthetic savings of the cohorts from wealth, which is described in Section 5.

We first describe in detail the construction of the $\pi_{t}^{i j}=1-W D_{t}^{i j}$ for debt. We begin by constructing the net chargeoff rate on mortgage and non-mortgage debt for debt borrowed by top $10 \%$ and the bottom $90 \%$ separately.

Using Call report data, we calculate net chargeoff rate on mortgage and non-mortgage consumer debt. While not all household debt is held on banks balance sheets, we proceed with the assumption that household debt held outside of the banking sector has similar net chargeoff rate as debt held by banks directly. Debt held by non-bank entities such as GSEs is likely to be less risky and hence have lower net chargeoff ratio. However, there are other non-bank entities in the shadow banking sector, such as hedge funds, that are likely to hold the most risky debt and hence have a higher net chargeoff rate. We assume that these two factors cancel out and use bank-held debt net chargeoff rate as representative of overall net chargeoff rate.

We construct annual net charge off rate as net charge offs divided by the total outstanding debt 
using information in Call report data. This gives us a net chargeoff rate series for mortgage debt from 1991 to 2016, and for non-mortgage consumer debt from 1983 to 2016 . Net charge off on mortgage debt is not available as a separate line item prior to 1991. We therefore impute net chargeoff rate on mortgage debt from 1983 to 1990 using non-mortgage consumer credit charge off rate and charge off rate on all loans issued by banks as predictors. In particular, we regress net chargeoff rate for mortgage debt between 1991 and 2016 on net chargeoff rate on non-mortgage consumer debt and net chargeoff rate on all bank loans. The R-sq of this regression is quite high at 0.75 . We then use the predicted coefficient to predict net chargeoff rate on mortgage debt from 1983 to 1990.

Prior to 1983, Call report data only allows us to construct an overall net chargeoff rate, i.e. chargeoff rate for all debt on banks balance sheets. We use this overall series to extend net chargeoff rate for mortgage and non-mortgage debt back to 1962 by regressing each of these two series (when available) directly on the overall net chargeoff rate series and using the predicted coefficients to predict net chargeoff rate back to 1962 .

Once we have annual net chargeoff rate on mortgage and non-mortgage debt, we calculate how much of debt write down was on debt borrowed by the top $10 \%$ versus the bottom $90 \%$. We do this using zipcode level data on consumer borrowing from Equifax and merging income data from the IRS. We first multiple total mortgage and total non-mortgage debt across zip codes in the U.S. to calculate the total dollar amount of debt written down every year. We then allocate the total written down amount to zip codes based on the share of total debt default that the zipcode has. We sort zip codes by their average income per capita (income measured by aggregate gross income) ${ }^{35}$ and categorize zip codes into top $10 \%$ and bottom $90 \%$ by income (population weighted). Finally, we calculate the ratio of total written down debt amount to total outstanding debt within each income category and for both mortgage and non-mortgage debt separately.

The above procedure allows us to compute debt write down rate $W D_{t}^{i j}$ for $j$ equal to mortgage and non-mortgage debt, and $i$ equal to top $10 \%$ and bottom $90 \%$ from 1991 to 2016 . There is no zip code level Equifax data prior to 1991. However, we can use Equifax-based estimates to impute $W D_{t}^{i j}$ for year prior to 1991 by regressing $W D_{t}^{i j}$ on US-level net chargeoff rate for mortgage and non-mortgage debt respectively for years 1991 to 2016. We then use the predicted coefficients and data on net chargeoffs at the US level to back-fill $W D_{t}^{i j}$ from 1962 to 1990 . Exact details of all of our procedure can be seen in the accompanying code that is made public.

Next we discuss the computation of $\pi_{t}^{j}$ for equity. The starting point for this imputation is the wealth-implied private saving in the aggregate, $\Theta_{t}=\sum_{j \in J}\left(\Delta W_{t}^{j}-\pi_{t}^{j} W_{t-1}^{j}\right)$. The key observation is that we know $\Theta_{t}$ at the aggregate level from NIPA. We have also calculated $\pi_{t}^{j}$ for all assets other than equity. We can therefore solve for $\pi_{t}^{j}$ for equity assets.

Is the implied $\pi_{t}^{j}$ from this exercise reasonable? One check for that is to compare it to capital

\footnotetext{
${ }^{35}$ The IRS data is missing for certain years early on, in which case we use the latest available IRS data.
} 
gain series for equity market as a whole. While for reasons mentioned in the draft, capital gain is not the same as asset inflation $\pi_{t}^{j}$ that we need, it should nonetheless be positively correlated. This is indeed the case. The correlation between our asset inflation measure $\pi_{t}^{j}$ and capital gains on equity series from the JST Macrohistory Database is 0.55 .

\section{B Appendix for Discussion of Capitalization Factors}

\section{B.1 Summary of issue}

Translating flows of income into stocks of wealth requires an assumption of the rate of return on assets, a process detailed in Saez and Zucman (2016) and Piketty et al. (2018). Recent research suggests that the baseline methodology in Saez and Zucman (2016) and Piketty et al. (2018) overstates the level of fixed income asset holdings of the top $1 \%$ given the assumption of a constant rate of return on fixed income assets when estimating fixed income wealth from fixed income asset cash flows (e.g., Bricker et al. (2018) and Smith et al. (2019b)). This manifests itself in the assumed capitalization factor one uses to multiply the fixed income asset cash flows to obtain fixed income wealth.

This section discusses this issue at length, but the bottom line is that none of the results of this study are materially affected by this issue before 2008. The reason is that this study focuses on changes over time in the wealth of the rich. The capitalization factor discussion mostly affects the level of wealth of the top 1\%, not the change from 1982 to $2008 .^{36}$ The results after 2008 are affected, but not in a material way under realistic assumptions on the rate of return on fixed income assets of the top $1 \%$ of the distribution.

The estimation of savings using the income less consumption approach in Section 3 is not significantly affected by this issue, given that it is based on income across the distribution instead of wealth. The wealth distribution plays a minor role in the PSZ income shares, which is related to how undistributed corporate profits and undistributed pension income are assigned to the top $1 \%$.

The capitalization factor issue is potentially more important for Sections 5 through 7 . To address this issue, we follow Saez and Zucman (2016), Bricker et al. (2018), and Smith et al. (2019b) by assuming a higher earned interest rate for the top $1 \%$ on fixed income assets. In particular, there are three assumptions on this rate of return: (1) that the top 1\% earn a rate of return similar to the U.S. 10-year Treasury rate, (2) that the top $1 \%$ earn a rate of return that is 100 basis points larger than the bottom $99 \%$, and (3) that the top $1 \%$ earn a rate of return that is 50 basis points larger than the bottom $99 \%$.

\footnotetext{
${ }^{36}$ To see the change versus level point, see, for example, the red, blue, and yellow lines in Figure 9 in the July 2019 version of Smith et al. (2019b). The level of the wealth share of the top 1\% is affected, but the trend is similar prior to 2008.
} 
Figure A2: Fixed Income Asset Returns of the Top 1\%

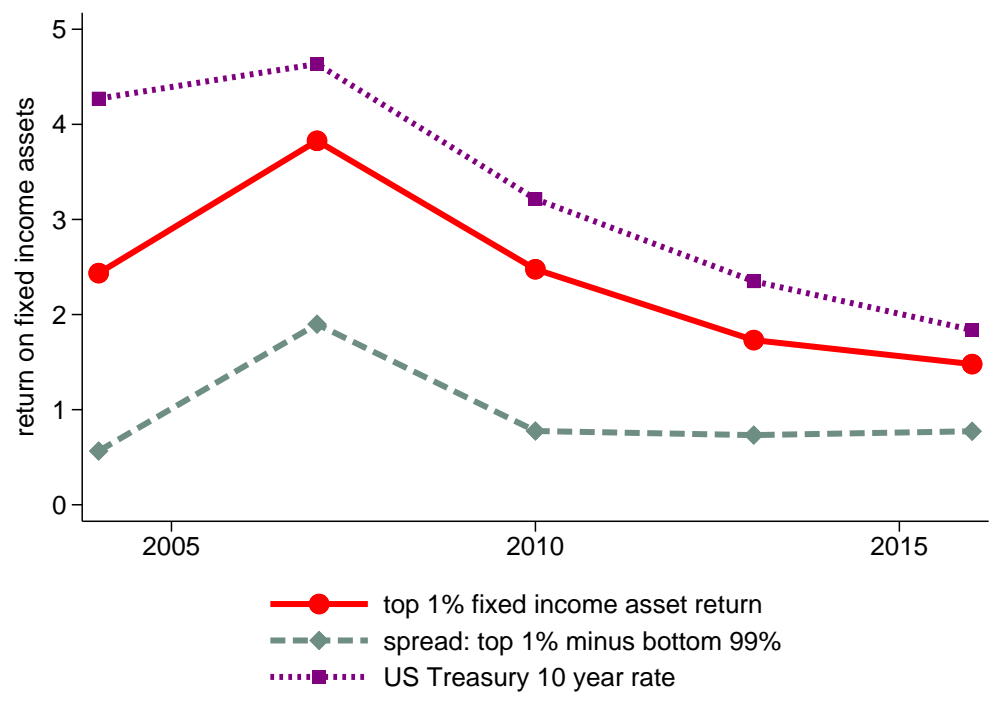

This figure plots the average fixed income asset return for the top $1 \%$ of the wealth distribution in the SCF, following the methodology in Bricker et al. (2018). The spread between the top $1 \%$ and bottom $99 \%$ return from the SCF is also plotted, along with the 10-year U.S. Treasury rate.

These assumptions are motivated by the analysis in Bricker et al. (2018), who use the SCF to estimate the rate or return on fixed income assets for the top 1\%. The solid red line in Figure A2 plots the average fixed income asset return for the top $1 \%$ of the wealth distribution from the SCF, following the methodology outlined by Bricker et al. (2018) (see footnote 22 in the March 30, 2018 version). Our replication attempt of Bricker et al. (2018) matches almost exactly the figures reported from Table 1 of Bricker et al. (2018). Figure A2 also plots the 10-year Treasury rate and the spread between the fixed income asset return of the top 1\% and the bottom $99 \%$ from the SCF. Based on this analysis, the 10-year Treasury rate is likely too conservative, given that the return on the 10-year Treasury is above the return for the top $1 \%$ in every year. The spread between the top $1 \%$ and bottom $99 \%$ return is between 50 and 100 basis points in every year except 2007.

\section{B.2 Robustness of wealth-based calculation of savings}

Table A2 shows the saving glut of the rich using the wealth-based approach where different assumptions are made on the rate of return earned by the top $1 \%$ on fixed income assets. This table corresponds to Table 5 in Section 5. The rise in savings is similar for all measures from the preperiod to the 1998 to 2007 period. The rise varies from $1.7 \%$ to $2.1 \%$. The saving glut of the rich is smaller from 2008 to 2015 under the assumption of a higher rate of return on fixed income assets of the top 1\%. As mentioned above, the results are similar for the 1998 to 2007 period because 
before 2008, the assumption of a higher rate of return on fixed income asset for the top $1 \%$ affects the level of wealth, but not the trend. After 2008, this assumption affects the trend as well.

Table A2: Savings across the Wealth Distribution, Robustness to Differential Returns

\begin{tabular}{ccccc}
\hline Period & Baseline & US Treasury 10y & 50 bp spread & 100 bp spread \\
\hline $63-82$ & 0.035 & 0.033 & 0.035 & 0.035 \\
$83-97$ & 0.040 & 0.035 & 0.038 & 0.037 \\
$98-07$ & 0.056 & 0.050 & 0.054 & 0.053 \\
$08-15$ & 0.068 & 0.045 & 0.058 & 0.050 \\
\hline
\end{tabular}

This table presents average annual savings to national income ratios for the top 1\%, assuming different rates of return on fixed income assets. Savings are calculated based on the wealth-based ratio: $\Theta_{i t}=\sum_{j \in J}\left(\Delta W_{i t}^{j}-\pi_{t}^{j} W_{i, t-1}^{j}\right)$.

\section{B.3 Robustness of household debt holdings of the rich}

Figure A3 shows the holdings of household debt by the top $10 \%$ of the income distribution under alternative assumptions of the rate of return on fixed income assets for the top 1\%. This figure corresponds to the left panel of Figure 14 in Section 6. Assuming a higher rate of return on fixed income assets lowers the increase in the amount of household debt held by the top 10\% from 1982 to 2007, but not materially. There is a more substantial reduction in the holdings of household debt by the top $10 \%$ after 2007 when a higher interest rate is assumed. 
Figure A3: Robustness of Methodology using Alternative Capitalization Factors

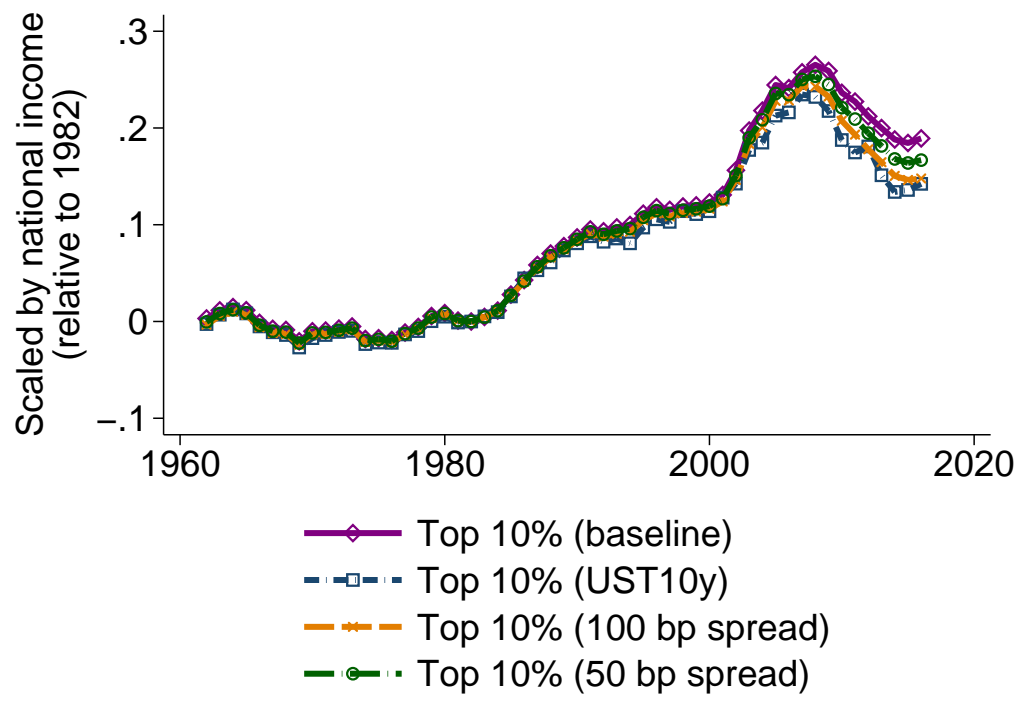

This figure shows the holdings of household debt by the top $10 \%$ of the income distribution. The lines differ based on the assumed rate of return on fixed income assets of the top 1\%. All series are scaled by national income, and the 1982 level is subtracted.

\section{B.4 Robustness of state-level analysis}

Tables A3 and A4 correspond to Table 7 in Section 7. The share of household debt held by a given income group in a given state is estimated using the different assumptions on the rate or return on fixed income assets of the top $1 \%$. 
Table A3: Robustness of Table 7 using Higher Rate of Return for the Rich: Top 6\% Holdings

\begin{tabular}{lcccc}
\hline \hline & $(1)$ & $(2)$ & $(3)$ & $(4)$ \\
\hline$\Delta_{82,07}$ Top 6\% Share & $1.767^{* * *}$ & $1.324^{* * *}$ & $1.658^{* * *}$ & $1.569^{* * *}$ \\
& $(0.205)$ & $(0.133)$ & $(0.187)$ & $(0.173)$ \\
& & & & \\
Top 6\% Share 1982 & $0.675^{*}$ & $0.619^{* *}$ & $0.665^{* *}$ & $0.658^{* *}$ \\
& $(0.255)$ & $(0.187)$ & $(0.238)$ & $(0.223)$ \\
& & & & \\
$\Delta_{82,07}$ Log Per Capita Income & 0.0615 & 0.0564 & 0.0597 & 0.0587 \\
& $(0.043)$ & $(0.030)$ & $(0.040)$ & $(0.037)$ \\
Log Per Capita Income 1982 & 0.0736 & 0.0544 & 0.0685 & 0.0647 \\
& $(0.066)$ & $(0.046)$ & $(0.061)$ & $(0.057)$ \\
$Y_{i s, 1982}$ & & & \\
& $-0.495^{*}$ & $-0.544^{* *}$ & $-0.522^{* *}$ & $-0.544^{* *}$ \\
\hline Type & $(0.196)$ & $(0.183)$ & $(0.187)$ & $(0.179)$ \\
$R^{2}$ & Baseline & UST 10y & $50 \mathrm{bp} \mathrm{spr}$ & $100 \mathrm{bp} \mathrm{spr}$. \\
Observations & 0.89 & 0.91 & 0.89 & 0.90 \\
\hline
\end{tabular}

Dependent variable, $\Delta_{82,07} Y_{p s}$, is the change in household debt held as a financial asset by group $p$ in state $s$ scaled by state income. Robust standard errors in parentheses. $* p<0.05, * * p<0.01, * * * p<0.001$. 
Table A4: Robustness of Table 7 using Higher Rate of Return for the Rich: Bottom 94\%

\begin{tabular}{|c|c|c|c|c|}
\hline & (1) & (2) & (3) & (4) \\
\hline \multirow[t]{2}{*}{$\Delta_{82,07}$ Top 6\% Share } & -0.00603 & 0.0691 & 0.0119 & 0.0264 \\
\hline & $(0.130)$ & $(0.178)$ & $(0.142)$ & $(0.152)$ \\
\hline \multirow[t]{2}{*}{ Top 6\% Share 1982} & $-0.642^{*}$ & $-0.752^{*}$ & $-0.672^{*}$ & $-0.694^{*}$ \\
\hline & $(0.259)$ & $(0.334)$ & $(0.277)$ & $(0.291)$ \\
\hline \multirow[t]{2}{*}{$\Delta_{82,07}$ Log Per Capita Income } & 0.0274 & 0.00706 & 0.0224 & 0.0185 \\
\hline & $(0.038)$ & $(0.051)$ & $(0.041)$ & $(0.043)$ \\
\hline \multirow[t]{2}{*}{ Log Per Capita Income 1982} & $0.109^{*}$ & 0.113 & 0.110 & 0.110 \\
\hline & $(0.054)$ & $(0.071)$ & $(0.058)$ & $(0.061)$ \\
\hline \multirow[t]{2}{*}{$Y_{i s, 1982}$} & $-0.509^{* * *}$ & $-0.419^{* * *}$ & $-0.473^{* * *}$ & $-0.448^{* * *}$ \\
\hline & $(0.085)$ & $(0.103)$ & $(0.092)$ & $(0.097)$ \\
\hline Type & Baseline & UST 10y & 50 bp spr. & $100 \mathrm{bp} \mathrm{spr}$. \\
\hline$R^{2}$ & 0.50 & 0.35 & 0.44 & 0.40 \\
\hline Observations & 51 & 51 & 51 & 51 \\
\hline
\end{tabular}

state income. Robust standard errors in parentheses. $* p<0.05$, ** $p<0.01$, *** $p<0.001$.

\section{Appendix for Financing Household Debt Section 6}

\section{C.1 Further details on unveiling}

This section contains a few extra notes on the unveiling process. All code and data for the unveiling exercise are included in the replication kit.

Formally, the unveiling procedure computes the entire set of household debt shares $\bar{F}_{c}$, including those asset classes $c$ that are not directly owned by households. Denote by $\bar{C}$ the number of all such asset classes. The equation pinning down $\bar{F}$ is a "financial input-output network". Specifically, denote by $\eta_{c^{\prime}, c}$ the share of asset class $c$ 's liabilities that are owned by asset class $c^{\prime}$; and denote 
by $\eta_{c}^{H H D}$ share of household debt directly owned by asset class $c$. Observe that

$$
\sum_{c=1}^{\bar{C}} \eta_{c}^{H H D}=1 \quad \text { and } \quad \sum_{c^{\prime}=1}^{\bar{C}} \eta_{c^{\prime}, c} \leq 1
$$

where the latter inequality is strictly less than 1 for any asset class $c$ that is partly owned by households. $\bar{F}$ must then satisfy

$$
\left[\begin{array}{c}
\bar{F}_{1} \\
\bar{F}_{2} \\
\vdots \\
\bar{F}_{\bar{C}}
\end{array}\right]=\left[\begin{array}{c}
\eta_{1}^{H H D} \\
\eta_{2}^{H H D} \\
\vdots \\
\eta_{\bar{C}}^{H H D}
\end{array}\right]+\left[\begin{array}{cccc}
\eta_{1,1} & \eta_{1,2} & \cdots & \eta_{1, \bar{C}} \\
\eta_{2,1} & \eta_{2,2} & \cdots & \eta_{2, \bar{C}} \\
\vdots & \vdots & \ddots & \vdots \\
\eta_{\bar{C}, 1} & \eta_{\bar{C}, 2} & \cdots & \eta_{\bar{C}, \bar{C}}
\end{array}\right]\left[\begin{array}{c}
\bar{F}_{1} \\
\bar{F}_{2} \\
\vdots \\
\bar{F}_{\bar{C}}
\end{array}\right]
$$

In words, this equation captures that the household debt share of asset class $c$ is equal to its directly owned share $\eta_{c}^{H H D}$, plus the indirectly owned share through other asset classes, $\sum_{c=1} \bar{C}_{c^{\prime}, c} \bar{F}_{c}$. The matrix product on the right hand side of this equation incorporates our assumption that the household debt owned by asset class $c$ is attributed to its liabilities in proportion to their liabilities shares. In matrix notation, (18) can be expressed as

$$
\bar{F}=\eta^{H H D}+H \bar{F}
$$

which yields the solution

$$
\bar{F}=(I-H)^{-1} \eta^{H H D}
$$

The Leontieff inverse matrix, $(I-H)^{-1}=I+H+H^{2}+\ldots$, captures any direct and indirect ownership of household debt after an arbitrary number of rounds of unveiling. As explained above, in our case at hand, seven rounds were sufficient to conduct the unveiling.

One important adjustment is made to the DFA shares based on defined benefit pensions. A substantial fraction of defined benefit pension wealth is unfunded. An unfunded DB pension cannot be a claim on household debt because there is no actual financial asset backing the unfunded part of the pension. We therefore exclude the unfunded portion of defined benefit pensions from the measure of wealth, and we re-calculate wealth shares for the top 1\%, next 9\%, and bottom $90 \%$.

Another issue that is currently ignored in the unveiling process is the fact that financial asset shares of DB and defined contribution pension funds vary across the income distribution (e.g., Devlin-Foltz et al. (2019)). Data kindly shared to us by Alice Henriques Volz based on DevlinFoltz et al. (2019) shows that from 1989 to 2016, the top 10\% share of DC assets was 53\% and the top $10 \%$ share of DB assets was $48 \%$. When excluding unfunded DB pensions, the shares of overall pensions should be adjusted given that the claim of lower income households on unfunded 
pensions is larger than their claim on DC pension assets. We do not currently make an adjustment given the fact that the DFA as currently structured does not provide financial asset shares separately for DB and DC pension assets. The lack of this adjustment means that the current methodology overstates the amount of household debt held as a financial asset by the bottom $90 \%$ of the income distribution through pensions.

Another issue involves equity of private depository institutions. The Financial Accounts does not include an estimate of the equity of private depository institutions, which must be taken into account when distributing the household debt held by the these institutions to other entitities. The estimate of private depository institution equity comes from publicly traded banks through CRSP data.

Finally, the unveiling process currently ignores the equity holdings in other financial intermediaries such as the Agency GSEs and life insurance companies. Taking into account these equity holdings will boost the share of household debt held by the top of the income distribution, given that the top of the income distribution holds a larger share of equity than other asset classes.

\section{C.2 Wealth sort for unveiling exercise}

Figures A4 and A5 show household debt holdings across the wealth distribution as opposed to the income distribution shown in Figures 14 and 15 above.

Figure A4: Who Holds Household Debt across the Wealth Distribution?

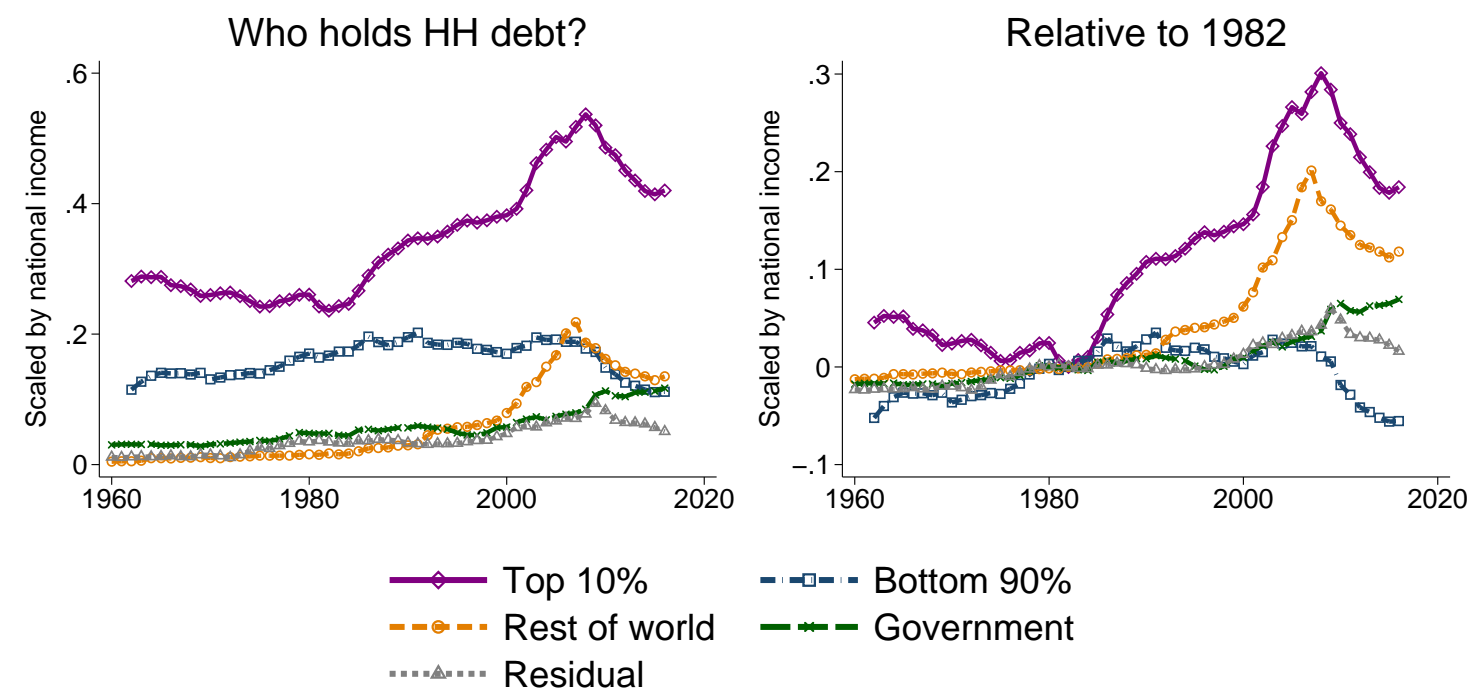

This figure decomposes the holdings of household debt by the U.S. household sector across the wealth distribution. All series are scaled by national income. 
Figure A5: Net Household Debt across Wealth Distribution Relative to 1982

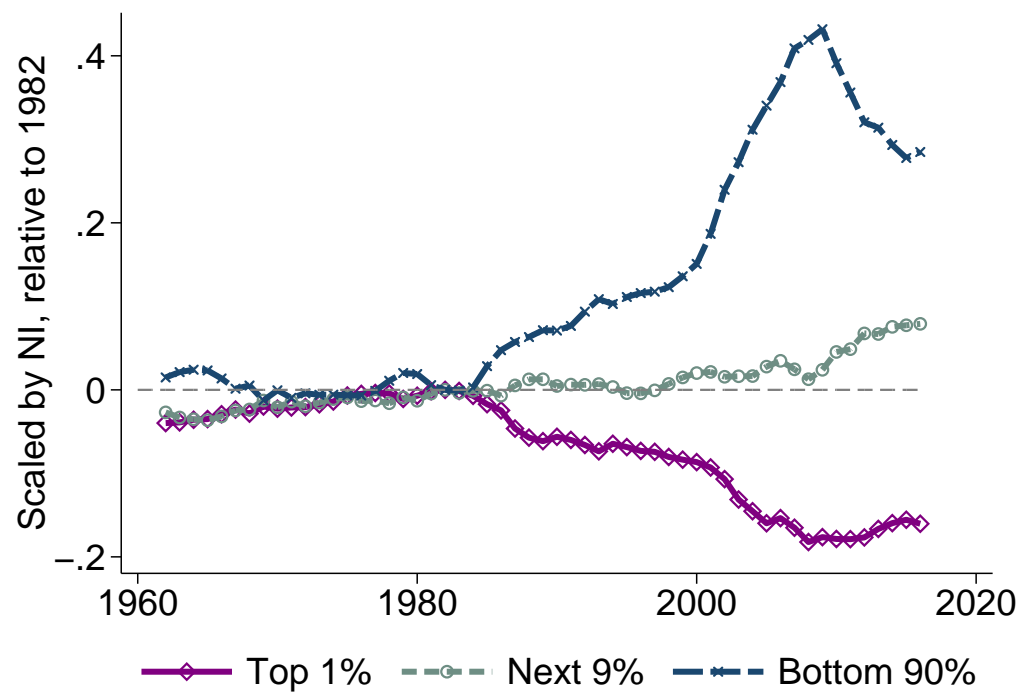

This figure shows net household borrowing by the U.S. household sector across the wealth distribution. Net household borrowing is defined as gross household borrowing minus household debt held as a financial asset. All series are scaled by national income, and the 1982 level is subtracted.

\section{C.3 Results using DFA}

In order to assign household debt owned by the household sector to various parts of the income distribution, the baseline methodology uses wealth shares from the PSZ microfiles. An alternative methodology would be to use the wealth shares from the DFA. There are two limitations when using the DFA. The first is that the DFA only cover 1989 onward. The second is that the DFA does not break down wealth shares by the top $10 \%$ of the income distribution. Instead, the DFA breaks down wealth shares for the top $1 \%$ of the income distribution and the 80th to 99th percentile of the income distribution.

The left panel of Figure A6 uses the DFA to plot the amount of household debt held by the top $1 \%$ of the income distribution and the top $1 \%$ of the wealth distribution. Both series are indexed to 1989. The two plots are nearly identical. This gives us confidence that the wealth share of the top $10 \%$ of the wealth distribution in the DFA is a good proxy for the wealth share of the top $10 \%$ of the income distribution in the DFA.

The right panel of Figure A6 plots the holdings of the top $10 \%$ of the wealth distribution using both the DFA wealth shares and the PSZ wealth shares. Both series are indexed to 1989. As the results show, the DFA wealth shares yield a substantial increase in the amount of household debt held by the top $10 \%$ of the wealth distribution, but it is 4.5 percentage points lower relative to the 
PSZ wealth shares as of 2007.

While the pattern looks similar for the top 10\% of the wealth distribution, the DFA and PSZ wealth shares imply substantial differences between the rise in household debt held as a financial asset by the top 1\% and next 9\%. This is shown in Figure A7. For this figure, the focus is again on household debt held as a financial asset across the wealth distribution. The DFA wealth shares imply a much larger increase in household debt held by the next 9\%, whereas the PSZ wealth shares imply a larger increase in holdings by the top $1 \%$.

Figure A6: Who Holds Household Debt across the Wealth Distribution? DFA
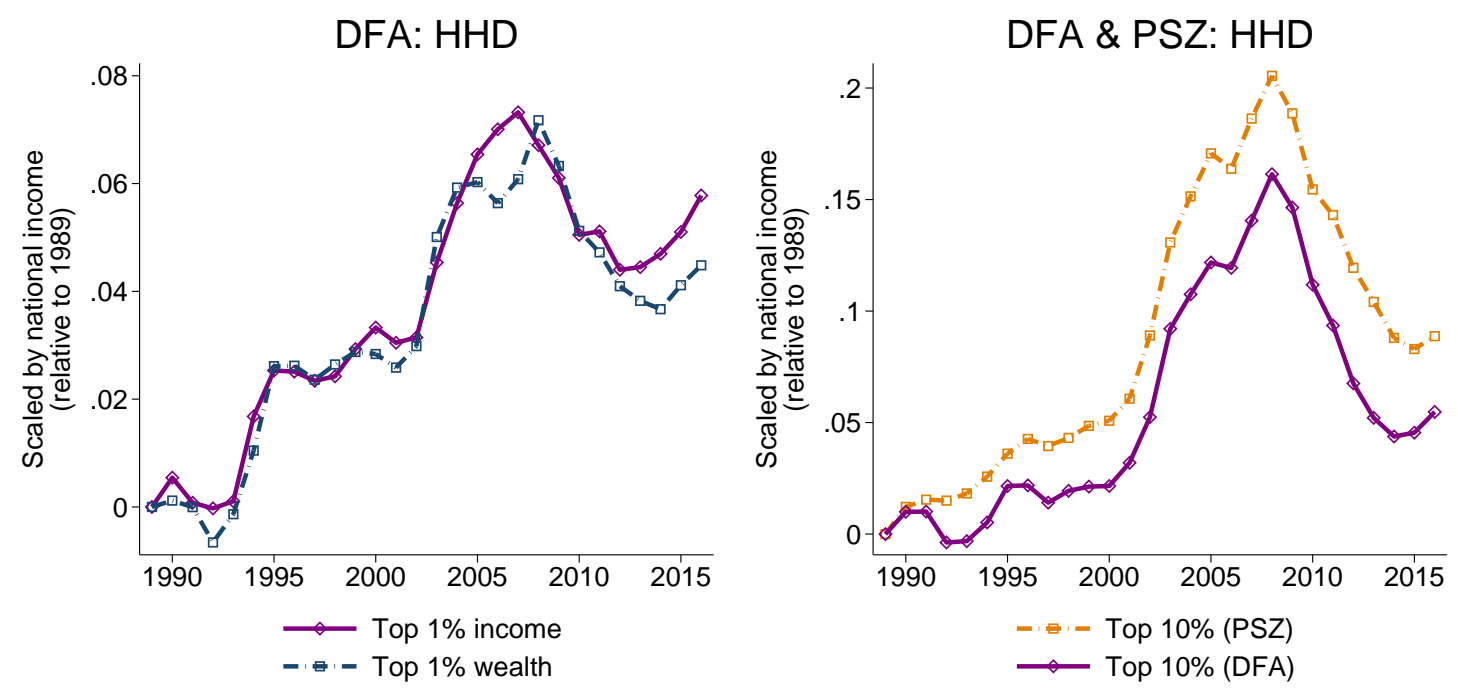

This figure compares holdings of household debt by the top 10\% of the distribution using wealth shares from both PSZ and the DFA. The left panel shows the amount of household debt held by the top $1 \%$ of the income distribution and top $1 \%$ of the wealth distribution in the DFA. The right panel shows the amount of household debt held by the top $10 \%$ of the wealth distribution using the PSZ and the DFA wealth shares. 
Figure A7: Who Holds Household Debt across the Wealth Distribution? Details

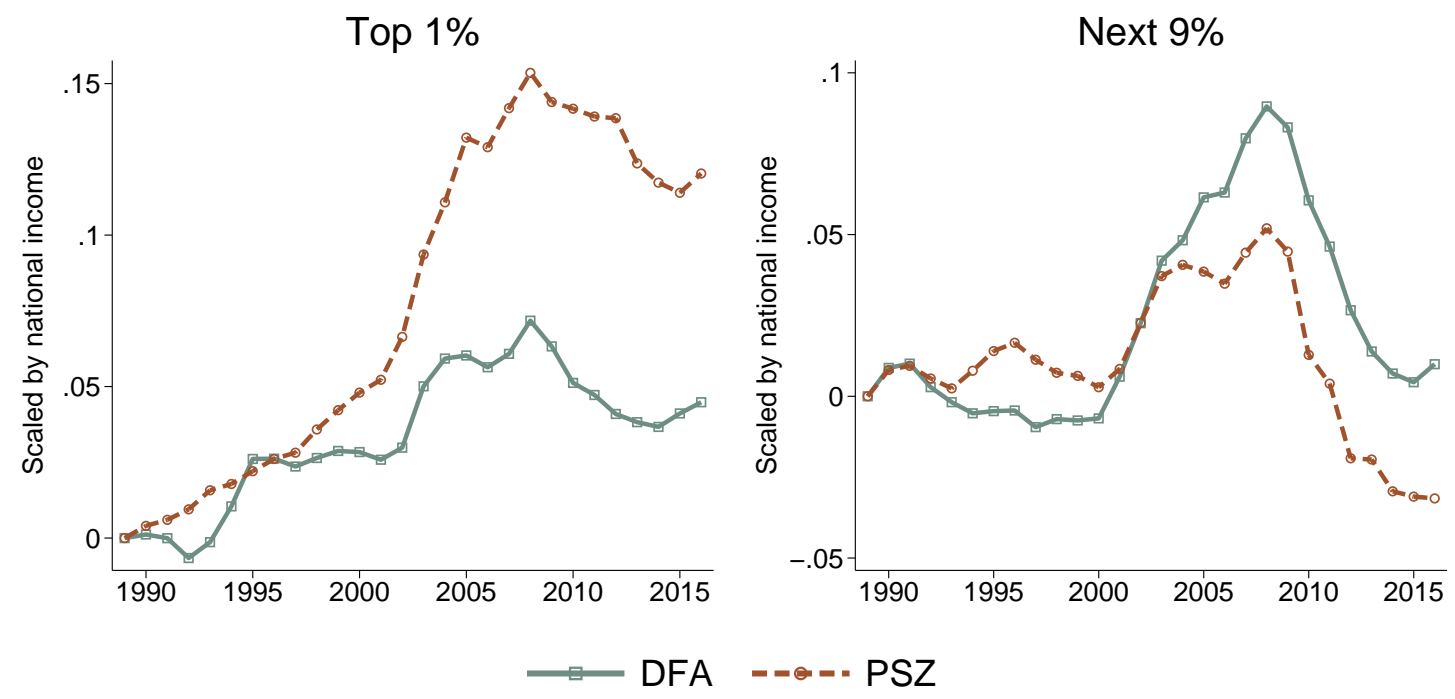

This figure decomposes the holdings of household debt by the U.S. household sector across the wealth distribution. The left panel uses the financial asset shares from Saez and Zucman (2016) and the right panel uses the financial asset shares from the DFA (described in Batty et al. (2019)). All series are scaled by national income.

\section{C.4 Additional graphs for Section 6}

Figure A8 provides details on the assets through which the U.S. household sector holds household debt. The left panel plots more equity-like instruments, and the right panel plots more fixed-income instruments. The most traditional channel through which households would lend to other households would be through bank deposits. Since 1980, however, this has not been an important source of the overall rise in household lending to other households. Instead, the most important channels through which households increasingly lend to other households are pensions, mutual funds, annuities (most of which are variable annuities sold by life insurance companies), equity, and bonds. 
Figure A8: Instruments through which Household Debt Held by Households
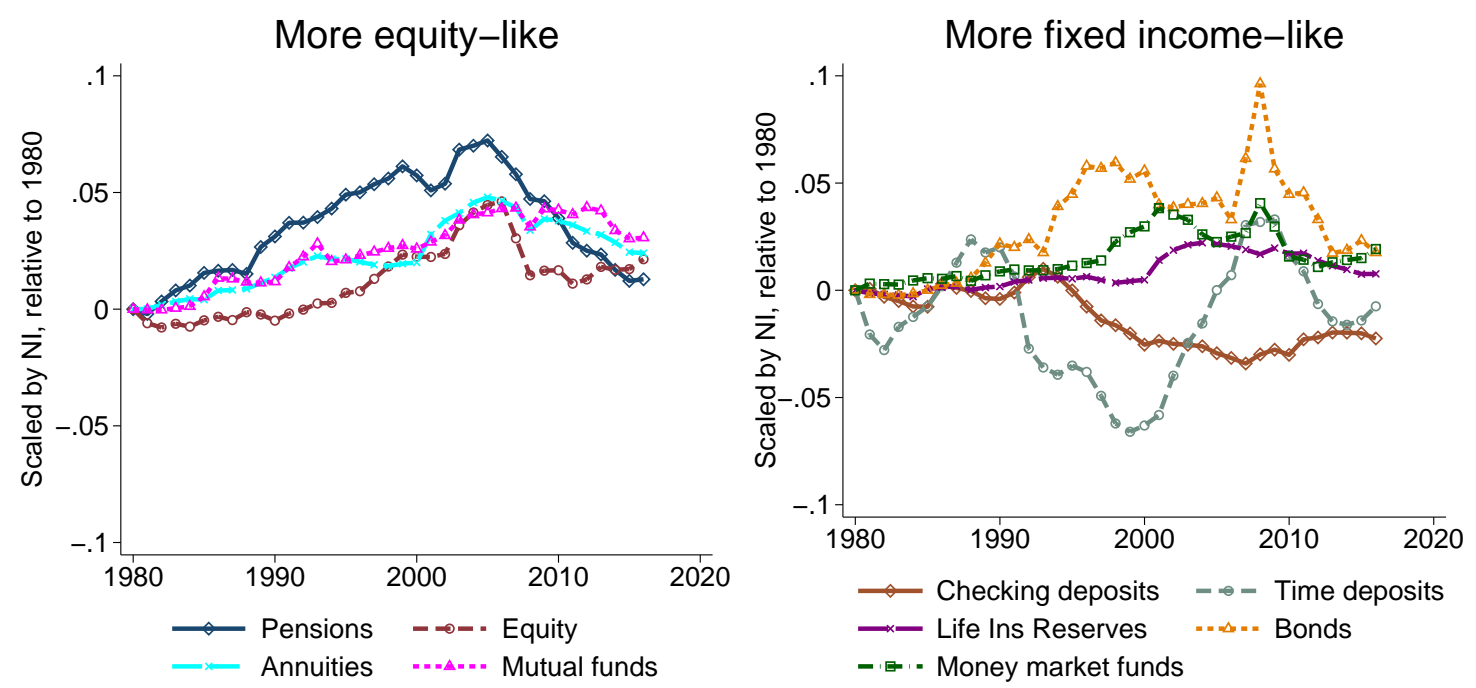

The two panels plot the asset class through which households hold household debt as a financial asset. Bonds include Agency GSE bonds, and bonds issued by financial and non-financial firms. Equity includes the equity of private depository institutions, and both corporate and non-corporate businesses. All series are scaled by national income.

In fact, the asset class for which lower wealth households in the United States traditionally hold a high share is checking deposits. As the right panel shows, holdings of household debt by households through checking deposits has actually declined substantially. This is an indication that the rise in household debt has not been financed by lower wealth households. The distribution of holdings of household debt in the United States is the central focus of the next sub-section.

Appendix Figure A9 uses the DFA allocation shares and shows the five largest asset classes through which the top 10\% held household debt as of 2007, and the five largest classes in terms of the rise in debt holdings of the top 10\% from 1992 to 2007. From 1992 to 2016, non-financial businesses increased their holdings of deposits and money market funds by 10 percentage points of National Income (see Appendix Figure A10). 
Figure A9: Through What Instruments Does Top 10\% Hold Household Debt?
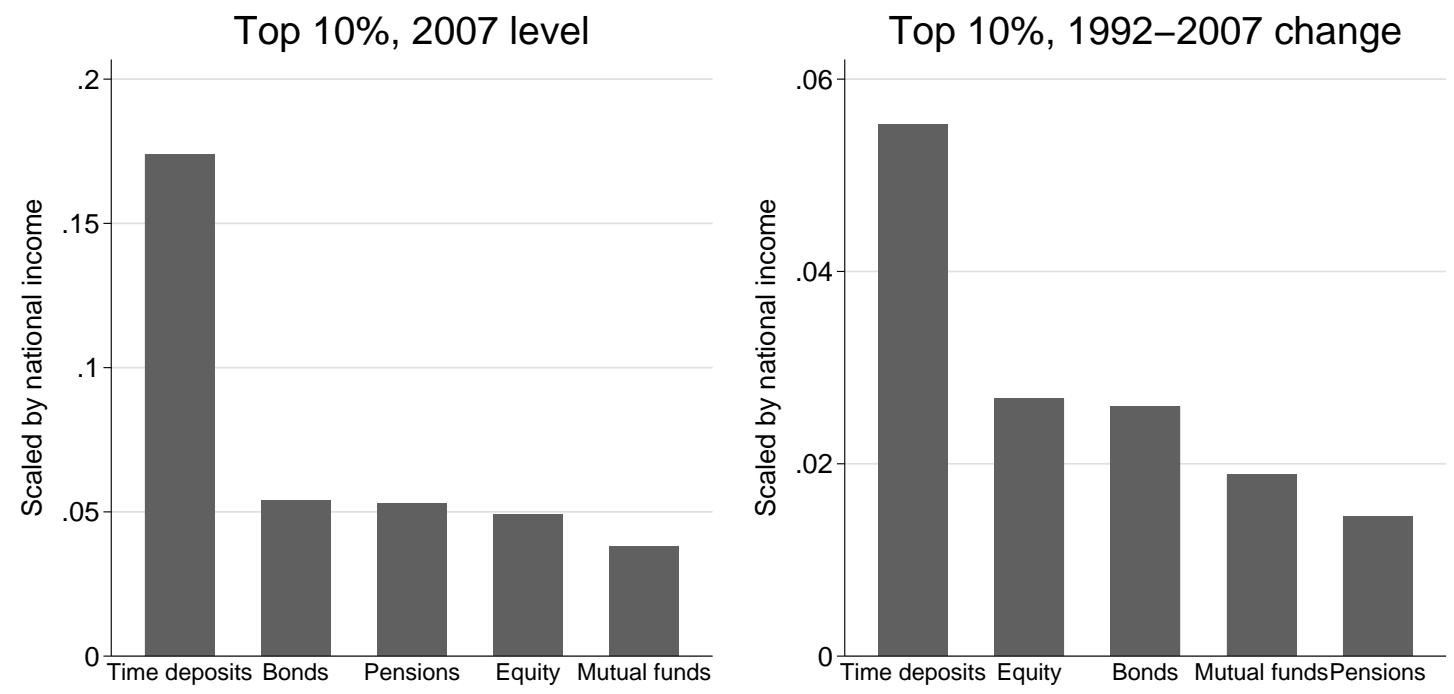

This figure shows the top 5 financial instruments through which the top $10 \%$ hold household debt as of 2007 (left panel), and the top 5 financial instruments through which the top 10\% increased their holdings of household debt from 1992 to 2007 (right panel).

Figure A10: Non-financial business deposits and money market fund holdings

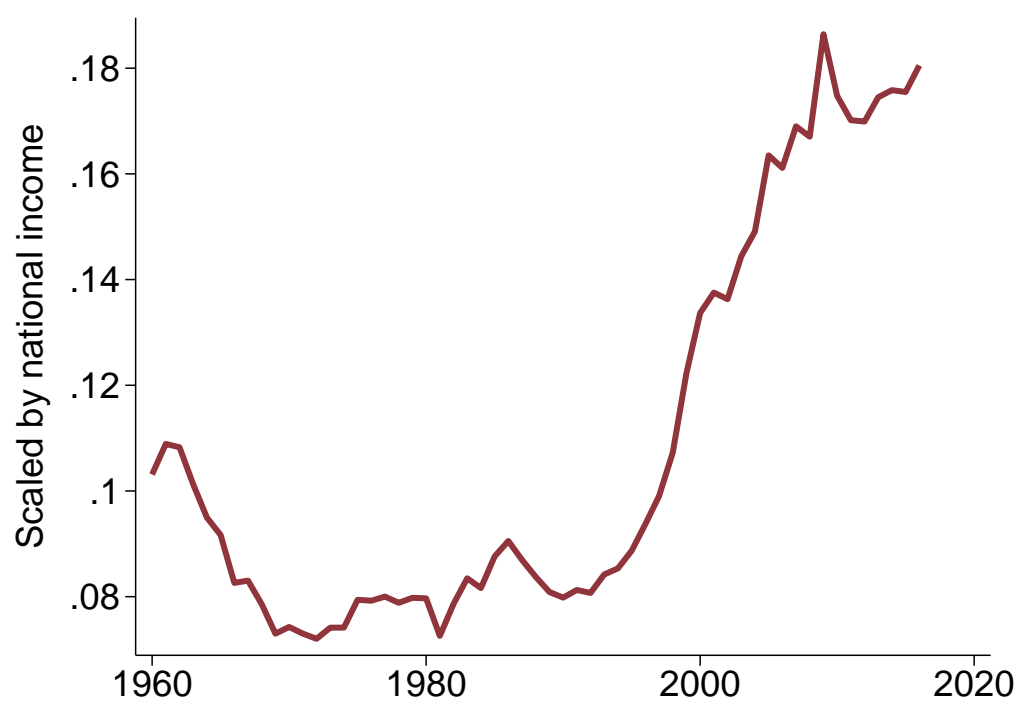

Data are from the Financial Accounts. 


\section{Appendix for State-Level Analysis in Section 7}

\section{D.1 More details on state-level data}

In this section we describe in detail our procedure for assigning tax returns with income above $200 \mathrm{~K}$ to individual states for the years 1989-2007. Recall that for 1982 we do not need to do this because the household-level public use tax files contain state identifiers for all observations.

As mentioned above, we obtain the mean interest, dividend, and taxable pension income for units with AGI above $\$ 200,000$ from the SOI aggregate data. In order to utilize these data in the Saez and Zucman (2016) capitalization technique, we also require the mean estate income and nontaxable pension income for these same units. To have data on all asset classes of interest, we additionally need the mean municipal bond and business wealth. To obtain these data, we rely on the US DINA microfiles made available by Piketty et al. (2018), in which we find these income variables and can directly construct the wealth variables with the Saez and Zucman (2016) technique. Given that state identifiers are missing for these top earners, we obtain state-level means by employing a probabilistic sampling approach.

Our key assumption in this approach is that for each state $s$ and year $y$ the distribution of income $I$ for units with AGI above $\$ 200,000$ is characterized by a Pareto distribution with probability density function $f_{s y}(I)=\frac{\alpha_{s y} 200000^{\alpha_{s y}}}{I^{\alpha_{s y}+1}}$ and mean $E_{s y}[I]=\frac{200000 \alpha_{s y}}{\alpha_{s y}-1}$. We in fact do know $E_{s y}[I]$ thanks to the aggregate state-income group level data from the SOI - this is simply the mean AGI for units with income above $\$ 200,000$. Thus, we can obtain

$$
\alpha_{s y}=\frac{E_{s y}[I]}{E_{s y}[I]-200000} .
$$

Similarly, we obtain $\alpha_{U S, y}$ using U.S.-level data. For each year, we assign each state a mean estate and nontaxable pension income, as well as a mean municipal bond wealth and business wealth for units with AGI above $\$ 200,000$ by taking a weighted mean over all observations in the household tax return file with AGI above $\$ 200,000$. The weights $w_{s y i}(I)$ we use are the population weights multiplied by the relative likelihood that a household lives in a state. We calculate this relative likelihood as the ratio between $f_{s y}(I)$ and $f_{U . S ., y}(I)$. Thus in each year $y$, for each observation $i$ with AGI $I_{i}$ and population weight $p_{i}$, the weight assigned to that observation when constructing the mean for state $s$ is

$$
w_{s y i}\left(I_{i}\right)=p_{i} \times \frac{f_{s y}\left(I_{i}\right)}{f_{U . S ., y}\left(I_{i}\right)}=p_{i} \times \frac{\alpha_{s y}}{\alpha_{U S A, y}} \times 200000^{\alpha_{s y}-\alpha_{U S A, y}} \times I_{i}^{\alpha_{U S A, y}-\alpha_{s y}} .
$$

Having done this, we assign each observation, representing all filers with AGI above \$200,000 in a state, the appropriate population weight based on the number of returns filed by households 
with AGI over $\$ 200,000$, as reported in the aggregate SOI data. We then have the mean business and municipal bond wealth for this income group in each state. We use the mean interest, dividend and taxable pension income from the SOI aggregates in conjunction with the mean estate income and nontaxable pension income obtained through this procedure to obtain the capitalized measures of fixed income, equity and pension wealth. Again, since the SOI aggregate data contains the total number of returns with AGI above $\$ 200,000$ by state, knowing these means is sufficient to know the totals.

We can use the same procedure to obtain the sampled mean AGI for units above $\$ 200,000$ by state. Doing this and comparing the values to the true SOI aggregate data, we obtain a correlation of 0.99 and a cross-sectional $R^{2}$ of 0.98 between the means in the SOI aggregates and in our sampling. This suggests that our sampling provides a close approximation to the true values of AGI. We make one final adjustment to ensure that our aggregate U.S. values match the true totals for all variables, by scaling as necessary without changing the distribution.

No imputation is required for earners below $\$ 200,000$ and for all households in 1982 - data for these earners, with state identifiers, are contained in the public-use tax files. From these capitalized measures of total fixed income, equity, business and pension wealth, we construct a data set that contains, for various income groups in a state and year, that group's share of the U.S. total. With this, we apply the same unveiling process used at the national level to construct a measure of how much household debt is owned as an asset in a state and year, as well as by different income groups therein. Our main groups of focus are the top $6 \%$ of earners and the bottom $94 \%$.

Table A5 shows which income variables are used in the Saez and Zucman (2016) capitalization process, as well as the source(s) and to what extent we rely on each variable in allocating household debt ownership. The sampling procedure is used whenever a variable is obtained from the individual data for filers with AGI above $\$ 200,000$. The final column shows the weight of each variable \& source in the final allocation of household debt ownership for the top 6\% from 2004 to 2007. In total, $58.5 \%$ of household debt allocated to this group relies on state-level data, while the other $41.5 \%$ relies on the sampled household data. 
Table A5: Weight of Capitalized Income Variables in Final Household Debt Ownership Allocation

\begin{tabular}{|c|c|c|c|c|c|c|}
\hline Type of Wealth & $\begin{array}{l}\text { Wealth Weight in Allocation } \\
\text { of Household Debt Owned }\end{array}$ & $\begin{array}{l}\text { Underlying Capitalized } \\
\text { Income Variables }\end{array}$ & $\begin{array}{l}\text { Level of } \\
\text { Source Data }\end{array}$ & Sampling Used & $\begin{array}{l}\text { Fraction of } \\
\text { Total Assets }\end{array}$ & $\begin{array}{l}\text { Source Weight in Allocation } \\
\text { of Household Debt Owned }\end{array}$ \\
\hline \multirow{4}{*}{ Bond } & \multirow{4}{*}{0.542} & \multirow{2}{*}{ Taxable interest income } & State & No & 0.150 & 0.336 \\
\hline & & & Individual & No & 0.026 & 0.059 \\
\hline & & \multirow{2}{*}{ Estate \& exempt interest income } & Individual & No & 0.010 & 0.022 \\
\hline & & & Individual & Yes & 0.056 & 0.125 \\
\hline \multirow{2}{*}{ Business } & \multirow{2}{*}{0.033} & \multirow{2}{*}{ Partnership, estate, sole prop., \& royalty income } & Individual & No & 0.021 & 0.005 \\
\hline & & & Individual & Yes & 0.115 & 0.028 \\
\hline \multirow{4}{*}{ Equity } & \multirow{4}{*}{0.130} & \multirow{2}{*}{ Dividend income } & State & No & 0.040 & 0.014 \\
\hline & & & Individual & No & 0.007 & 0.002 \\
\hline & & \multirow{2}{*}{ Estate \& S-Corp income } & Individual & No & 0.022 & 0.008 \\
\hline & & & Individual & Yes & 0.309 & 0.106 \\
\hline \multirow{4}{*}{ Pension } & \multirow{4}{*}{0.295} & \multirow{2}{*}{ Taxable pension \& annuity income } & State & No & 0.018 & 0.022 \\
\hline & & & Individual & No & 0.032 & 0.038 \\
\hline & & \multirow{2}{*}{ Estate \& nontaxable pension income } & Individual & No & 0.065 & 0.078 \\
\hline & & & Individual & Yes & 0.129 & 0.156 \\
\hline
\end{tabular}

This applies only to 2004-2007. Source for all variables in 1982 is the individual-level data. Sampling procedure is utilized whenever the individual-level data is used for filers with AGI above $\$ 200,000$. No sampling is used when relying on state-level data, or when calculating wealth for filers in the top $6 \%$ of a state who earn less than $\$ 200,000$. All numeric columns sum up to 1 . In total, $41.5 \%$ of household debt owned is allocated through data that rely on the sampling procedure. 


\section{D.2 State-level analysis: additional tables and figures}

Table A6: Relationships Between Controls and Rise in Top Income Share

\begin{tabular}{|c|c|c|c|c|c|c|c|}
\hline & (1) & (2) & (3) & (4) & (5) & (6) & (7) \\
\hline \multirow[t]{2}{*}{ Top 6\% Share 1982} & 0.519 & & & & & & 0.143 \\
\hline & $(0.270)$ & & & & & & $(0.287)$ \\
\hline \multirow[t]{2}{*}{$\Delta_{82,07}$ Log Per Capita AGI } & & $0.125^{* *}$ & & & & & \\
\hline & & $(0.038)$ & & & & & \\
\hline \multirow[t]{2}{*}{ Log Per Capita AGI 1982} & & & $0.139^{*}$ & & & & \\
\hline & & & $(0.060)$ & & & & \\
\hline \multirow[t]{2}{*}{ Top 6\% Debt Holdings 1982} & & & & 0.183 & & & 0.0496 \\
\hline & & & & $(0.192)$ & & & $(0.216)$ \\
\hline \multirow[t]{2}{*}{ Skill sh } & & & & & $0.318^{* * *}$ & & 0.0236 \\
\hline & & & & & $(0.074)$ & & $(0.124)$ \\
\hline \multirow[t]{2}{*}{ Farm/Agg } & & & & & & $-0.317^{*}$ & -0.0220 \\
\hline & & & & & & $(0.148)$ & $(0.168)$ \\
\hline \multirow[t]{2}{*}{$\Delta_{82,07}$ Log Per Capita Income } & & & & & & & $0.145^{*}$ \\
\hline & & & & & & & $(0.056)$ \\
\hline \multirow[t]{2}{*}{ Log Per Capita Income 1982} & & & & & & & $0.216^{* *}$ \\
\hline & & & & & & & $(0.067)$ \\
\hline$R^{2}$ & 0.08 & 0.24 & 0.20 & 0.02 & 0.21 & 0.12 & 0.49 \\
\hline Observations & 51 & 51 & 51 & 51 & 51 & 51 & 51 \\
\hline
\end{tabular}


Table A7: Effect of Change in Top 6\% Share on Household Debt Holding For Different Top Income Groups

\begin{tabular}{lccccc}
\hline \hline Panel A: No Controls & $(1)$ & $(2)$ & $(3)$ & $(4)$ & $(5)$ \\
& Top 6\% & Top 5\% & Top 4 \% & Top 3 \% & Top 2 \% \\
\hline$\Delta_{82,07}$ Top 6\% Share & $1.969^{* * *}$ & $1.884^{* * *}$ & $1.696^{* * *}$ & $1.734^{* * *}$ & 0.249 \\
& $(0.115)$ & $(0.160)$ & $(0.210)$ & $(0.295)$ & $(0.380)$ \\
\hline$R^{2}$ & 0.85 & 0.79 & 0.75 & 0.72 & 0.11 \\
Observations & 51 & 47 & 43 & 36 & 7 \\
\hline \hline Panel B: Controls & $(1)$ & $(2)$ & $(3)$ & $(4)$ & $(5)$ \\
& Top 6\% & Top 5\% & Top 4 \% & Top 3\% & Top 2\% \\
\hline$\Delta_{82,07}$ Top 6\% Share & $1.767^{* * *}$ & $1.678^{* * *}$ & $1.357^{* *}$ & $1.527^{*}$ & 0.852 \\
& $(0.197)$ & $(0.295)$ & $(0.396)$ & $(0.653)$ & $(0.601)$ \\
\hline$R^{2}$ & 0.76 & 0.58 & 0.30 & 0.25 & 0.28 \\
Observations & 51 & 47 & 43 & 36 & 7 \\
\hline \hline
\end{tabular}

Panel A estimates column (2) of Table 7 for different top income groups. Panel B estimates column (5) of Table 7 for these same groups. Robust standard errors in parentheses. ${ }^{*} p<0.05, * * p<0.01, * * * p<0.001$.

Figure A11: Change in Top 1\% Share Against Change in Top 6\% Share

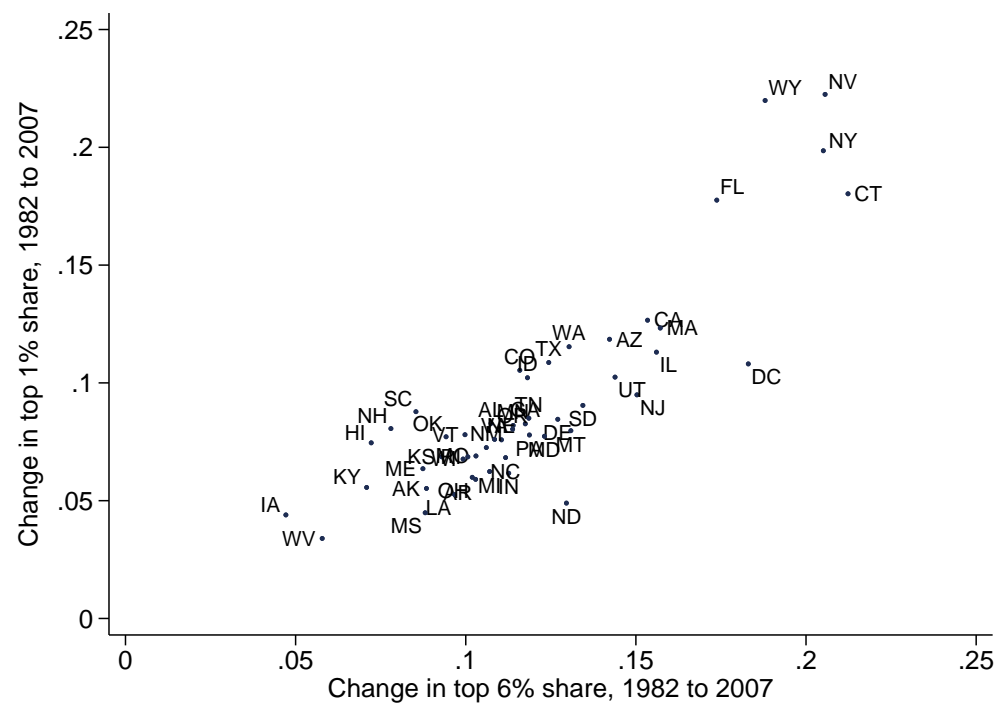


Table A8: Robustness to other controls

\begin{tabular}{|c|c|c|c|c|c|c|c|c|c|}
\hline & (1) & (2) & (3) & (4) & (5) & (6) & (7) & (8) & (9) \\
\hline \multirow{2}{*}{$\Delta_{82,07}$ Top 6\% Share } & $1.767^{* * *}$ & $1.741^{* * *}$ & $1.772^{* * *}$ & $1.795^{* * *}$ & $1.769^{* * *}$ & $1.658^{* * *}$ & $1.803^{* * *}$ & $1.758^{* * *}$ & $1.758^{* * *}$ \\
\hline & $(0.205)$ & $(0.197)$ & $(0.183)$ & $(0.172)$ & $(0.213)$ & $(0.181)$ & $(0.223)$ & $(0.185)$ & $(0.222)$ \\
\hline \multirow[t]{2}{*}{ Top 6\% Share 1982} & $0.675^{*}$ & $0.681^{*}$ & $0.665^{*}$ & $0.847^{* * *}$ & $0.696^{*}$ & $0.903^{* *}$ & $0.585^{*}$ & $0.735^{* *}$ & $0.631^{*}$ \\
\hline & $(0.255)$ & $(0.302)$ & $(0.255)$ & $(0.235)$ & $(0.300)$ & $(0.260)$ & $(0.226)$ & $(0.257)$ & $(0.251)$ \\
\hline \multirow[t]{2}{*}{$\Delta_{82,07}$ Log Per Capita Income } & 0.0615 & 0.0729 & 0.101 & 0.0489 & 0.0618 & $0.115^{*}$ & 0.0684 & $0.0851^{*}$ & 0.0616 \\
\hline & $(0.043)$ & $(0.053)$ & $(0.057)$ & $(0.041)$ & $(0.053)$ & $(0.046)$ & $(0.042)$ & $(0.042)$ & $(0.045)$ \\
\hline \multirow[t]{2}{*}{ Log Per Capita Income 1982} & 0.0736 & 0.0518 & 0.0523 & 0.0638 & 0.0777 & 0.00874 & 0.0402 & 0.0758 & 0.0697 \\
\hline & $(0.066)$ & $(0.075)$ & $(0.080)$ & $(0.053)$ & $(0.075)$ & $(0.062)$ & $(0.061)$ & $(0.053)$ & $(0.063)$ \\
\hline \multirow[t]{2}{*}{ Household Debt Holdings 1982} & $-0.495^{*}$ & $-0.523^{*}$ & $-0.500^{* *}$ & $-0.406^{*}$ & $-0.495^{*}$ & $-0.820^{* * *}$ & $-0.544^{*}$ & $-0.502^{* *}$ & $-0.453^{* *}$ \\
\hline & $(0.196)$ & $(0.206)$ & $(0.180)$ & $(0.164)$ & $(0.196)$ & $(0.204)$ & $(0.211)$ & $(0.163)$ & $(0.163)$ \\
\hline \multirow[t]{2}{*}{ Control (level) } & & 0.0109 & 0.230 & -0.174 & -0.0207 & $-0.287^{* *}$ & 0.254 & $0.720^{*}$ & 0.00203 \\
\hline & & $(0.138)$ & $(0.233)$ & $(0.168)$ & $(0.101)$ & $(0.099)$ & $(0.335)$ & $(0.279)$ & $(0.006)$ \\
\hline \multirow[t]{2}{*}{ Control (change) } & & -0.193 & $-0.380^{*}$ & $0.430^{*}$ & -0.0706 & -0.0783 & -0.214 & 0.221 & -0.142 \\
\hline & & $(0.142)$ & $(0.155)$ & $(0.205)$ & $(0.243)$ & $(0.150)$ & $(0.230)$ & $(0.398)$ & $(0.460)$ \\
\hline Control & None & Skill sh & High skill sh & Old dep. ratio & Young dep. ratio & Manufac. sh & Fin. sh & Cons. sh & Dereg \\
\hline$R^{2}$ & 0.89 & 0.90 & 0.91 & 0.92 & 0.89 & 0.92 & 0.90 & 0.91 & 0.89 \\
\hline Observations & 51 & 51 & 51 & 51 & 51 & 51 & 51 & 51 & 51 \\
\hline
\end{tabular}

This table presents the specification that is analogous to column 5 of Table 7 with additional controls. The controls, in order, are the skilled and high skilled shares of labor (at least 1 year of post-secondary education and at least 4 years of post-secondary education, respectively), the old and young dependency ratios, the manufacturing, finance, and construction shares of employment, and the deregulation measure from Mian et al. (2020). In all cases, we control for both the level of the measure and the change in the measure between 1982 and 2007. Data come from the US Census and the BEA. * $p<0.05, * * p<0.01, * * * p<0.001$. 
Table A9: Robustness to labor income share instead of total income share

\begin{tabular}{lcccccc}
\hline \hline & $(1)$ & $(2)$ & $(3)$ & $(4)$ & $(5)$ & $(6)$ \\
\hline$\Delta_{82,07}$ Top 6\% Share & $1.931^{*}$ & $1.947^{* *}$ & -0.0158 & $2.590^{* * *}$ & $2.467^{* * *}$ & 0.0315 \\
& $(0.787)$ & $(0.680)$ & $(0.315)$ & $(0.445)$ & $(0.490)$ & $(0.255)$ \\
& & & & & & \\
Top 6\% Share 1982 & & & & 0.648 & $1.227^{* *}$ & -0.471 \\
& & & & $(0.482)$ & $(0.445)$ & $(0.279)$ \\
$\Delta_{82,07}$ Log Per Capita Income & & & & $0.337^{* * *}$ & $0.313^{* * *}$ & 0.0233 \\
& & & & $(0.087)$ & $(0.084)$ & $(0.044)$ \\
Log Per Capita Income 1982 & & & & & & \\
& & & & $\left(0.406^{* * *}\right.$ & $0.295^{* * *}$ & 0.0999 \\
& & & & & $(0.082)$ & $(0.055)$ \\
$Y_{i s, 1982}$ & & & & $-0.672^{* * *}$ & $-0.653^{* *}$ & $-0.497^{* * *}$ \\
& & & & $(0.092)$ & $(0.213)$ & $(0.079)$ \\
\hline Group & All & Top 6 & Bot. 94 & All & Top 6 & Bot. 94 \\
$R^{2}$ & 0.17 & 0.22 & 0.00 & 0.77 & 0.71 & 0.46 \\
Observations & 51 & 51 & 51 & 51 & 51 & 51 \\
\hline
\end{tabular}

This table presents results from specifications similar to Table 7 except that the key right hand side variable is the change in top $6 \%$ share of labor income instead of total income. ${ }^{*} p<0.05, * * p<0.01, * * * p<0.001$. 
Table A10: Effect of Change in Top Income Share on Net Wealth Excluding Housing

\begin{tabular}{|c|c|c|c|c|c|c|}
\hline & (1) & (2) & (3) & (4) & $(5)$ & (6) \\
\hline$\Delta_{82,07}$ Top 6\% Share & $\begin{array}{c}8.354^{* * *} \\
(1.048)\end{array}$ & $\begin{array}{c}8.210^{* * *} \\
(0.609)\end{array}$ & $\begin{array}{c}0.144 \\
(0.746)\end{array}$ & $\begin{array}{c}7.684^{* * *} \\
(1.191)\end{array}$ & $\begin{array}{c}7.536^{* * *} \\
(0.701)\end{array}$ & $\begin{array}{c}0.138 \\
(1.065)\end{array}$ \\
\hline Top 6\% Share 1982 & & & & $\begin{array}{c}1.296 \\
(1.627)\end{array}$ & $\begin{array}{l}3.846^{* *} \\
(1.259)\end{array}$ & $\begin{array}{l}-1.971 \\
(1.609)\end{array}$ \\
\hline$\Delta_{82,07}$ Log Per Capita Income & & & & $\begin{array}{c}0.587 \\
(0.293)\end{array}$ & $\begin{array}{c}0.545^{* *} \\
(0.177)\end{array}$ & $\begin{array}{l}0.0508 \\
(0.229)\end{array}$ \\
\hline Log Per Capita Income 1982 & & & & $\begin{array}{c}0.690 \\
(0.428)\end{array}$ & $\begin{array}{c}0.321 \\
(0.257)\end{array}$ & $\begin{array}{c}0.336 \\
(0.317)\end{array}$ \\
\hline Group Wealth 1982 & & & & $\begin{array}{c}-0.615^{* * *} \\
(0.097)\end{array}$ & $\begin{array}{c}-0.670^{* * *} \\
(0.151)\end{array}$ & $\begin{array}{c}-0.531^{* * *} \\
(0.104)\end{array}$ \\
\hline Group & All & Top 6 & Bot. 94 & All & Top 6 & Bot. 94 \\
\hline$R^{2}$ & 0.55 & 0.80 & 0.00 & 0.81 & 0.91 & 0.41 \\
\hline Observations & 51 & 51 & 51 & 51 & 51 & 51 \\
\hline
\end{tabular}

Dependent variable, $\Delta_{82,07} Y_{i s}$, is the change in net wealth excluding housing by group $\imath$ in state $s$ scaled by state income. Robust standard errors in parentheses. $* p<0.05$, ** $p<0.01$, *** $p<0.001$. 
Table A11: Effect of Change in Top Income Share on Net Wealth Including Housing

\begin{tabular}{|c|c|c|c|c|c|c|}
\hline & (1) & (2) & (3) & (4) & (5) & (6) \\
\hline$\Delta_{82,07}$ Top 6\% Share & $\begin{array}{c}9.665^{* * *} \\
(1.460)\end{array}$ & $\begin{array}{c}9.321^{* * *} \\
(0.689)\end{array}$ & $\begin{array}{c}0.344 \\
(1.171)\end{array}$ & $\begin{array}{l}5.279^{*} \\
(1.981)\end{array}$ & $\begin{array}{c}8.427^{* * *} \\
(0.834)\end{array}$ & $\begin{array}{l}-3.015 \\
(1.767)\end{array}$ \\
\hline Top 6\% Share 1982 & & & & $\begin{array}{c}0.291 \\
(1.939)\end{array}$ & $\begin{array}{c}6.035^{\text {*** }} \\
(1.562)\end{array}$ & $\begin{array}{l}-1.552 \\
(1.536)\end{array}$ \\
\hline$\Delta_{82,07}$ Log Per Capita Income & & & & $\begin{array}{c}2.628^{* * *} \\
(0.486)\end{array}$ & $\begin{array}{l}0.646^{* *} \\
(0.212)\end{array}$ & $\begin{array}{l}1.763^{* *} \\
(0.532)\end{array}$ \\
\hline Log Per Capita Income 1982 & & & & $\begin{array}{l}2.227^{*} \\
(1.097)\end{array}$ & $\begin{array}{c}0.638 \\
(0.397)\end{array}$ & $\begin{array}{l}1.610^{*} \\
(0.718)\end{array}$ \\
\hline Group Wealth 1982 & & & & $\begin{array}{c}-0.531^{* * *} \\
(0.111)\end{array}$ & $\begin{array}{c}-0.929^{* * *} \\
(0.137)\end{array}$ & $\begin{array}{c}-0.414^{* * *} \\
(0.080)\end{array}$ \\
\hline Group & All & Top 6 & Bot. 94 & All & Top 6 & Bot. 94 \\
\hline$R^{2}$ & 0.38 & 0.68 & 0.00 & 0.77 & 0.92 & 0.47 \\
\hline Observations & 51 & 51 & 51 & 51 & 51 & 51 \\
\hline
\end{tabular}

